Universidade de São Paulo

Faculdade de Medicina de Ribeirão Preto

\title{
2017
}

Sensibilidade e especificidade da avaliação da postura

craniocervical: fotogrametria em relação à análise de

$$
\text { inspeção visual }
$$
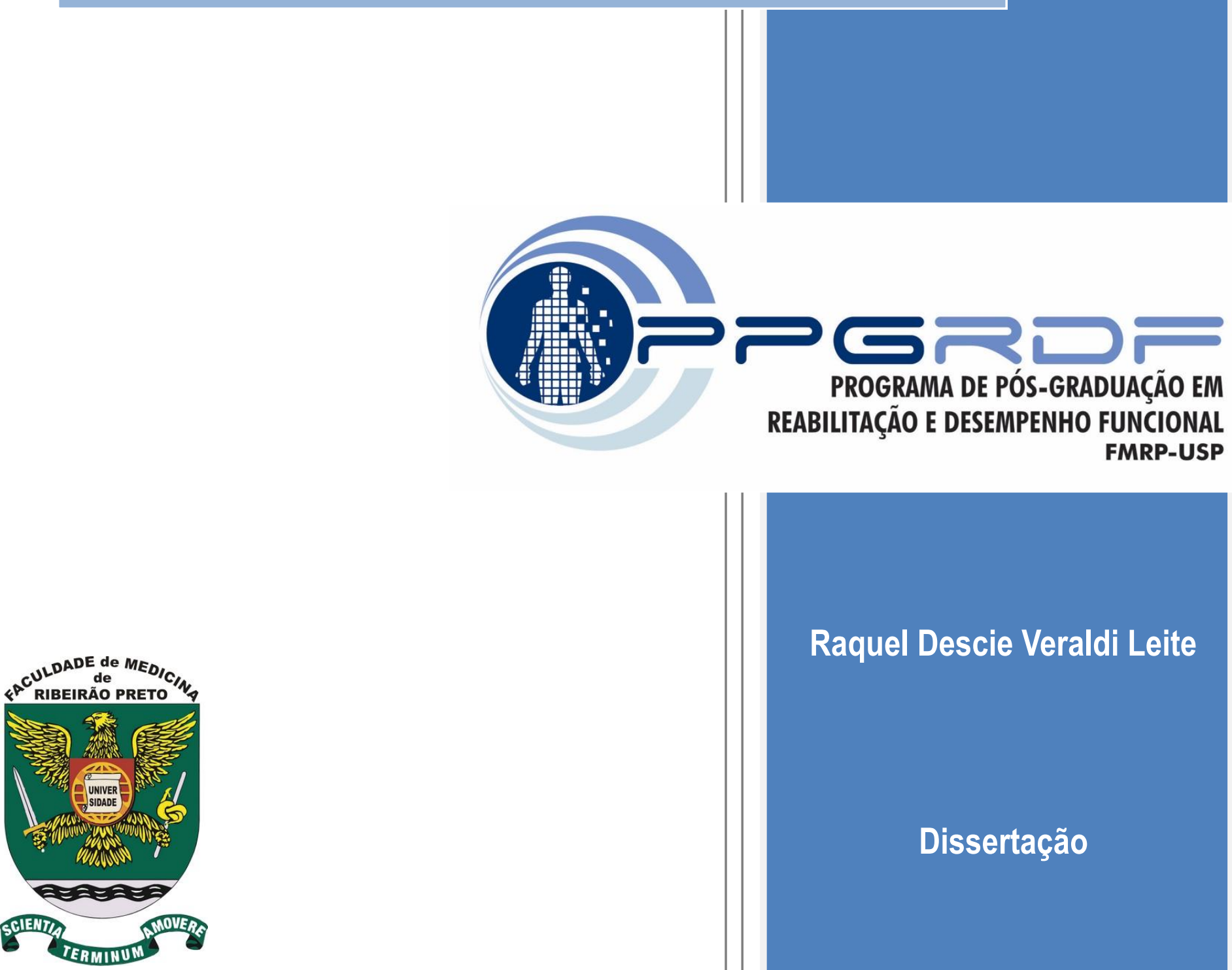

Raquel Descie Veraldi Leite 
UNIVERSIDADE DE SÃO PAULO

FACULDADE DE MEDICINA DE RIBEIRÃO PRETO

Departamento de Neurociências e Ciências do Comportamento

Raquel Descie Veraldi Leite

\section{Sensibilidade e especificidade da avaliação da postura craniocervical: fotogrametria em relação à análise de inspeção visual}

Dissertação apresentada à Faculdade de Medicina de Ribeirão Preto da Universidade de São Paulo junto ao Departamento de Neurociências e Ciências do Comportamento, para obtenção do título de mestre em Reabilitação e Desempenho Funcional

Área de concentração: Fisioterapia Orientadora: Profa. Dra. Thaís Cristina Chaves

Ribeirão Preto 


\section{UNIVERSIDADE DE SÃO PAULO \\ FACULDADE DE MEDICINA DE RIBEIRÃO PRETO}

Departamento de Neurociências e Ciências do Comportamento

Raquel Descie Veraldi Leite

\section{Sensitivity and specificity of craniocervical posture evaluation: photogrammetry in relation to visual inspection analysis}

Dissertação apresentada à Faculdade de Medicina de Ribeirão Preto da Universidade de São Paulo junto ao Departamento de Neurociências e Ciências do Comportamento, para obtenção do título de mestre em Reabilitação e Desempenho Funcional

Área de concentração: Fisioterapia Orientadora: Profa. Dra. Thaís Cristina Chaves 
Autorizo a reprodução e divulgação total ou parcial deste trabalho, por qualquer meio convencional ou eletrônico, para fins de estudo e pesquisa, desde que citada a fonte.

\section{Catalogação da Publicação}

Faculdade de Medicina de Ribeirão Preto da Universidade de São Paulo

Leite, Raquel Descie Veraldi Leite

Sensibilidade e especificidade da avaliação da postura craniocervical: fotogrametria em relação à análise de inspeção visual. Ribeirão Preto, 2017.

$$
\text { p.107: } 11.12 ; 30 \mathrm{~cm}
$$

Dissertação de Mestrado apresentada à Faculdade de Medicina de Ribeirão Preto/USP Programa de Pós-Graduação em Reabilitação e Desempenho Funcional. Área de concentração: Fisioterapia.

Orientador: Chaves, Thaís Cristina.

1.Fotogrametria . 2.Postura craniocervical. 3.Ângulo craniovertebral. 4. Ângulo lordose cervical. 5. Acurácia 


\title{
UNIVERSIDADE DE SÃO PAULO \\ FACULDADE DE MEDICINA DE RIBEIRÃO PRETO
}

Departamento de Neurociências e Ciências do Comportamento

\author{
RAQUEL DESCIE VERALDI LEITE
}

Sensibilidade e especificidade da avaliação da postura craniocervical: fotogrametria em relação à análise de inspeção visual

Ribeirão Preto 


\section{FOLHA DE APROVAÇÃo}

Raquel Descie Veraldi Leite

Sensibilidade e especificidade da avaliação da postura craniocervical: fotogrametria em relação à análise de inspeção visual.

Dissertação apresentada à Faculdade de Medicina de Ribeirão Preto da Universidade de São Paulo junto ao Departamento de Neurociências e Ciências do Comportamento, para obtenção do título de mestre em Reabilitação e Desempenho Funcional

Área de concentração: Fisioterapia

Aprovado em: 24/03/2017

\section{Banca Examinadora}

Profa Dra Thaís Cristina Chaves

Instituição: Curso de Terapia Ocupacional - Faculdade de Medicina de Ribeirão Preto - USP

Profa Dra Fabíola Dach

Instituição: Departamento de neurologia - Faculdade de Medicina de Ribeirão Preto - USP

Profa Dr (a) Marisa de Cássia Registro Fonseca

Instituição: Curso de Fisioterapia - Faculdade de Medicina de Ribeirão Preto - USP

Profa Dr (a) Delaine Rodrigues Bigaton

Instituição: Curso de Fisioterapia - Universidade Metodista de Piracicaba - UNIMEP 
Dedico aos homens da minha vida, meu pai Elcio, meu irmão Henrique e ao meu companheiro da vida Rafael por serem o meu porto seguro perante as dificuldades e o meu alicerce perante a vida. 


\section{Agradecimentos}

Desafio tão grande quanto escrever esta tese, foi utilizar apenas duas páginas para agradecer as pessoas que fizeram parte desta minha trajetória.

Agradeço primeiramente à Deus por me amparar nos momentos difíceis, me dar força interior para superar as dificuldades, mostrar os caminho nas horas incertas e me suprir em todas as minhas necessidades. Sem Ele eu nada seria. Sem minha fé N'Ele talvez eu nem conseguisse prosseguir em minha caminhada com força e coragem, e hoje não colheria os frutos de minhas escolhas baseadas em Seus mandamentos e amor infinito.

Agradeço aos meus pais, pela educação, amor e suporte me dados. Minha mãe Rita, apesar da nossa convivência de apenas 12 anos, me ensinou neste pouco tempo o que algumas mães levam a vida toda tentando ensinar aos seus filhos. Seus ensinamentos serão carregados por mim pelo resto da minha vida, sabendo assim que te faço sorrir onde está. Em especial agradeço ao meu pai Elcio que sacrificou sua própria vida pelos seus filhos, nos dedicando seu tempo e amor, exercendo de forma quase que exaustiva o papel de um homem digno de ser chamado de pai. Aprendi, aprendo e aprenderei sempre ao seu lado, e espero te deixar orgulhoso com minhas escolhas e vitórias, pois o senhor foi meu primeiro amor da vida e assim continuará. Minha eterna admiração, meu pai.

Agradeço ao meu irmão Henrique que foi um anjo enviado por Deus pra me fazer uma pessoa melhor, foi o presente mais lindo que ganhei, uma bênção dada a mim, transformandoo assim, em meu filho do coração. Te criar ao lado de nosso pai não foi, nem é, uma tarefa fácil, mas você se tornou meu "motivo" para viver.

Agradeço, de forma especial, meu companheiro de vida Rafael, que por tantas vezes teve paciência e me deu força para continuar. Meu agradecimento mais profundo só poderia ser à você. O tempo todo ao meu lado, incondicionalmente. Nos momentos mais difíceis, que não foram raros, me incentivou e me fez acreditar que tudo valeria a pena. Sou grata a cada 
gesto carinhoso, sorriso e a cada abraço confortante. Simplesmente sou grata por todos esses anos de companheirismo, amor e dedicação.

Agradeço à minha orientadora Prof. ${ }^{a}$ Dr. ${ }^{a}$ Thais Cristina Chaves, pela oportunidade dada e confiança depositada em mim. Agradeço pelo tempo dedicado à realização deste sonho em forma de estudo, à todo conhecimento e aprendizado que me proporcionou, e todo incentivo me impulsionando a ser uma pessoa digna à carregar este título.

Queria agradecer também, ao meus familiares por todo apoio e carinho. Aos meus amigos queridos, que são a família que escolhi ter. Não poderia citar nomes, pois Deus me permitiu suprir abundantemente a falta de laços sanguíneos por laços de amor, me proporcionando assim carregar por onde eu passasse mais e mais membros verdadeiros desta "família escolhida". Vocês são fontes de sinceros sorrisos e eterna admiração.

Aos colaboradores, que fizeram parte deste projeto com tanta entrega e profissionalismo, proporcionando que este sonho se tornasse realidade.

Aos membros do LAPIDOM, que me auxiliaram direta e indiretamente em tantos momentos. Aos meus colegas de pós-graduação, em especial à Marcela, Carina e Mirela, que por tantas vezes me auxiliaram a superar meus desafios, me ensinando com paciência e carinho, deixando de lado muitas vezes seus próprios problemas.

Por fim, agradeço à todos que torceram pelo meu sucesso e fizeram parte dele, obrigada! 
“As pessoas estão sempre a culpar as circunstâncias por aquilo que se tornam. Não acredito em circunstâncias. As pessoas que estão mais adiantadas neste mundo são as pessoas que se levantam e procuram as circunstancias que desejam, e se não as encontram, criam-nas." 



\section{Resumo}

As avaliações de postura craniocervical podem ser realizadas através de métodos qualitativos e quantitativos. Apesar das vantagens no emprego das análises quantitativas, a ausência de valores clínicos de referência para determinação da presença/ausência de desalinhamentos posturais é uma limitação para uso do recurso na prática clínica. Objetivo: Identificar os valores de acurácia, sensibilidade e especificidade da fotogrametria em relação inspeção visual para avaliação da postura craniocervical através da análise de fotografias no plano sagital, além de verificar a confiabilidade destes métodos. Método: Foram avaliadas 157 imagens no plano sagital de mulheres (35,6 DP:10,36 anos). As imagens foram analisadas através da avaliação qualitativa (inspeção visual) e através da análise quantitativa (fotogrametria) considerando-se dois ângulos: ângulo craniovertebral (ACV) e lordose cervical (ALC). Os voluntários com dor cervical também foram submetidos a avaliação de intensidade de dor e incapacidade relacionada à dor cervical. A inspeção visual foi realizada por 5 fisioterapeutas experientes. Da mesma forma a avaliação por fotogrametria foi realizada por 2 avaliadores. Todas as avaliações foram repetidas após uma semana. Para análise estatística foi utilizado o Coeficiente de Correlação Intraclasse (CCI) para analisar a confiabilidade e o Kappa de Cohen para a concordância. Além disso, os valores de acurácia, sensibilidade e especificidade foram identificados através do Receiver Operating Characteristic (ROC). Resultados: Foram observados níveis aceitáveis de confiabilidade para o ACV e ALC $(\mathrm{CCI}<0,98)$ por meio da fotogrametria e valores de PABAK para a concordância intra-examinador entre 0,63-0,91 (ACV) e 0,46-0,89 (ALC) e para a concordância interexaminadores de 0,51-0,85 (ACV) e 0,16-0,59 (ALC). Foi observada uma acurácia moderada $(0,7<\mathrm{ROC}<0,9)$ para os valores de corte do ACV $\left(42^{\circ}, \mathrm{EPM} \pm 0,73^{\circ}\right)$ e ALC $\left(12^{\circ}-15^{\circ}, E P M \pm 0,42^{\circ}\right)$ com níveis aceitáveis de sensibilidade e especificidade $(<0,63)$. Assim, foi encontrada uma acurácia moderada $(0,7<\mathrm{ROC}<0,9)$ para os valores de corte dos ACV $\left( \pm 42^{\circ}\right)$ e ALC $\left( \pm 13^{\circ}\right)$ estabelecidos pelo estudo, com níveis adequados de sensibilidade e especificidade dos mesmos. Também não foram verificados níveis aceitáveis de sensibilidade, especificidade e acurácia dos ângulos de postura craniocervical para detecção dos grupos sintomático vs. assintomático para dor cervical, e para identificação dos subgrupos com e sem incapacidade relacionda a dor cervical. Conclusão: Nossos resultados dão suporte para o uso de ângulos na análise postural quantitativa que discriminam indivíduos com protrusão da cabeça moderada/severa e indivíduos com alterações da postura cervical em hiperlordose e retificação/cifose cervical em relação à postura considerada normal através da avaliação qualitativa. Entretanto, ambos os ângulos estudados não demonstraram bons índices para discriminar indivíduos sintomáticos vs. assintomáticos para dor cervical ou subgrupos com e sem incapacidade relacionda à dor cervical.

Palavras Chave: Sensibilidade, Especificidade, Fotogrametria, Avaliação postural, Inspeção visual, Postura craniocervical. 


\begin{abstract}
Evaluations of craniocervical posture can be performed through qualitative and quantitative methods. Although the advantages in the use of quantitative analyzes, the absence of clinical reference values to determine the presence / absence of postural misalignments is a limitation for the use of the resource in clinical practice. Objective: To identify the accuracy, sensitivity and specificity values of the photogrammetry in relation to the visual inspection to evaluate the craniocervical posture through the analysis of photographs in the sagittal plane, besides verifying the reliability of these methods. Method: 157 images were evaluated in the sagittal plane of women (35.6 SD: 10.36 years). The images were analyzed through qualitative evaluation (visual inspection) and quantitative analysis (photogrammetry) considering two angles: craniovertebral angle (CVA) and cervical lordosis (LCA). Cervical pain volunteers were also assessed for pain intensity and disability related to cervical pain. Visual inspection was performed by 5 experienced physiotherapists. Likewise, the evaluation by photogrammetry was performed by 2 evaluators. All evaluations were repeated after one week. For statistical analysis, the Intraclass Correlation Coefficient (ICC) was used to analyze reliability and Cohen's Kappa for agreement. In addition, the values of accuracy, sensitivity and specificity were identified through the Receiver Operating Characteristic (ROC). Results: Acceptable levels of reliability for CVA and LCA (ICC <0.98) were observed by photogrammetry and PABAK values for intra-examiner agreement between 0.63-0.91 (CVA) and 0.46- 0.89 (LCA) and for the inter-examiner agreement of 0.51-0.85 (CVA) and 0.16-0.59 (LCA). A moderate accuracy $(0.7<$ ROC $<0.9)$ was observed for the cut values of the CVA $\left(42^{\circ}, \mathrm{SME} \pm 0.73^{\circ}\right)$ and LCA $\left(12^{\circ}-15^{\circ}, \mathrm{SME} \pm 0.42^{\circ}\right)$ with acceptable levels of Sensitivity and specificity $(<0.63)$. Thus, a moderate accuracy $(0.7<\mathrm{ROC}<0.9)$ was found for the cutoff values of the CVA $\left( \pm 42^{\circ}\right)$ and LCA $\left( \pm 13^{\circ}\right)$ established by the study, with adequate levels of sensitivity and specificity. Also, no acceptable levels of sensitivity, specificity and accuracy of the craniocervical posture angles were detected for symptomatic groups vs. Asymptomatic for cervical pain, and to identify the subgroups with and without disability related to cervical pain. Conclusion: Our results support the use of angles in the quantitative postural analysis that discriminate individuals with moderate / severe head protrusion and individuals with altered cervical posture in hyperlordosis and rectification / cervical kyphosis in relation to the posture considered normal through the qualitative evaluation. However, both angles studied did not show good indices to discriminate symptomatic individuals vs. Asymptomatic for cervical pain or subgroups with and without disability related to cervical pain.
\end{abstract}

Key-words: Sensitivity, Specificity, Photogrammetry, Postural evaluation, Visual inspection, Craniocervical posture. 


\section{LISTA DE TABELAS}

Tabela 1. Identificação dos pontos anatômicos para demarcação.

Tabela 2. Valores médios de PABAK (Prevalence and Bias Adjusted Kappa), Coeficiente de Correlação Intraclasse (CCI) e intervalos de confiança 95\% (IC 95\%) da confiabilidade intraexaminador para as avaliações de postura craniocervical obtidas através dos métodos quantitativos (ACV e ALC) e qualitativos (inspeção visual).

Tabela 3. Valores médios de PABAK (Prevalence and Bias Adjusted Kappa), Coeficiente de Correlação Intraclasse (CCI) e intervalos de confiança (IC 95\%) para as medidas de confiabilidade interexaminadores para avaliações da postura craniocervical obtidas através dos métodos quantitativos (ângulos ACV e ALC) e qualitativos (inspeção visual).

Tabela 4. Dados resultantes da análise de erro padrão da medida (EPM) e mínima diferença detectável (MDD) do Coeficiente de Correlação Intraclasse (CCI) e intervalos de confiança 95\% (IC 95\%), para a confiabilidade intra-examinador para os ângulos de craniovertebral e lordose cervical, obtidos através da fotogrametria

Tabela 5. Pontuação Média dos ângulos craniovertebrais (ACV) de acordo com níveis de sensibilidade e especificidade.

Tabela 6. Pontuação média dos ângulos da lordose cervical (ALC) de acordo com bons níveis de sensibilidade e especificidade.

Tabela 7. Níveis de acurácia, sensibilidade e especificidade do Ângulo Craniovertebral (ACV) em relação aos subgrupos classificados através da análise qualitativa (inspeção visual) 
Tabela 8. Níveis de acurácia, sensibilidade e especificidade do Ângulo de Lordose Cervical (ACL) em relação aos subgrupos classificados através da análise qualitativa (inspeção visual).

Tabela 9. Acurácia, sensibilidade e especificidade do ACV (ângulo craniovertebral) dos indivíduos com presença ou ausência de relato de dor dos indivíduos com e sem dor de intensidade maior que 3 em uma Escala Numérica de Dor (END) graduada de 0-10.

Tabela 10. Acurácia, Sensibilidade e especificidade da avaliação postural através de fotogrametria para o ALC (ângulo lordose cervical) dos indivíduos com e sem dor divididos em subgrupos normal vs. hiperlordose e normal vs. retificação vs. inversão.

Tabela 11- Acurácia, sensibilidade e especificidade das medidas do ACV (ângulo craniovertebral) e ALC (ângulo lordose cervical) por fotogrametria para detectar incapacidade relacionada à dor cervical através do NDI-BR (Índice de incapacidade relacionada ao pescoço)

Tabela 12- Acurácia das medidas de ACV e ALC por inspeção visual para detectar o relato positivo de dor cervical com intensidade maior que 3 em uma escala numérica de dor graduada de 0-10 (END) e incapacidade relacionada a dor.

Tabela 13- Valor médio dos ângulos entre os grupos com e sem dor e grupos com e sem incapacidade dos ângulos craniovertebral (ACV) e lordose cervical (ALC) da postura craniocervical 


\section{LISTA DE FIGURAS}

Figura 1. Imagem adotada para análise da postura da cabeça e cervical. Os seguintes pontos (demarcados previamente nas voluntárias) foram considerados para análise postural: A protuberância occipital, B - processo espinhoso da quarta vértebra cervical $(\mathrm{C} 4), \mathrm{C}$ - processo espinhoso da sétima vertebra cervical $(\mathrm{C} 7)$ and D - tragus da orelha. Outras marcações não foram consideradas.

Figura 2. Pontos e ângulos avaliados no plano sagital: PO (protuberância occipital); C4 (processo espinhoso C4); $\mathrm{C7}$ (processo espinhoso C7); TO (tragus). ACV (ângulo craniovertebral) e ALC (ângulo lordose cervical).

Figura 3. Escala numérica de dor (END)

Figura 4. Curva ROC (receiver operator characteristic). Área sob a curva (AUC) para avaliação postural da lordose cervical por fotogrametria considerando os grupos normal (composto pelos subgrupos normal, normal/leve, leve e leve/moderado) e protrusão de cabeça. Acurácia moderada para o valor de corte $42,07^{\circ}$.

Figura 5. Curva ROC (receiver operator characteristic). Área sob a curva (AUC) para avaliação postural da lordose cervical por fotogrametria considerando os grupos normal e hiperlordose. Acurácia moderada para o valor de corte de $12,05^{\circ}$.

Figura 6. Curva ROC (receiver operator characteristic). Área sob a curva (AUC) para avaliação postural da lordose cervical por fotogrametria considerando os grupos normal, inversão e retificação. Acurácia moderada para o valor de corte $15,38^{\circ}$.

Figura 7. Curva ROC (receiver operator characteristic). Área sob a curva (AUC) da avaliação postural da lordose cervical por fotogrametria considerando os grupos normal, retificação e inversão. Acurácia moderada para o valor de corte $14,42^{\circ}$. 
Figura 8. Curva ROC (receiver operator characteristic). Área sob a curva (AUC) para avaliação postural da protrusão de cabeça por fotogrametria nos grupos normal, leve, moderado e severo relacionados com o relato da presença ou ausência de dor. Baixa acurácia para o valor de corte de $44,42^{\circ}$.

Figura 9. Curva ROC (receiver operator characteristic). Área sob a curva (AUC) para avaliação postural da lordose cervical por fotogrametria nos grupos normal e hiperlordose relacionados com o relato da presença ou ausência de dor. Baixa acurácia para o valor de corte de $14,02^{\circ}$

Figura 10. Curva ROC (receiver operator characteristic). Área sob a curva (AUC) para avaliação postural da lordose cervical por fotogrametria nos grupos normal, retificação e inversão relacionados com o relato da presença ou ausência de dor. Baixa acurácia para o valor de corte de $14,37^{\circ}$.

Figura 11. Curva ROC (receiver operator characteristic). Área sob a curva (AUC) para avaliação postural dos ângulos craniovertebral (ACV) e lordose cervical (ALC) por fotogrametria verificando a presença ou ausência de dor incapacidade relacionada à dor cervical. Baixa acurácia para o valor de corte de $42,74^{\circ}$ para protrusão de cabeça e resultado ao acaso para o valor de corte $13,25^{\circ}$ para lordose cervical.

Figura 12. Curva ROC (receiver operator characteristic). Área sob a curva (AUC) para avaliação postural dos ângulos craniovertebral (ACV) e lordose cervical (ALC) por inspeção visual relacionando o relato da presença ou ausência de incapacidade relacionada à dor cervical. AUC ACV 0,5 (baixa acurácia) e AUC ALC 0,5 (baixa acurácia). 



\section{LISTA DE SIGLAS}

ACV: Ângulo Craniovertebral

ALC: Ângulo Lordose Cervical

ANOVA: Analysis of Variance

AUC: Area Under the Curve

C4: Processo Espinhoso C4

C7: Processo Espinhoso C7

CCI: Coeficiente de Correlação Intraclasse

DP: Desvio Padrão

DTM: Disfunção Temporo Mandibular

END: Escala Numérica de Dor

EPM: Erro Padrão da medida

IC: Intervalos de Confiança

IIRP: Índice de Incapacidade Relacionada à Dor no Pescoço

LAPIDOM: Laboratório de Pesquisa Interdisciplinar na Dor Musculoesquelética

LC: Lordose Cervical

MDD: Mínima Diferença Detectável

PABAK: Prevalence and Bias Adjusted Kappa-Ordinal Scale

PC: Protrusão de Cabeça

PO: Protuberância Occipital

ROC: Receiver Operating Characteristic

STARD: Statement for Reporting Studies of Diagnostic Accuracy

TO: Tragus da Orelha 
SUMÁRIO

1. INTRODUÇÃ

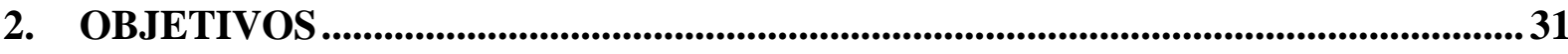

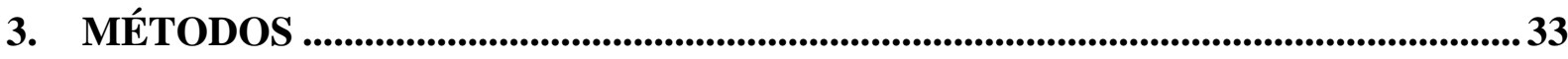

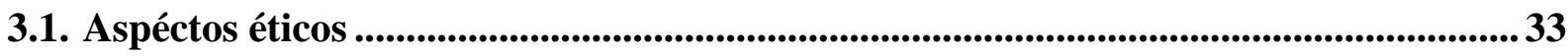

3.2. Amostra, critérios de inclusão e exclusão................................................................ 33

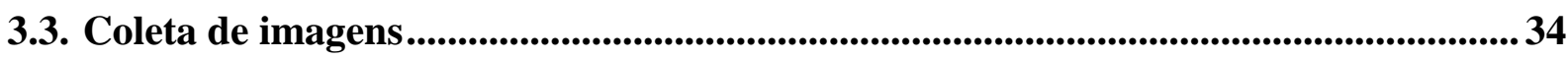

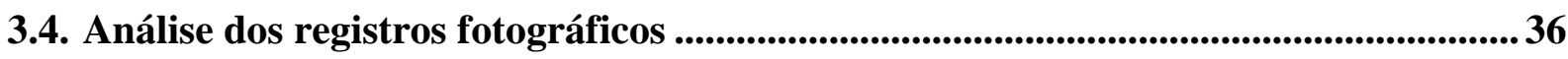

3.4.1. Avaliação Qualitativa .............................................................................................36

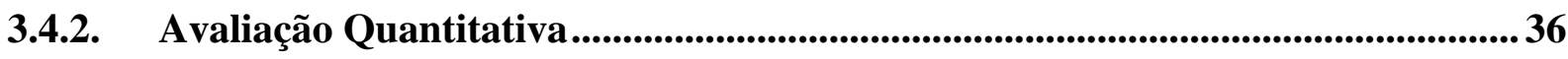

3.6. Índice de Incapacidade Relacionada à Dor no Pescoço - NDI-BR (Neck Disability

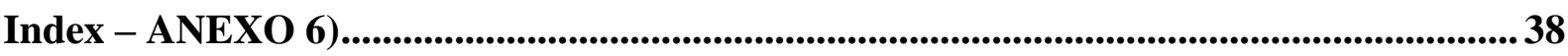

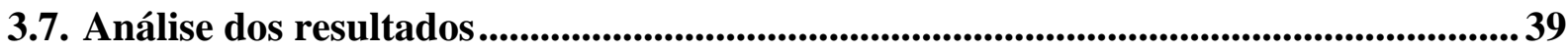

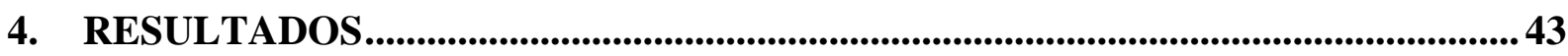

4.1. Concordância intra e interexaminadores para avaliação dos ângulos por inspeção

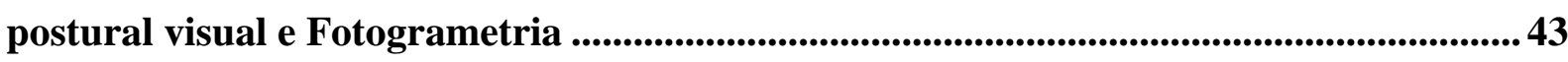

4.2. Acurácia das medidas do ângulo craniovertebral e ângulo lordose cervical por avaliação postural por fotogrametria ........................................................................5

4.2.1. Protrusão de cabeça .................................................................................................50

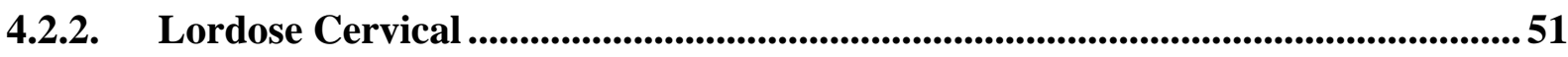

4.3. Acurácia das medidas de postura craniocervical obtidas por fotogrametria para detectar a presença ou ausência de relato de dor cervical .......................................................54 
4.4. Acurácia das medidas de postura craniocervical obtidas por fotogrametria para detectar a presença ou ausência de incapacidade relacionada à cervical através do questionário Índice de Incapacidade Relacionada à Dor no Pescoço (NDI-BR) 58

4.5. Acurácia das medidas de postura craniocervical por inspeção visual para detectar a presença ou ausência incapacidade relacionada à dor cervical (NDI-BR).

\section{DISCUSSÃO}

5.1. Concordância intra e interexaminadores para avaliação dos ângulos por inspeção postural visual e fotogrametria

5.2. Acurácia das medidas de protrusão de cabeça e lordose cervical da fotogrametria em relação à inspeção visual

5.3. Classificação dos subgrupos por inspeção visual e dos ângulos traçados pela avaliação postural através da fotogrametria

5.4. Acurácia das medidas de protrusão de cabeça e lordose cervical por fotogrametria e inspeção visual para detectar a presença ou ausência de relato de dor cervical e incapacidade

6. CONCLUSÃO

7. REFERÊNCIAS

ANEXO 1 - Documento de aprovação do projeto "Sensibilidade e especificidade da avaliação da postura craniocervical: fotogrametria versus análise de inspeção visual" pelo Comitê de Ética em Pesquisa

ANEXO 2 - Documento de aprovação do projeto "Presença de alterações degenerativas e posturais da coluna cervical e aspectos de funcionalidade e incapacidade globais em pacientes com cefaleia" pelo Comitê de Ética em Pesquisa 
ANEXO 3 - Documento de aprovação do projeto "Dor cervical crônica e postura em trabalhadores de escritório usuários de computador" pelo Comitê de Ética em Pesquisa99

ANEXO 4 - Termo de Consentimento Livre e Esclarecido do projeto "Presença de alterações degenerativas e posturais da coluna cervical e aspectos de funcionalidade e incapacidade globais em pacientes com cefaleia"

ANEXO 5 - Termo de Consentimento Livre e Esclarecido do projeto "Dor cervical crônica e postura em trabalhadores de escritório usuários de computador"

ANEXO 6 - Índice de Incapacidade Relacionada à Dor no Pescoço - NDI-BR (Neck Disability Index)

APÊNDICE A - FICHA DE AVALIAÇÃO PROTRUSÃO DE CABEÇA.................... 105

APÊNDICE B - FICHA DE AVALIAÇÃO LORDOSE CERVICAL ........................... 106 


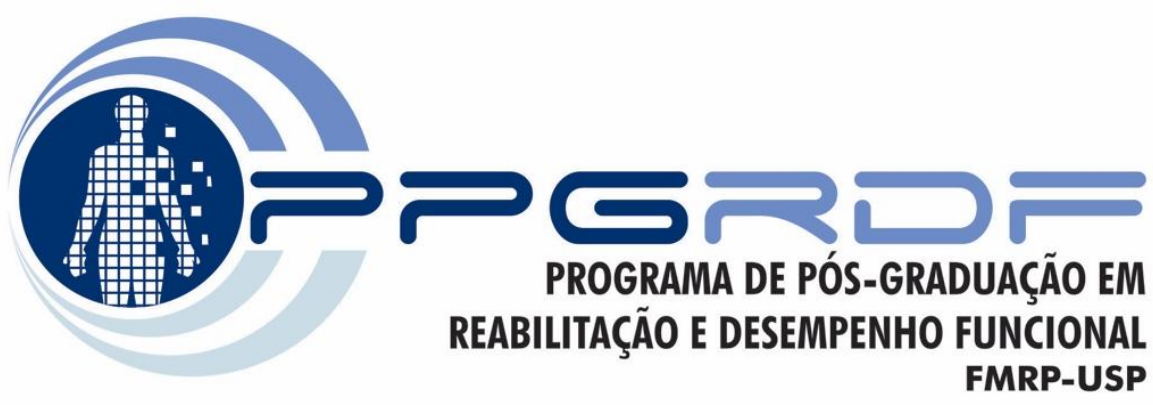

INTRODUÇÃO

"Agradeço todas as dificuldades que enfrentei; não fosse por elas, eu não teria saído do lugar. As facilidades nos impedem de caminhar. Mesmo as críticas nos auxiliam muito." 


\section{INTRODUÇÃO}

A postura ereta bípede do ser humano pode ser interpretada como uma tarefa para manter o equilíbrio do corpo sobre uma pequena área de suporte, contrapondo-se à ação da força gravitacional. Neste aspecto, a manutenção da postura corporal é influenciada pela integração de vários tipos de informação sensorial e por meio das propriedades passivas do sistema músculoesquelético (DUARTE, 2000).

Ainda, a postura corporal pode ser definida como um arranjo relativo de partes do corpo em um dado momento, estas partes são as articulações (FERRARIO et al. 1995; KENDALL, 2007). Neste sentido, acredita-se que a postura correta, ou adequada, é a posição na qual um mínimo de estresse é aplicado em cada articulação (MAGEE, 2002), ou seja, é um estado de equilíbrio músculoesquelético, que garante quantidade mínima de esforço e sobrecarga, protegendo as estruturas corporais contra lesões ou deformidades, independente da posição na qual estas estruturas estão trabalhando ou repousando (SACCO et al. 2007).

Nessa situação, considerando-se a postura ereta e o plano sagital, a linha de gravidade passa anteriormente às articulações atlanto-occipitais, através dos corpos das vértebras lombares, pela articulação do quadril, anteriormente à articulação do joelho e do tornozelo, projetando-se no centro do quadrilátero de sustentação, equidistante dos dois pés (KENDALL et al. 2007).

No que se refere ao equilíbrio músculoesquelético, a postura estática não é sustentada por músculos isolados, mas por cadeias musculares posturais. Estas cadeias determinam uma interdependência das diversas articulações do corpo, assim, o desequilíbrio em um segmento, pode afetar os segmentos adjacentes, o que por sua vez pode contribuir para gerar desequilíbrios globais na postura corporal. A desorganização de um segmento do corpo implicará em uma nova organização de todos os outros, podendo ocasionar o desenvolvimento de uma postura compensatória que influenciará as funções motoras dependentes (MARQUES, 2005; SOUCHARD, 2003). 
Segundo Kendall (2007), a boa postura é um bom hábito que contribui para o bem estar do indivíduo, enquanto que a estrutura e a função do corpo provêm o potencial para se atingir e se manter uma boa postura. Assim, sob tais condições, os músculos funcionam de forma eficaz e permitem as posições ideais para os órgãos abdominais e torácicos. Por sua vez, uma postura inadequada pode causar dor e alterações funcionais em vários sistemas (YIP et al. 2008; BRINK et al. 2014). A boa postura, segundo Bricot (2001), reflete um equilíbrio entre os estímulos internos e externos do corpo, ocasionando uma resposta de mínimo gasto energético muscular.

A avaliação da postura da cabeça e coluna cervical é comumente empregada como parte do exame de pacientes com cervicalgia, dores de cabeça (FERRACINI et al. 2016) e Disfunções Temporomandibulares (CHAVES et al. 2014). Tem sido postulado que uma postura alterada da cabeça e pescoço pode causar e/ou predispor a condições dolorosas, alterando a biomecânica e o equilíbrio muscular da região craniocervical (ARMIJO-OLIVO et al. 2011). A avaliação postural é geralmente empregada para auxiliar na determinação das estratégias de tratamento e monitorar o progresso do paciente (SAHRMANN, 2002).

A avaliação da postura craniocervical pode abranger a avaliação da postura da cabeça e da curvatura da coluna cervical. A avaliação clínica da postura craniocervical pode ser realizada pela observação visual da posição da cabeça/coluna cervical em relação aos pontos anatômicos de referência (SILVA et al. 2009).

Uma vez que, a cabeça representa $6 \%$ do peso total do corpo, em uma postura mais anteriorizada uma cascata de compensações descendentes pode ser iniciada e afetar significativamente a biomecânica do controle da postura humana, movimentos e atividades (BRICOT, 2001; SZCZYGIEL et al. 2015).

Segundo Cailliet (1997), a postura anteriorizada da cabeça pode ser responsável por lesões de nervos cervicais. Isto ocorre porque a cabeça, fletida para frente, tem peso relativamente maior, 
acentuando a lordose cervical, o que pode levar a um estreitamento dos forames intervertebrais, com consequente compressão dos nervos cervicais.

A exemplo, no estudo de Szczygieł et al. (2015) avaliou-se o efeito da postura da cabeça sobre os movimentos do tórax. Para isso, a pesquisa foi conduzida em um grupo de 65 pacientes. A postura da cabeça e os movimentos do tórax foram avaliados utilizando-se um método fotogramétrico. Por fim, constatou-se que a mudança da posição da cabeça provocou perturbações na forma tridimensional do tórax e dos seus movimentos respiratórios.

Sendo assim, é importante salientar que medir o ângulo craniocervical é um dos métodos comumente empregados para a avaliação da postura da cabeça. Ele é o ângulo formado por uma linha horizontal traçada através do processo espinhoso da sétima vértebra cervical e uma linha que une o processo espinhoso desta vértebra com o tragus da orelha (WATSON e TROTT, 1993; YIP et al. 2008; LAU et al. 2010). Adicionalmente, o alinhamento ideal da cabeça e do pescoço é aquele no qual a cabeça está numa posição bem equilibrada mantida com esforço muscular mínimo. No plano sagital a linha de referência coincide com o lobo da orelha, a cabeça está nivelada baseando-se no fato de que "os olhos buscam o nível do olhar" e a cervical apresenta sua curva anterior normal, discretamente convexa (KENDALL, 2007).

Os métodos de avaliação da postura estática relatados na literatura incluem métodos qualitativos, tais como a observação visual, e métodos quantitativos, como a fotogrametria, no qual as imagens são analisadas usando um software específico (FERRARIO et al. 1995; VAN MAANEN et al. 1996).

A inspeção visual é o método mais comumente utilizado para avaliar a postura na prática clínica (SANTOS, 2011). A avaliação é feita a partir de pontos anatômicos, assim, observa-se a altura dos pontos, seu nivelamento e se as curvaturas são compatíveis com o alinhamento considerado ideal. A vantagem deste método é que ele não requer equipamentos sofisticados (SANTOS, 2001). Porém, os dados quantitativos não podem ser obtidos, e pequenas alterações 
posturais não são detectadas (IUNES et al. 2009). Neste sentido, para este tipo de avaliação qualitativa, alguns estudos referem pobres níveis de concordância inter-examinadores e níveis moderados para a concordância intra-examinador (ERIKSSON et al., 2000; FEDORAK et al., 2003; SILVA et al., 2010).

Passier et al. (2010), por exemplo, realizaram um estudo com o objetivo de determinar a confiabilidade da avaliação por inspeção visual do alinhamento da cabeça e cervical realizada por fisioterapeutas. Os autores concluíram que a avaliação da postura craniocervical realizada pelos avaliadores foi de validade questionável na identificação dos desvios em até 5 graus a partir da postura neutra, quando comparados com as análises quantificadas da postura. Apesar disso, a inspeção visual ainda é o método mais utilizado devido ao seu baixo custo e por ser uma técnica mais rápida de avaliação (GADOTTI e BIASOTTO-GONZALEZ, 2010).

No âmbito da pesquisa, embora alguns estudos utilizem a imagem fotográfica na avaliação postural, apenas através de análise qualitativa, como uma forma de documentação e sem o uso de ferramentas para quantificar tais desvios, verifica-se na literatura que esse é um recurso cada vez mais difundido e discutido. (FARKAS et al. 1980; LEE et al., 1995; WATSON e DONNCHA, 2000; PEREIRA, 2003; PENHA et al., 2005).

Logo, um método viável para obter dados quantitativos é a fotogrametria computadorizada. O nome deste método deriva de três palavras gregas: foto (luz), gramma (registro), e métrica (medida). Em resumo, significa: medir e registrar com o auxílio da luz (EY-CHMIELEWSKA, 2015). Neste método, as fotografias dos sujeitos são tomadas no plano sagital ou frontal com uma câmera montada sobre um tripé nivelado, que está colocada a alguma distância a partir dos indivíduos. As fotografias obtidas são transferidas para um sistema de computador em formato digital. Elas são utilizadas para calcular os ângulos posturais com a ajuda de um software (SACCO et al., 2007). 
A American Society of Photogrammetry, em 1979, definiu fotogrametria como sendo: “a arte, ciência e tecnologia de obtenção de informação confiável sobre objetos físicos e o meio ambiente através de processos de gravação, medição e interpretação de imagens fotográficas e padrões de energia eletromagnética radiante e outras fontes" (TOMMASELLI et al., 1999).

Moradi et al. (2014) enfatizam o uso do método quantitativo em áreas de investigação, seja clínica ou pesquisa. Assim, na prática clínica, além de garantir dados quantificáveis, uma outra vantagem deste método é a possibilidade de medir a postura corporal sem a necessidade de exposição dos pacientes aos raios-X e sem os custos do método radiográfico (DRZAL-GRABIEC et al., 2014; SINGLA e VEQAR, 2014). Além disso, essa é uma técnica relativamente simples e facilmente realizável, utilizada devido às suas vantagens e efetividade na aplicação clínica, como facilidade de fotointerpretação, alta precisão e reprodutibilidade dos resultados (IUNES et al. 2005).

Destaca-se alguns cuidados metodológicos que devem ser tomados para obter registros comparáveis. Desta forma, é fundamental utilizar a mesma câmera, posicioná-la sempre à mesma distância do paciente, ter treinamento fotográfico, utilizar tripé e marcar o chão para posicionar o paciente. Também é preconizado que a fotogrametria postural seja de alta qualidade e nitidez, livre de distorções (paralaxe e zoom), e com dimensão que permita observações e contrastes, que pequenos detalhes corporais sejam visíveis, evitando equívocos na análise (WATSON, 1998).

Os protocolos de coleta de dados nos estudos utilizando fotogrametria como ferramenta de avaliação tendem a ser muito semelhantes, diferindo minimamente de acordo com a finalidade de cada avaliação. Os métodos são baseados em procedimentos básicos, tais como: (1) preparação preliminar do local de coleta com a localização padronizada da câmera e o objeto; (2) A palpação e marcação de pontos de referência anatômicos; e (3) registros fotográficos de indivíduos em determinadas posições (DUNK, LALONDE, CALLAGHAN, 2005; EDMONDSTON et al., 2012). 
No plano sagital, valores angulares são mais frequentemente utilizados do que os valores lineares para avaliar as curvaturas ântero-posterior da coluna vertebral (FURLANETTO et al., 2016).

Fortin et al. (2011) em uma revisão de literatura destacam que no geral, estudos prévios demonstram níveis aceitáveis de confiabilidade dos traçados de fotogrametria, porém poucos relacionados à postura craniocervical.

Nas últimas duas décadas, alguns trabalhos foram conduzidos a fim de descrever a reprodutibilidade das análises qualitativas e quantitativas da postura craniocervical. Foram relatados níveis de confiabilidade excelentes para a análise de postura craniocervical quantitativa. Iunes et al. (2005) verificaram que o método proposto para a quantificação das assimetrias posturais globais, pela fotogrametria, foi satisfatoriamente confiável para a maioria das medidas angulares que foram estudadas, sendo que para a protrusão de cabeça (PC) a confiabilidade foi excelente. Já o ângulo de lordose cervical obteve níveis de confiabilidade aceitáveis. Por outro lado, níveis de reprodutibilidade pobres são no geral associados à análise qualitativa (GADOTTI et al., 2013; SILVA et al., 2010).

Alguns estudos prévios compararam os resultados obtidos através das análises quantitativa e qualitativa da postura craniocervical. No estudo de Iunes et al. (2009), pôde-se observar maior concordância entre examinadores diferentes para a avaliação por meio de fotogrametria do que entre examinadores diferentes que realizaram a avaliação postural global por observação visual. No estudo em questão os dados não se mostraram intercambiáveis com os resultados da análise postural qualitativa, sugerindo, desta forma, que os valores da análise postural encontrados na fotogrametria não podem ser utilizados como referência na avaliação postural visual. Este estudo, porém, não avaliou a sensibilidade e a especificidade das ferramentas de avaliação utilizadas.

Gadotti e Biasotto-Gonzalez (2010) verificaram diferenças nos valores angulares obtidos na fotogrametria entre subgrupos com diferentes níveis de protrusão de cabeça classificados por 
meio da inspeção visual. Já Silva et al. (2010) verificaram pobre correlação entre os métodos (validade de construto). Salahzadeh et al. (2014) realizaram um estudo determinando se a fotogrametria poderia discriminar três grupos categorizados com base no método observacional, encontrando valores de corte referente aos mesmos grupos. Entretanto, apenas a postura da cabeça foi considerada nesses estudos e análises de acurácia, sensibilidade e especificidade, não foram empregadas. Em estudos de acurácia diagnóstica, o consenso Statement for Reporting Studies of Diagnostic Accuracy (STARD) recomenda o emprego das análises estatísticas de especificidade, sensibilidade e acurácia (BOSSUYT et al., 2003; BOSSUYT et al., 2015).

A acurácia de um teste é caracterizada pelos valores de sensibilidade e especificidade de uma dada medida (AKOBENG, 2007). Trata-se de uma técnica gráfica para descrever e comparar a precisão de testes de diagnóstico (AKOBENG, 2007). Por sua vez a sensibilidade é a proporção de indivíduos que apresentam uma determinada condição e cujo teste comparativo fornece resultado positivo e a especificidade refere-se à proporção de indivíduos sem a condição, e cujo teste comparativo fornece resultado negativo (MAHER, LATIMER, COSTA, 2007).

Sabe-se que a avaliação qualitativa é suscetível a erros e a variações entre diferentes examinadores, prejudicando a detecção de pequenas alterações posturais (FEDORAK et al., 2003; NORMAND et al., 2002). Apesar das vantagens no emprego das análises quantitativas, a ausência de valores clínicos de referência para determinação da presença/ausência de desalinhamentos posturais é uma limitação do recurso na prática clínica. Nesse sentido, se faz necessária a verificação da acurácia das mensurações quantitativas em relação a parâmetros qualitativos (medida de referência) e a condução de estudos que visem auxiliar no fornecimento de parâmetros clínicos para utilização das medidas quantitativas de postura craniocervical.

Assim, a justificativa para realização deste estudo é verificar os níveis de acurácia, sensibilidade e especificidade entre a fotogrametria e a avaliação postural visual para avaliação da postura craniocervical. 
A hipótese deste estudo, portanto, é que a fotogrametria demonstrará bons níveis de sensibilidade, especificidade e acurácia para detecção da postura craniocervical obtida através da análise qualitativa (inspeção visual), considerada neste estudo como referência para avaliação postura craniocervical. 


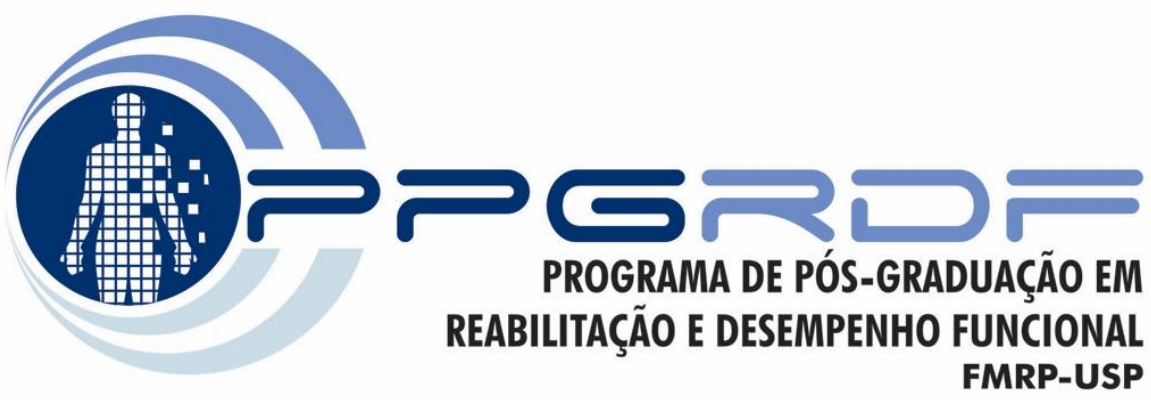

“O sucesso nasce do querer, da determinação e persistência em se chegar a um objetivo. Mesmo não atingindo o alvo, quem busca e vence obstáculos, no mínimo fará coisas admiráveis."

José de Alencar 


\section{OBJETIVOS}

\section{Objetivo Geral}

Identificar os valores de acurácia, sensibilidade e especificidade da fotogrametria em relação a inspeção visual para avaliação da postura craniocervical através da análise de fotografias no plano sagital.

\section{Objetivos Específicos}

1. Verificar a confiabilidade intra e interexaminadores da avaliação por inspeção visual da postura craniocervical no plano sagital;

2. Verificar a confiabilidade intra e interexaminadores da fotogrametria para avaliação da postura craniocervical no plano sagital;

3. Analisar a acurácia da análise por inspeção visual e fotográfica de protrusão de cabeça e lordose cervical para identificar os indivíduos com relato de dor positivo ou negativo

4. Analisar a acurácia da análise por inspeção visual e fotográfica de protrusão de cabeça e lordose cervical para identificar os indivíduos com presença ou ausência de incapacidade relacionada à dor cervical;

5. Verificar o Erro Padrão da Medida (EPM) e a Mínima Diferença Detectável (MDD) das medidas angulares utilizadas para análise da postura craniocervical no plano sagital. 


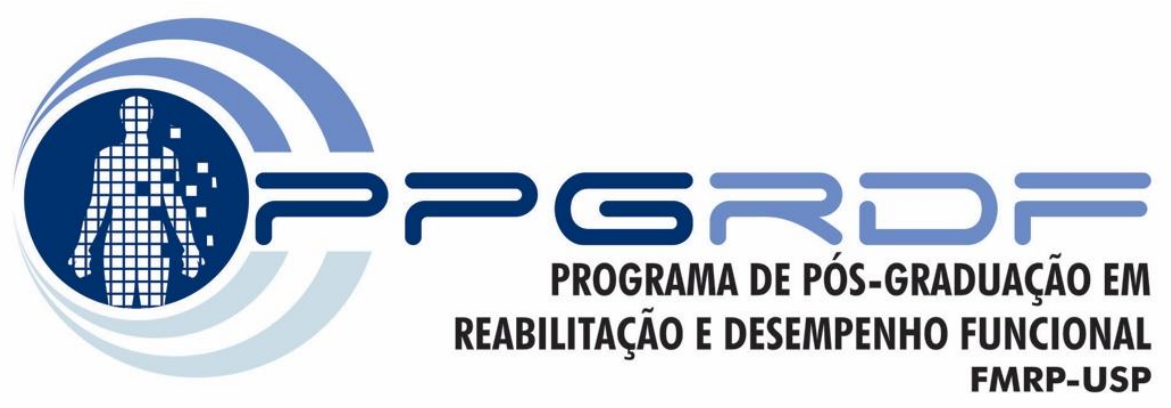

MÉTODOS

"Cada dia que amanhece assemelha-se a uma página em branco, na qual gravamos os nossos pensamentos, ações e atitudes.

Na essência, cada dia é a preparação de nosso próprio amanhã." Chico Xavier 


\section{MÉTODOS}

\subsection{Aspéctos éticos}

O desenvolvimento da pesquisa obteve a aprovação do comitê de ética em pesquisa da Faculdade de Medicina de Ribeirão Preto da Universidade de São Paulo (Protocolo 17328/2015) (ANEXO 1). Esta pesquisa utilizou amostras de um banco de dados codificado do Laboratório de Pesquisa Interdisciplinar na Dor Musculoesquelética (LAPIDOM). Todos os voluntários assinaram termo de consentimento livre e esclarecido. O protocolo experimental deste estudo, foi aprovado pelo Comitê de Ética e Pesquisa envolvendo seres humanos do Hospital das Clínicas de Ribeirão Preto (Protocolo 17328/2015).

\subsection{Amostra, critérios de inclusão e exclusão}

Para a realização deste estudo foram avaliadas 157 voluntárias, mulheres, com idade entre 20 e 60 anos, com e sem relato de dor cervical crônica. Para o cálculo amostral foi considerada a tabela de tamanho amostral descrita por Flahault et al (2005), considerando-se um valor de sensibilidade de pelo menos 0,7 com limite inferior do intervalo de confiança de $95 \%$ de pelo menos 0,55 e power de $95 \%$. O tamanho amostral mínimo necessário seria de 114 indivíduos.

O banco de dados foi codificado, sendo assim, não tivemos acesso a nenhuma informação pessoal das participantes. Esses dados foram oriundos de projetos já aprovados pelo Comitê de Ética em Pesquisa da Faculdade de Medicina de Ribeirão Preto (ANEXOS 2 e 3). Todas as voluntárias assinaram o termo de consentimento livre e esclarecido dos respectivos projetos que participaram (ANEXOS 4 e 5)

Os critérios de exclusão foram indivíduos com síndrome de whiplash cervical e outras condições traumáticas, doenças degenerativas sistêmicas com acometimento de várias articulações, deformidades congênitas de membros superiores e coluna vertebral, história de 
cirurgia na coluna, discrepâncias de membros inferiores verdadeiras, gestantes, lactantes e pósparto (até um ano). Além disso os voluntários foram escolhidos desde que tivessem bom estado geral de saúde, não apresentassem doenças sistêmicas ou neurológicas, lesões ou deformidades musculoesqueléticas evidentes na inspeção e que concordaram em participar da pesquisa.

\subsection{Coleta de imagens}

Esta etapa foi realizada por um único examinador previamente treinado e cego para obtenção das medidas. As voluntárias foram submetidas aos registros fotográficos no plano sagital do corpo inteiro. Para isso, mulheres em trajes de banho foram posicionadas confortavelmente, relaxadas em posição ortostática com os pés paralelos entre si e os braços ao longo do corpo, no mesmo local e em mesmas condições de iluminação. Os registros fotográficos foram obtidos com uma mesma máquina fotográfica digital (Canon, EOS Rebel, Ti3®), que foi posicionada sobre um tripé fotográfico, cujo centro foi posicionado a uma distância fixa de $4 \mathrm{~m}$ de todas as voluntárias (RAINE e TWOMEY, 1997).

Para as imagens englobarem o corpo todo, o centro da lente da máquina fotográfica foi fixado na altura correspondente ao ponto médio da altura máxima da voluntária, sendo utilizada uma objetiva de $35 \mathrm{~mm}$ (NAYLER, 2003; RAINE e TWOMEY, 1997). As imagens foram armazenadas digitalmente para análises posteriores.

Um fio de prumo foi fixado verticalmente e paralelamente a voluntária, a uma distância fixa de $33 \mathrm{~cm}$ das voluntárias, as quais foram posicionadas sobre um caixote de madeira de $15 \mathrm{~cm}$ de altura, 40cm de comprimento e 30cm de largura (BELLI et al., 2009). Os pontos anatômicos pré-estabelecidos foram previamente posicionados, por um único avaliador, no corpo das voluntárias da pesquisa, mediante a colocação de adesivos colantes de $1 \mathrm{~cm}^{2}$ de borracha (Figura 1). A descrição dos pontos anatômicos pode ser encontrada na tabela 1. 
Métodos $\mid 35$

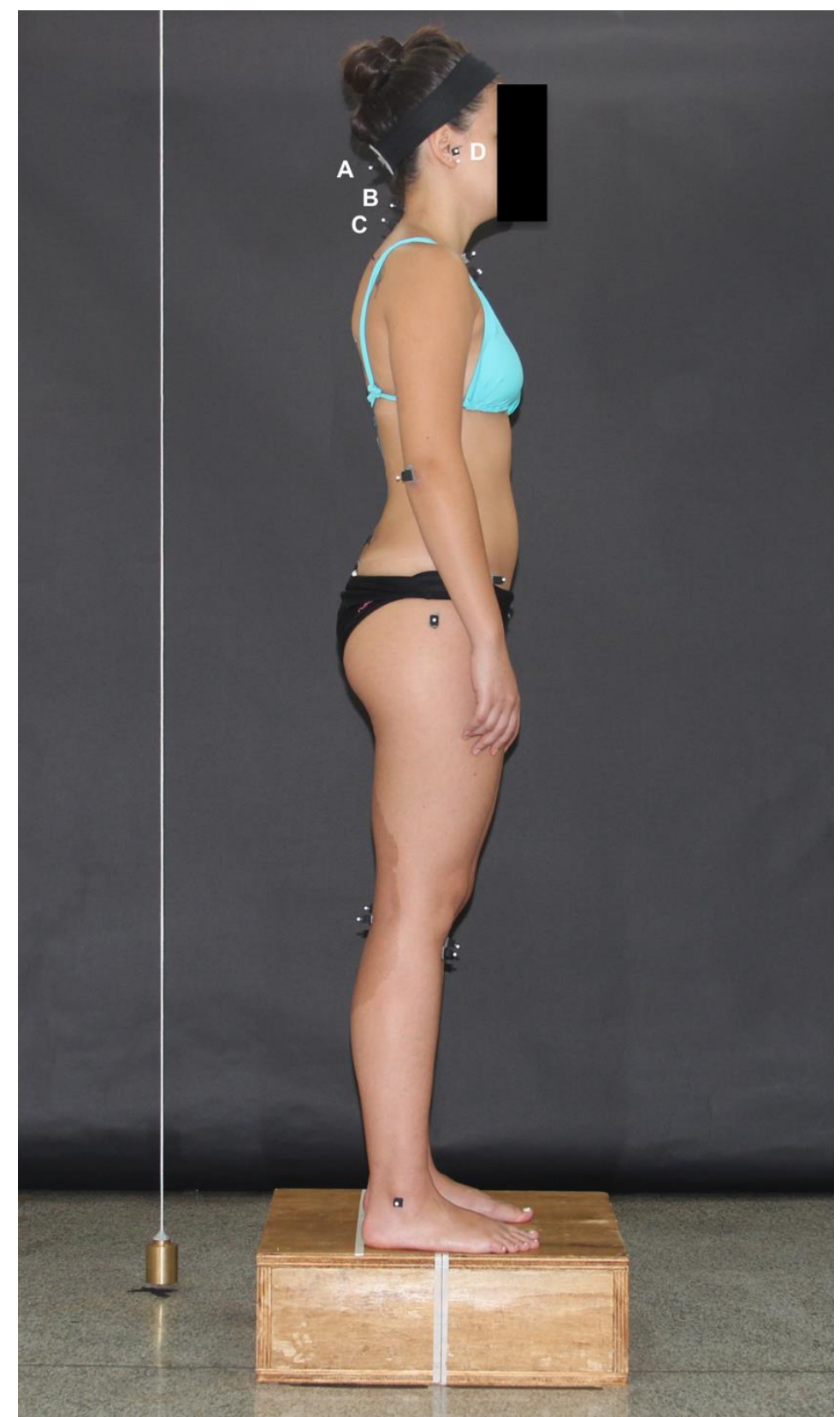

Figura 1. Imagem adotada para análise da postura da cabeça e cervical. Os seguintes pontos (demarcados previamente nas voluntárias) foram considerados para análise postural: A - protuberância occipital, B - processo espinhoso da quarta vértebra cervical (C4), C - processo espinhoso da sétima vertebra cervical (C7) and D - tragus da orelha. Outras marcações não foram consideradas.

Tabela 1. Identificação dos pontos anatômicos para demarcação. PONTOS ANATÔMICOS

Tragus da orelha Ângulo inferior da escápula

Protuberância occipital Olécrano da ulna

Processo espinhoso de C4

Processo espinhoso de C7 


\subsection{Análise dos registros fotográficos}

\subsubsection{Avaliação Qualitativa}

Foram convidados como avaliadores deste projeto, com o intuito de realizar avaliação postural por inspeção visual, 5 fisioterapeutas experientes, com pelo menos 5 anos ou mais de prática clínica na área de ortopedia. Cada um deles realizou as avaliações através do preenchimento de um formulário que continha os itens e opções de alterações posturais previamente determinados, sendo eles:

- Postura da cabeça: Normal, Hiperlordose, Inversão da curvatura e Retificação da curvatura.

- Postura cervical: Normal, Protrusão Leve, Protrusão Moderada e Protrusão Severa. Após o período de pelo menos uma semana, os mesmos avaliadores realizaram reavaliações das mesmas fotos com o propósito de analisar a concordância intra-examinadores. Todos os examinadores realizaram as avaliações independentemente, sem comunicação com os demais examinadores. As faces das voluntárias nas imagens analisadas foram tarjadas para evitar qualquer identificação. Além disso, as análises das imagens foram todas realizadas no mesmo computador do laboratório de pesquisa, protegido com senhas e sem acesso de outros, para minimizar o risco de compartilhamento indevido de imagens. Além disso, os examinadores não acessaram este computador com dispositivos móveis de dados tais como pen-drives e Hds.

As fotos foram apresentadas aleatoriamente em apresentação de Power point e os avaliadores tinham a liberdade de realizar as avaliações com duração livre. Ao final das avaliações, as respostas assinaladas pelos examinadores eram consideradas como códigos numéricos para fins estatísticos de comparação.

\subsubsection{Avaliação Quantitativa}


A avaliação quantitativa das imagens foi realizada através do software CorporisPro versão 3.1 (DataHominis, 2010), com a finalidade de detectar e quantificar simetrias e assimetrias bem como desalinhamentos craniocervicais presentes em cada voluntário. Esta avaliação foi realizada por dois avaliadores, e cada avaliador era cego para a avaliação do outro

As fotos do projeto foram analisadas em um computador Hp Pavilon 23 AiOPCBR, com processador i5 e Windows 8. Foi selecionada 1 foto (formato JPEG) de cada voluntária no plano sagital. Após o cadastro das fotos no programa, foi realizada a calibração vertical e horizontal de cada foto. Para realizar a calibração foi utilizado zoom de $33 \%$ nas mesmas. Após realizar a calibração vertical, a calibração horizontal foi projetada automaticamente. Após esta etapa foram feitas as análises dos ângulos utilizando um zoom de 73\%. Os ângulos eram formados pelas linhas traçadas a partir dos pontos anatômicos demarcados na paciente. Cada foto foi analisada 3 vezes com um intervalo de sete dias entre as avaliações.

A análise da confiabilidade inter e intra-examinador dos traçados foi realizada com todos os registros dos participantes do estudo. Os traçados foram feitos inicialmente e, em seguida, repetidos após um período de sete dias. As análises foram realizadas por dois examinadores previamente treinados (20 horas de treinamento) (FERREIRA et al., 2014).

No plano sagital, os ângulos mensurados estão descritos a seguir (Figura 2):

- Ângulo da lordose cervical - ALC: formado pela intersecção entre a reta formada da protuberância occipital até o prolongamento horizontal do processo espinhoso de $\mathrm{C} 4$ até o fio de prumo e a reta formada do processo espinhoso de $\mathrm{C} 7$ até o prolongamento horizontal do processo espinhoso de $\mathrm{C} 4$ até o fio de prumo;

- Ângulo craniovertebral- ACV: formado pela intersecção entre a reta formada do tragus da orelha até o processo espinhoso de $\mathrm{C} 7$ e a reta paralela ao solo; 

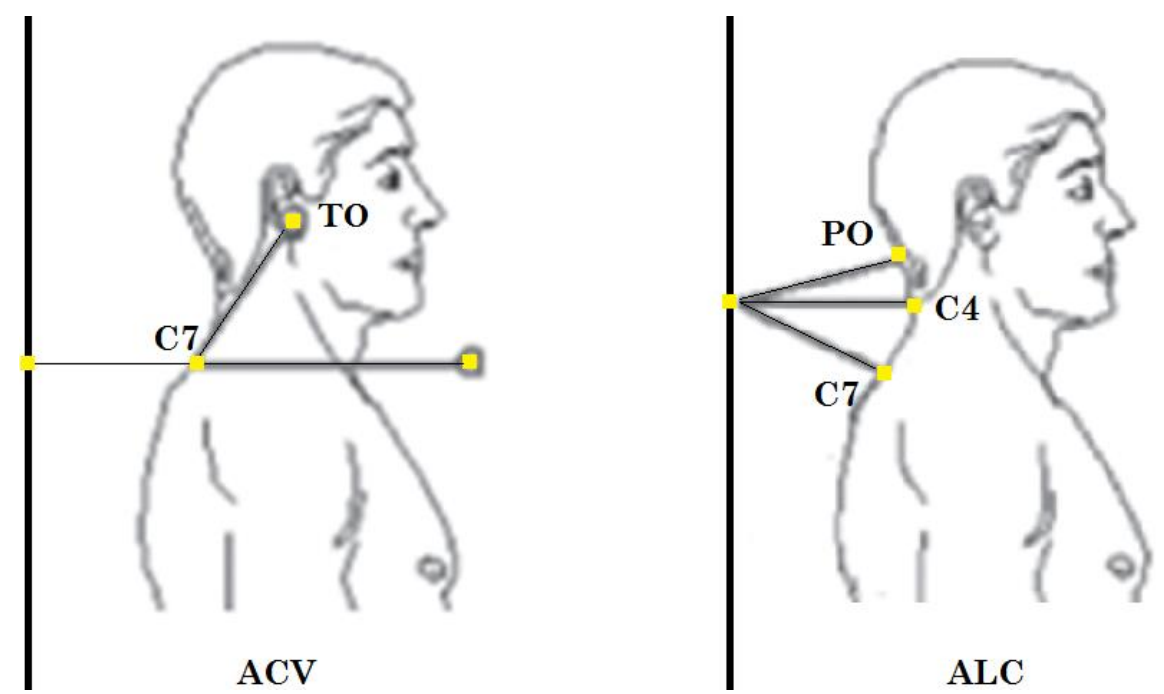

Figura 2. Pontos e ângulos avaliados no plano sagital: PO (protuberância occipital); C4 (processo espinhoso C4); C7 (processo espinhoso C7); TO (tragus). ACV (ângulo craniovertebral) e ALC (ângulo lordose cervical).

\subsection{Escala numérica de dor (END)}

Todas as voluntárias graduaram o relato de presença ou ausência de dor no momento da avaliação em uma escala numérica de dor (END) (Figura 3) considerando 0 sem dor e 10 a pior dor possível. A escala numérica de 10 pontos demonstrou níveis aceitáveis de confiabilidade teste-reteste (CLELAND, CHILDS; WHITMAN; 2008), bem como demonstrou bons níveis de responsividade (FERREIRA-VALENTE, PAIS-RIBEIRO, JENSEN; 2011).

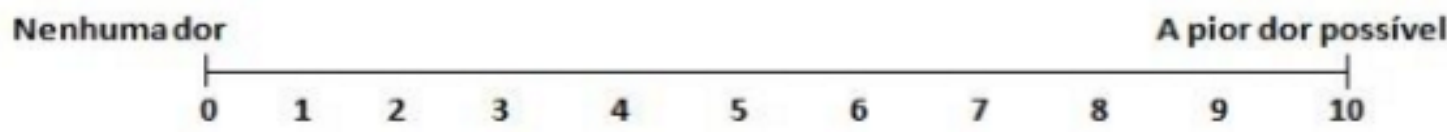

Figura 3. Escala numérica de dor (END)

3.6. Índice de Incapacidade Relacionada à Dor no Pescoço - NDI-BR (Neck Disability Index - ANEXO 6) 
Uma das ferramentas mais utilizadas para avaliação da incapacidade cervical é o Índice de Incapacidade Relacionada à Dor no Pescoço (Neck Disability Index, VERNON et al., 2008), um instrumento com confiabilidade moderada e responsividade adequada (ICC 0,50 IC95\% 0,42 e AUC 0,83 IC95\% 0,15) (CLELAND, CHILDS, WHITMAN, 2008). Este questionário foi aplicado de forma auto-administrável em todas as voluntárias que relataram dor cervical crônica. (Anexo 6).

O NDI-BR é composto por 10 itens: 1) intensidade dor, 2) Cuidado pessoal, 3) Levantar coisas, 4) Leitura, 5) Dores de Cabeça, 6) Prestar a atenção, 7) Trabalho, 8) Dirigir automóveis, 9) Dormir e 10) Diversão (STERLING e REBBECK, 2005). Foi inicialmente proposto por Vernon e Mior (1991) e a versão adaptada para o português-brasileiro será utilizada (COOK et al., 2006). A versão em português brasileiro apresentou bons níveis de consistência interna (0.74) e confiabilidade teste-reteste. As questões do NDI-BR possuem 6 possíveis respostas variando entre 0 a 5. A classificação de incapacidade (alteração mínima detectável é de 5 pontos ou 10\%) é considerada da seguinte maneira:

- $10-28 \%$ (5-14 pontos) - incapacidade leve;

- $30-48 \%$ (15- 24 pontos) - incapacidade moderada;

- $50-68 \%$ (25 - 35 pontos) - incapacidade severa;

- $72 \%$ ou mais (36 pontos ou mais) - incapacidade completa.

\subsection{Análise dos resultados}

A precisão de um teste de diagnóstico é caracterizada pela sua sensibilidade e especificidade. A sensibilidade e especificidade de um teste, no entanto, depende do nível que foi escolhida como o ponto de corte para o normal/não normal. O receiver operating characteristic (ROC) é amplamente aceito como um método para selecionar um ponto de corte ótimo para um teste e para comparar a precisão dos testes de diagnóstico (ALTMAN; BLAND, 1994; 
OBUCHOWSKI; LIEBER; WIANS, 2004). A curva é gerada através da representação gráfica da sensibilidade de todos os possíveis pontos de corte para o teste no eixo y como uma função de 1especificidade no eixo $x$, e pode ser usada para selecionar ótimos valores de corte para um resultado de teste, para avaliar a precisão de um teste de diagnóstico, e para comparar a utilidade de diferentes testes. A classificação da área sob a curva ROC é a seguinte: AUC>0,9: alta acurácia, 0,7<AUC<0,9: moderada acurácia, 0,5<AUC<0,7: baixa acurácia e AUC<0,5: resultado ao acaso (AKOBENG, 2007). Para a análise de acurácia, sensibilidade e especificidade, os participantes foram agrupados em 5 subgrupos para análise qualitativa da postura da cabeça: protrusão normal/leve, protrusão leve, protrusão leve/moderada e protrusão moderada/severa. E em 4 subgrupos para análise qualitativa da postura cervical: normal, hiperlodose, hiperlordose/retificação e retificação/cifose. Os grupos mistos, por exemplo: protrusão moderada/severa, obtiveram classificações de ambos os perfis posturais. Ou seja, 2 examinadores classificaram o participante como protrusão de cabeça moderada e 2 examinadores como protrusão de cabeça severa. Para definição da alocação dos participantes em cada subgrupo pelo menos 2 examinadores deveriam concordar sobre o perfil postural do voluntário. Assim, coincidência nos perfis atribuídos entre 2 examinadores foi considerada $40 \%$ de concordância, coincidência entre 3 examinadores $60 \%$, coincidência entre 4 examinadores $80 \%$ e entre 5 examinadores $100 \%$ de concordância na atribuição do perfil postural.

Para realizar a cross-validation da análise de sensibilidade e especificidade uma ANOVA foi utilizada para comparação dos valores angulares das medidas de postura craniocervical entre os subgrupos divididos de acordo com a classificação da inspeção visual. Foi utilizado o post hoc de Bonferroni $(\mathrm{p}<0.05)$.

A confiabilidade/reprodutibilidade das avaliações posturais foi avaliada utilizando-se o Coeficiente de Correlação Intraclasse (CCI) e seus respectivos intervalos de confiança (IC) a 95\%, considerando-se os níveis de classificação descritos por Fleiss et al (2003), sendo CCI <0.40 
considerado pobre, $0.40<\mathrm{CCI}<0.75$, moderado e $\mathrm{CCI}>0.75$, excelente. (MAHER; LATIMER; COSTA, 2007).

Para classificação dos valores de Kappa ponderado (K) foi utilizada a seguinte categoria de classificação: $\mathrm{K}<0=$ pobre; $0 \leq \mathrm{K} \leq 0.20=$ leve, $0.21 \leq \mathrm{K} \leq 0.40=$ razoável; $0.41 \leq \mathrm{K} \leq 0.60=$ moderado; $0.61 \leq \mathrm{K} \leq 0.80=$ muito bom e $0.81 \leq \mathrm{K} \leq 1.00=$ excelente (Sim e Wright, 2005).

Para análise do Erro Padrão da Medida (SEM - Standard Error of Measurement) foi utilizada a fórmula descrita por Weir (2005): EPM = DP $\sqrt{ }$ CCIx(1 - CCI) (WEIR, 2005) na qual DP = desvio padrão. Já a Mínima Diferença Detectável foi calculada considerando-se: MDD = $1,96 \times \sqrt{ } 2 \times \operatorname{EPM}($ WEIR, 2005).

Para comparação entre os valores médios dos ângulos de postura crânio-cervcial entre os grupos com e sem dor, com e sem incapacidade relacionada à dor cervical foi utilizado o teste-t de student $(\mathrm{p}<0,05)$.

Todas as análises foram realizadas através do software estatístico Statistical Package for Social Science for Windows (SPSS) versão 22.0 ((IBM Corp. Released 2013. Armonk, NY: IBM Corp.). 


\section{RESULTADOS}

A amostra foi constituída de 157 voluntárias do gênero feminino, com média de idade de 35,60 e desvio padrão $(\mathrm{DP})=10,36$ anos, média de peso de $68,16 \mathrm{DP}=13,41$ $\mathrm{kg}$ e média de altura de $1,63 \mathrm{DP}=0,07 \mathrm{~m}$.

Dos 157 indivíduos, 52\% (n=82) relataram dor cervical há mais de 3 meses, e $48 \%(\mathrm{n}=75)$ asintomáticos. A intensidade de dor média entre os indivíduos com dor foi de $5,76 \mathrm{DP}=1,86$.

Para obtenção da classificação dos voluntários quanto aos perfis posturais na análise de inspeção visual, para a postura da cabeça, a amostra foi dividida em subgrupos, sendo eles: normal $(n=99)$, normal/leve $(n=12)$, leve $(n=26)$, leve/moderado $(n=3)$ e moderado/severo $(n=17)$. Já para a classificação da lordose cervical, a amostra foi subdividida em normal $(n=102)$, hiperlordose $(n=31)$, hiperlordose/retificação $(n=5)$ e retificação/inversão $(n=19)$.

\subsection{Concordância intra e interexaminadores para avaliação dos ângulos por inspeção postural visual e Fotogrametria}

Os valores de concordância intra-examinadores obtidos para a análise de postura craniocervical qualitativa foram descritos como valores de Kappa e porcentagem obtida nas diferentes categorias de classificação. $\mathrm{Na}$ análise da concordância intra-examinadores foram observados valores médios de Kappa considerados muito bons em $80 \%$ das avaliações de teste-reteste para as análises qualitativas da postura da cabeça. Já para a avaliação qualitativa da postura cervical foram observados valores médios de Kappa considerados muito bons $60 \%$ e excelentes também em $20 \%$ das avaliações de teste-reteste (Tabela 2). Na análise intra-examinador 
da avaliação da postura craniocervical quantitativa obtivemos valores de CCI médios excelentes para ambos os ângulos considerados para ambos os examinadores (Tabela 2).

Já para a análise da concordância interexaminadores na avaliação qualitativa foram observados valores médios de Kappa considerados moderados em $60 \%$ e muito bons em $30 \%$ das comparações entre pares de examinadores para a avaliação de postura da cabeça. Também foram observados valores considerados de concordância considerados moderados em 50\% das comparações entre pares de examinadores para a avaliação da postura cervical (Tabela 3). Ao observarmos os valores médios de CCI para as medidas de confiabilidade interexaminadores para análise postural qualitativa foram obtidos valores considerados excelentes para postura da cabeça 0,84 (IC95\%:0,83-0,90) e moderados para postura cervical 0,48 (IC95\%:0,35-0,60) (Tabela 2). Já para a análise interexaminadores da análise postural quantitativa novamente também foram observados apenas valores de CCI considerados excelentes para ambos os ângulos considerados neste estudo (Tabela 3).

Tabela 2. Valores médios de kappa, Coeficiente de Correlação Intraclasse (CCI) e intervalos de confiança (IC 95\%) para confiabilidade intra-examinador para avaliações de postura craniocervical obtidas por meio de métodos quantitativos (Ângulo Craniovertebral e Ângulo Lordose Cervical) e qualitativos (inspeção visual).

\begin{tabular}{lcc}
\hline Examinadores & Postura da cabeça & Postura da lordose cervical \\
\hline Examinador $1^{\alpha}$ & Análise postural qualitativa (Kappa/IC 95\%) \\
Examinador $2^{\alpha}$ & $0.78(0.61-0.99)$ & $0.41(0.26-0.49)$ \\
Examinador $3^{\alpha}$ & $0.71(0.48-0.92)$ & $0.61(0.31-0.92)$ \\
Examinador $4^{\alpha}$ & $0.75(0.6-0.87)$ & $0.76(0.65-0.85)$ \\
Examinador $5^{\alpha}$ & $0.94(0.83-1)$ & $0.84(0.77-0.92)$ \\
\hline $\mathrm{K}<0$ & $0.79(0.76-0.83)$ & $0.57(0.37-0.76)$ \\
$0<\mathrm{K}<0.2$ & 0 & 0 \\
$0.21<\mathrm{K}<0.4$ & 0 & 0 \\
$0.41<\mathrm{K}<0.6$ & 0 & $\mathrm{n}=1(20 \%)$ \\
$0.61<\mathrm{K}<0.8$ & 0 & $\mathrm{n}=3(60 \%)$ \\
$0.81<\mathrm{K}<1.0$ & $\mathrm{n}=4(80 \%)$ & $\mathrm{n}=1(20 \%)$ \\
\hline
\end{tabular}




\section{Análise postural quantitativa (CCI/ IC 95\%)}

\begin{tabular}{lcc}
\hline Examinador 1 (IC 95\%) & $0.98(0.97-0.98)$ & $0.99(0.98-1.00)$ \\
Examinador 2 (IC 95\%) & $0.99(0.99-1.00)$ & $0.98(0.97-0.99)$ \\
\hline $\mathrm{K}:$ Kappa, $\mathrm{K}<0=$ pobre; $0<\mathrm{K}<0.2=$ leve; $0.21<\mathrm{K}<0.4=$ razoável; $0.41<\mathrm{K}<0.6=$ moderado; $0.61<\mathrm{K}<0.8=$ muito \\
bom; $0.81<\mathrm{K}<1.0=$ excelente \\
CCI $<0,40=$ pobre; $0,40<\mathrm{CCI}<0,7=$ moderado; $\mathrm{CCI}>0,75=$ excelente \\
ACV: Ângulo craniocervical; ALC: Ângulo lordose cervical.
\end{tabular}

Tabela 3. Valores médios de kappa, Coeficiente de Correlação Intraclasse e intervalos de confiança (IC 95\%) para medidas de confiabilidade interexaminadores para avaliações de postura craniocervical obtidas a partir de métodos quantitativos (ACV e ALC) e qualitativos (inspeção visual).

\begin{tabular}{|c|c|c|}
\hline Examinadores & Postura da cabeça & $\begin{array}{c}\text { Postura da lordose } \\
\text { cervical }\end{array}$ \\
\hline \multicolumn{3}{|c|}{ Análise postural qualitativa (Kappa/IC 95\%) } \\
\hline Examinadores 1 e 2 & $0.57(0.37-0.77)$ & $0.60(0.42-0.79)$ \\
\hline Examinadores 1 e 3 & $0.55(0.35-0.75)$ & $0.45(0.26-0.67)$ \\
\hline Examinadores 1 e 4 & $0.56(0.18-0.95)$ & $0.32(0.18-0.33)$ \\
\hline Examinadores 1 e 5 & $0.70(0.53-0.88)$ & $0.54(0.35-0.72)$ \\
\hline Examinadores 2 e 3 & $0.83(0.65-0.93)$ & $0.53(0.32-0.75)$ \\
\hline Examinadores 2 e 4 & $0.41(0.22-0.58)$ & $0.27(0.06-0.46)$ \\
\hline Examinadores 2 e 5 & $0.65(0.45-0.86)$ & $0.58(0.38-0.77)$ \\
\hline Examinadores 3 e 4 & $0.44(0.17-0.73)$ & $0.30(0.09-0.48)$ \\
\hline Examinadores 3 e 5 & $0.64(0.45-0.86)$ & $0.70(0.52-0.85)$ \\
\hline Examinadores 4 e 5 & $0.47(0.15-0.81)$ & $0.44(0.25-0.63)$ \\
\hline $\mathrm{K}<0$ & 0 & 0 \\
\hline $0<\mathrm{K}<0.2$ & 0 & 0 \\
\hline $0.21<\mathrm{K}<0.4$ & 0 & $\mathrm{n}=3(30 \%)$ \\
\hline $0.41<\mathrm{K}<0.6$ & $\mathrm{n}=6(60 \%)$ & $\mathrm{n}=6(50 \%)$ \\
\hline $0.61<\mathrm{K}<0.8$ & $\mathrm{n}=3(30 \%)$ & $\mathrm{n}=1(10 \%)$ \\
\hline $0.81<\mathrm{K}<1.0$ & $\mathrm{n}=1(10 \%)$ & 0 \\
\hline Confiabilidade total (CCI) & $0.84(0.83-0.90)$ & $0.48(0.35-0.60)$ \\
\hline \multicolumn{3}{|c|}{ Análise postural quantitativa (CCI/ IC 95\%) } \\
\hline Confiabilidade interexaminadores (1 vs. 2 / IC 95\%) & $0.99(0.98-1.0)$ & $0.96(0.92-0.98)$ \\
\hline
\end{tabular}




\subsubsection{Erro Padrão da Medida (EPM) e Mínima Diferença Detectável (MDD)}

Foram observados valores de Erro Padrão da Medida (EPM) para o ACV de 0,73 e para o ALC de 0,42 e Mínima Diferença Detectável (MDD) de 2,02 e 1,16 para ACV e ALC, respectivamente (Tabela 4).

Tabela 4. Dados resultantes da análise de erro padrão da medida (EPM) e mínima diferença detectável (MDD) do Coeficiente de Correlação Intraclasse (CCI) e intervalos de confiança 95\% (IC 95\%), para a confiabilidade intra-examinador para os ângulos de craniovertebral e lordose cervical, obtidos através da fotogrametria

$\begin{array}{llll}\text { Postura } & \text { CCI (IC 95\%) } & \text { EPM* } & \text { MDD** }\end{array}$

ACV $\quad 0,98(0,97-0,98) \quad 0,73 \quad 2,02$
ALC
$0,99(0,98-1,00)$
0,42
1,16

$* \mathrm{EPM}=\mathrm{DP} \sqrt{\mathrm{CCCx}}(1-\mathrm{CCI})$

$* * \mathrm{MDD}_{95}=1.96 \times \mathrm{EPM} \times \sqrt{ } 2$

DP: desvio padrão da amostra

\subsection{Classificação dos subgrupos}

Através de procedimento exploratório dos dados, foram testados diferentes valores de ângulos de ACV e ALC obtidos na fotogrametria que melhor discriminassem (melhores níveis de acurácia, sensibilidade e especificidade) os subgrupos de voluntários obtidos através da análise de inspeção visual (ângulo craniovertebral: normal, protrusão leve, protrusão moderada ou protrusão severa e ângulo de lordose cervical: normal, hiperlordose, retificação, cifose).

Para obtenção da classificação dos voluntários quanto aos perfis posturais na análise de inspeção visual, foi considerado a porcentagem de concordância entre os examinadores. Para a postura da cabeça, $13 \%$ dos voluntários $(n=21)$ foram 
classificados considerando-se uma porcentagem de concordância interexaminadores de 40\% (2 examinadores concordantes), 32\% $(n=50)$ foram classificados considerando-se uma porcentagem de concordância interexaminadores de $60 \%$ (ao menos 3 examinadores concordantes), 33\% ( $\mathrm{n}=52)$ foram classificados considerandose uma porcentagem de concordância interexaminadores de 80\% (ao menos 4 examinadores concordantes) e $22 \%(\mathrm{n}=34)$ foram classificados considerando-se uma porcentagem de concordância interexaminadores de 100\% (todos os examinadores concordando na classificação). Ou seja, para a maioria dos voluntários $(87 \%=32 \%+$ $33 \%+22 \%$ ) foi observada concordância no perfil postura adotado para análises do estudo em pelo menos $60 \%$ das avaliações.

Já para a postura cervical, $15 \%$ dos voluntários $(n=24)$ foram classificados considerando-se uma porcentagem de concordância interexaminadores de 40\%, $41 \%$ ( $n=65)$ foram classificados considerando-se uma porcentagem de concordância interexaminadores de $60 \%, 36 \%(n=56)$ foram classificados considerando-se uma porcentagem de concordância interexaminadores de $80 \%$ e $8 \% \quad(n=12)$ foram classificados considerando-se uma porcentagem de concordância interexaminadores de $100 \%$. Ou seja, para a maioria dos voluntários $(85 \%=41 \%+36 \%+8 \%)$ foi observada concordância no perfil postura adotado para análises do estudo em pelo menos $60 \%$ das avaliações.

Considerando a classificação de avaliação qualitativa da postura da cabeça foi observado que a maioria dos voluntários foi classificada na categoria normal para postura da cabeça $(71 \%, \mathrm{n}=111)$ (Tabela 5). Também foi verificada diferença significativa entre os valores médios do ângulo ACV nos subgrupos classificados de acordo com a análise de postura qualitativa. O grupo protrusão moderada/severa obteve valor médio significativamente menor para o ACV em relação aos grupos 
normal e leve (Tabela 5).

Já para a postura cervical, na classificação de avaliação qualitativa da postura cervical foi observado que a maioria dos voluntários foi classificada na categoria lordose normal (65\%) (Tabela 6). Foi observada diferença significativa entre os subgrupos para o ALC (Tabela 6).

Tabela 5. Pontuação Média dos ângulos craniovertebrais (ACV) de acordo com níveis de sensibilidade e especificidade.

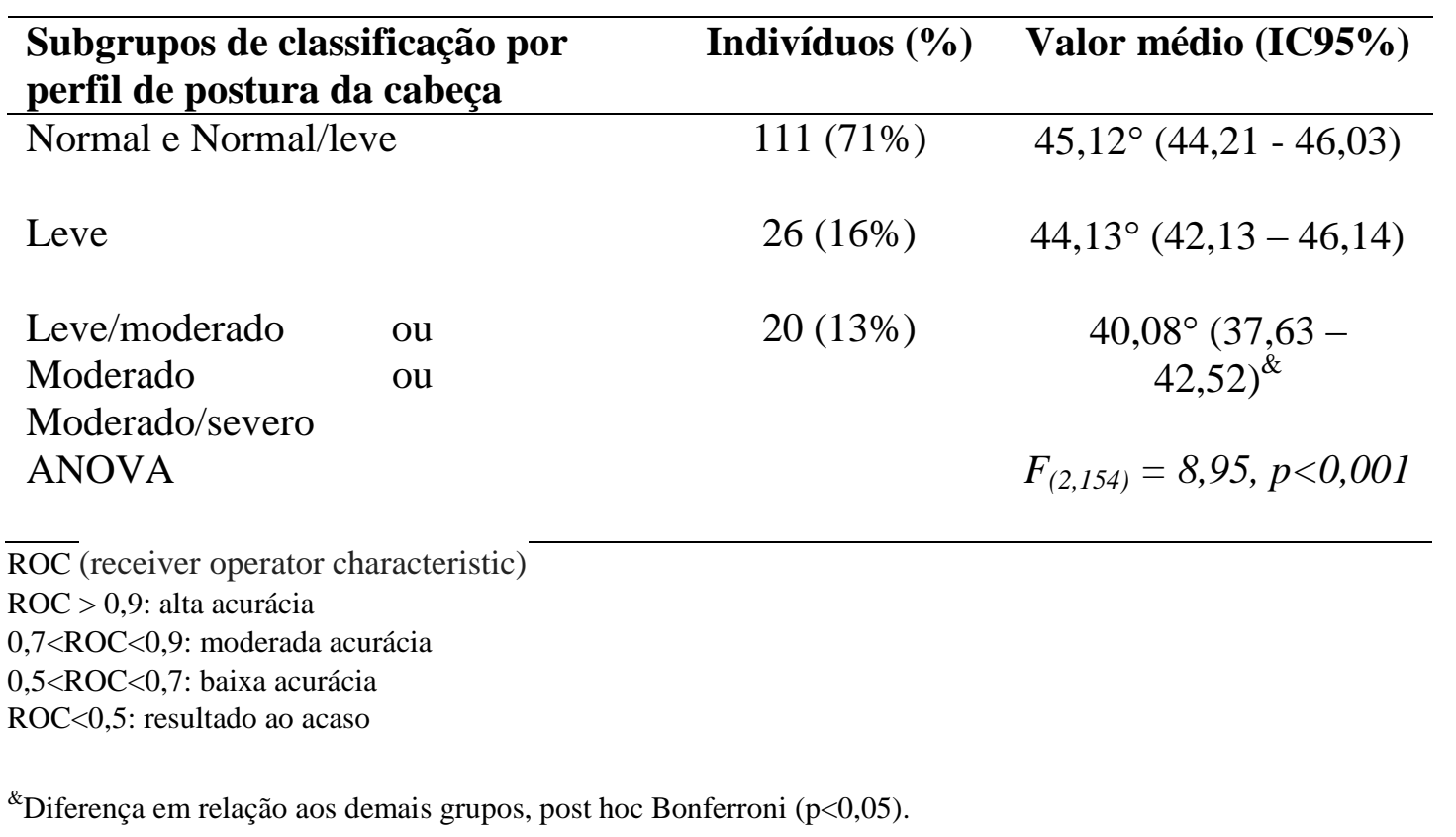

Tabela 6. Pontuação média dos ângulos da lordose cervical (ALC) de acordo com bons níveis de sensibilidade e especificidade.

\begin{tabular}{lcc}
\hline $\begin{array}{l}\text { Subgrupos de classificação por } \\
\text { perfil de postura da cervical }\end{array}$ & Indivíduos (\%) & Valor médio (IC95\%) \\
\hline Normal & $102(65 \%)$ & $13,90^{\circ}(13,19-14,62)^{\&}$ \\
Hiperlordose & $31(20 \%)$ & $11,09^{\circ}(9,44-12,74)^{\&}$ \\
Hiperlordose/retificação & $24(15 \%)$ & $16,49^{\circ}(14,79-18,20)^{\&}$ \\
e Retificação/Inversão & & \\
ANOVA & & $F_{(2,154)}=13,32, p<0,001$ \\
\hline
\end{tabular}


ROC > 0,9: alta acurácia

$0,7<\mathrm{ROC}<0,9$ : moderada acurácia

$0,5<$ ROC $<0,7$ : baixa acurácia

$\mathrm{ROC}<0,5$ : resultado ao acaso

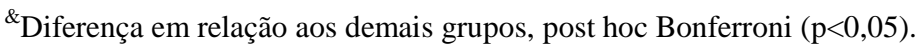


4.2. Acurácia das medidas do ângulo craniovertebral e ângulo lordose cervical por avaliação postural por fotogrametria

\subsubsection{Protrusão de cabeça}

Foram observados valores de acurácia moderada $(0,8)$ para o valor de corte do $\operatorname{ACV}$ de $42,07^{\circ}$ (0,70 para sensibilidade e 0,72 para especificidade) na comparação dos subgrupos normal + normal/leve + leve para protrusão de cabeça $v s$. Leve/Moderado, Moderado, Moderado/Severo, Severo para protrusão de cabeça. Dessa maneira, o valor de $42,07^{\circ}$ mostrou-se adequado para identificar o subgrupo com protrusão moderada/severa dos demais subgrupos (Tabela 7/ Figura 4).

Tabela 7. Níveis de acurácia, sensibilidade e especificidade do Ângulo Craniovertebral (ACV) em relação aos subgrupos classificados através da análise qualitativa (inspeção visual)

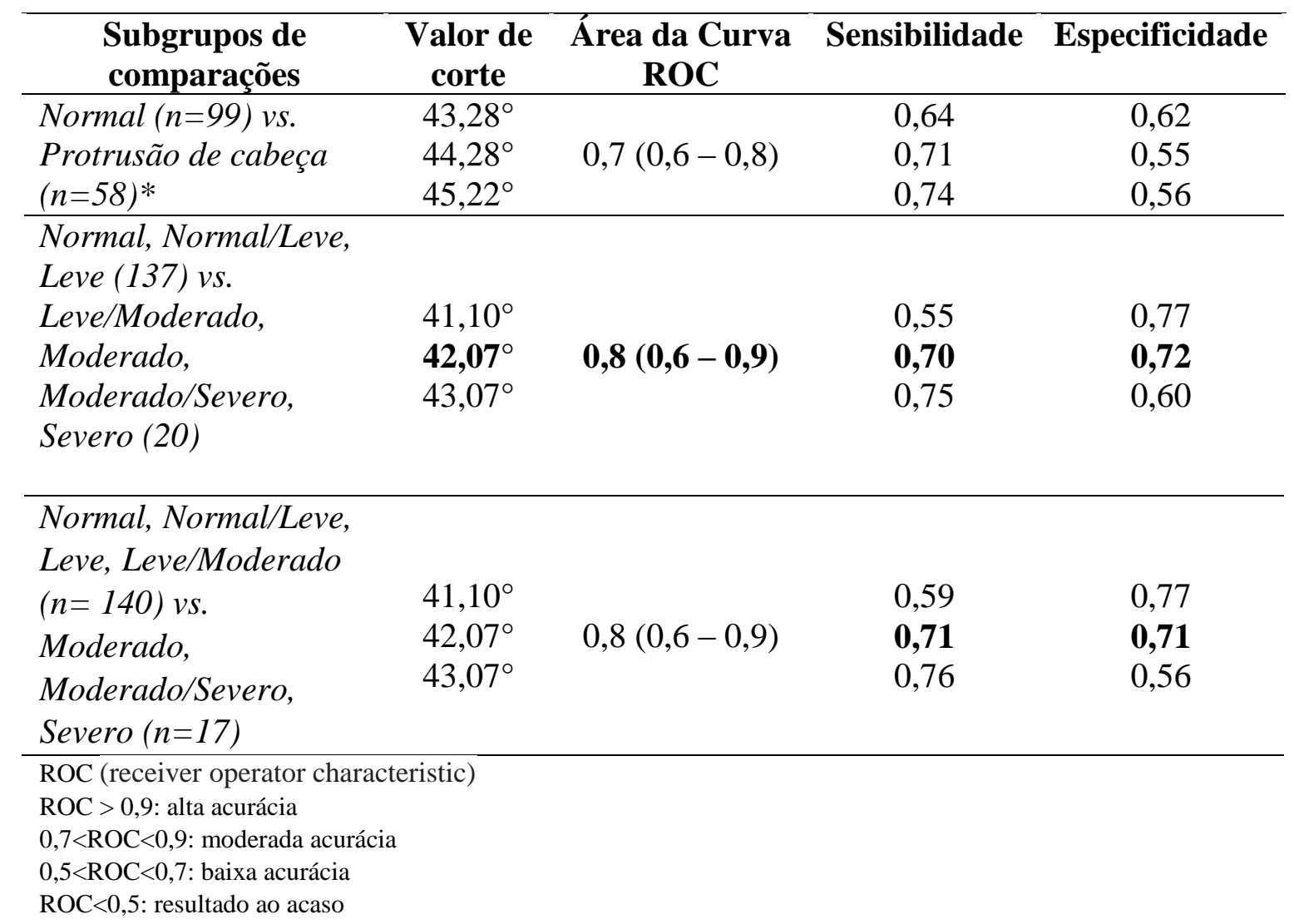


${ }^{\&}$ Diferença em relação aos demais grupos, post hoc Bonferroni $(\mathrm{p}<0,05)$.

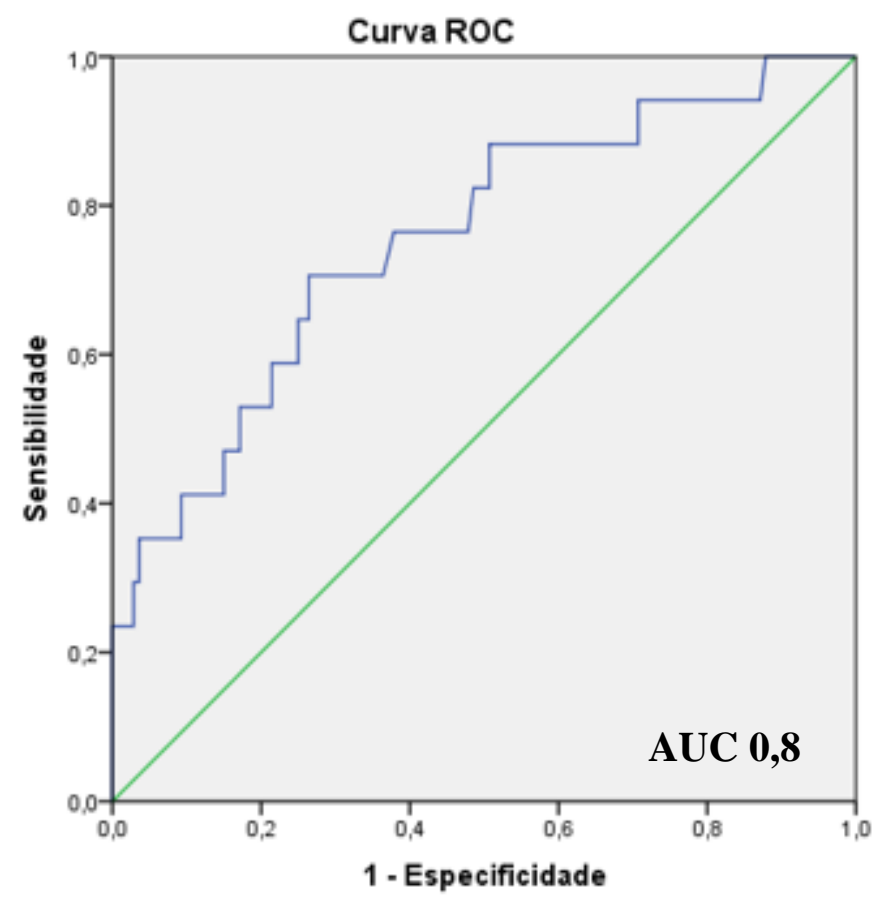

Figura 4. Curva ROC (receiver operator characteristic). Área sob a curva (AUC) para avaliação postural craniovertebral por fotogrametria considerando os grupos normal (composto pelos subgrupos normal, normal/leve, leve) e protrusão de cabeça. Acurácia moderada para o valor de corte $42,07^{\circ}$.

\subsubsection{Lordose Cervical}

Para as classificações do ALC, considerando os subgrupos normal vs. hiperlordose, foram obtidos valores de acurácia de 0,7 , o melhor valor de corte do ALC foi de $12,05^{\circ}$ com valores de sensibilidade e especificidade de 0,74 e 0,72 , respectivamente. Já quando consideramos os subgrupos Normal vs. Retificação/cifose, obtivemos um melhor valor de acurácia de 0,8 para o valor de corte do ALC de 15,38 com valores de 0,80 para sensibilidade e 0,63 para especificidade. Por fim, quando utilizamos a classificação dos subgrupos normal/retificação vs. cifose, o valor de acurácia obtido foi 0,7 para o valor de corte angular de $14,42^{\circ}$ com valores de 
sensibilidade e especificidade de 0,70 e 0,57, respectivamente (Tabela 8/ Figuras 5, 6 e 7).

Tabela 8. Níveis de acurácia, sensibilidade e especificidade do Ângulo de Lordose Cervical (ACL) em relação aos subgrupos classificados através da análise qualitativa (inspeção visual).

\begin{tabular}{|c|c|c|c|c|}
\hline $\begin{array}{l}\text { Subgrupos de } \\
\text { comparações }\end{array}$ & $\begin{array}{l}\text { Valor de } \\
\text { corte }\end{array}$ & $\begin{array}{c}\text { Área da Curva } \\
\text { ROC }\end{array}$ & Sensibilidade & Especificidade \\
\hline \multirow{3}{*}{$\begin{array}{c}\text { Normal }(n=102) \text { vs. } \\
\text { Hiperlordose } \\
(n=31)\end{array}$} & $13,15^{\circ}$ & & 0,74 & 0,56 \\
\hline & $12,05^{\circ}$ & $0,7(0,6-0,8)$ & 0,74 & 0,72 \\
\hline & $11,15^{\circ}$ & & 0,61 & 0,76 \\
\hline \multirow{3}{*}{$\begin{array}{l}\text { Normal }(n=102) \text { vs. } \\
\text { Retificação e Cifose } \\
\qquad(n=24)\end{array}$} & $14,37^{\circ}$ & & 0,80 & 0,52 \\
\hline & $15,38^{\circ}$ & $\mathbf{0 , 8}(\mathbf{0 , 6}-\mathbf{1 , 0})$ & $\mathbf{0 , 8 0}$ & 0,63 \\
\hline & $16,32^{\circ}$ & & 0,60 & 0,70 \\
\hline \multirow{3}{*}{$\begin{array}{c}\text { Normal e } \\
\text { Retificação }(n=103) \\
\text { vs. Cifose }(n=23)\end{array}$} & $13,40^{\circ}$ & & 0,78 & 0,47 \\
\hline & $14,42^{\circ}$ & $0,7(0,5-0,8)$ & 0,70 & 0,57 \\
\hline & $15,38^{\circ}$ & & 0,65 & 0,67 \\
\hline $\begin{array}{l}\text { ROC (receiver operator ch } \\
\text { ROC }>0,9 \text { : alta acurácia } \\
0,7<\text { ROC }<0,9 \text { : moderada } \\
0,5<\text { ROC }<0,7 \text { : baixa acur } \\
\text { ROC }<0,5 \text { : resultado ao ac }\end{array}$ & $\begin{array}{l}\text { racteristic) } \\
\text { curácia } \\
\text { cia } \\
\text { so }\end{array}$ & & & \\
\hline
\end{tabular}




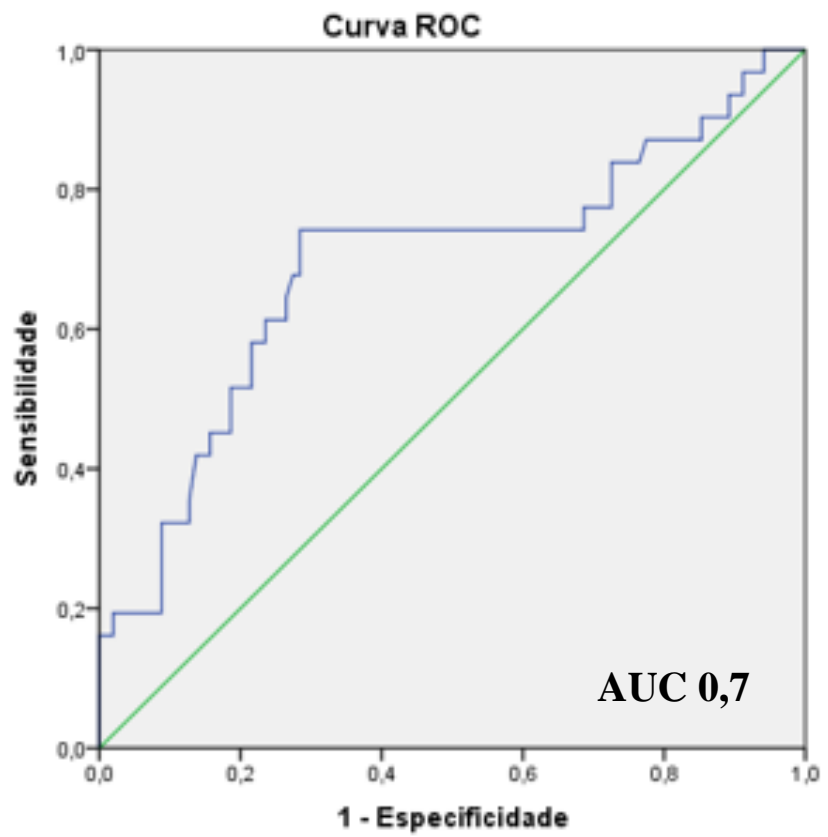

Figura 5. Curva ROC (receiver operator characteristic). Área sob a curva (AUC) para avaliação postural da lordose cervical por fotogrametria considerando os grupos normal e hiperlordose. Acurácia moderada para o valor de corte de $12,05^{\circ}$.

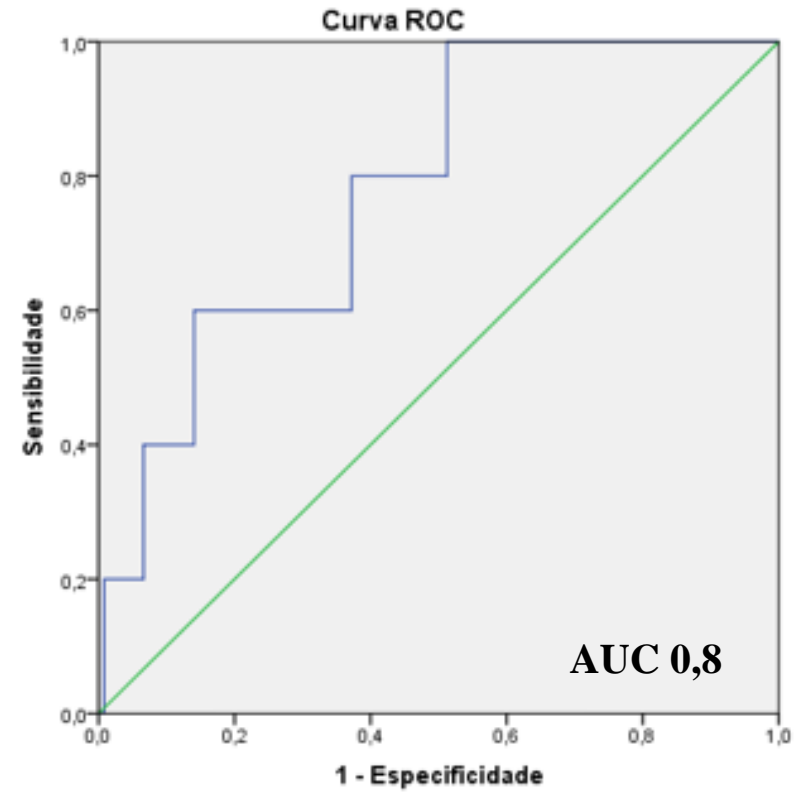

Figura 6. Curva ROC (receiver operator characteristic). Área sob a curva (AUC) para avaliação postural da lordose cervical por fotogrametria considerando os grupos normal vs. inversão e retificação. Acurácia moderada para o valor de corte $15,38^{\circ}$. 


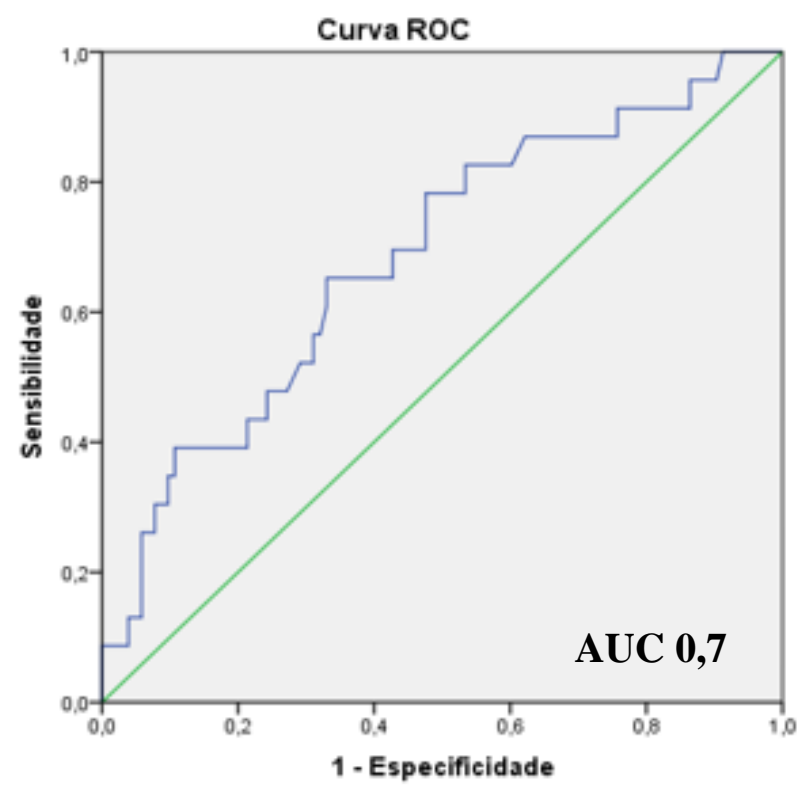

Figura 7. Curva ROC (receiver operator characteristic). Área sob a curva (AUC) da avaliação postural da lordose cervical por fotogrametria considerando os grupos normal e retificação vs. inversão. Acurácia moderada para o valor de corte $14,42^{\circ}$.

\subsection{Acurácia das medidas de postura craniocervical obtidas por fotogrametria para detectar a presença ou ausência de relato de dor cervical}

\subsubsection{Protrusão de cabeça}

Quando observamos a análise de acurácia da avaliação postural de protrusão de cabeça através da fotogrametria considerando-se os indivíduos em subgrupos quanto à presença ou ausência do relato de dor cervical, podemos notar uma acurácia de valor 0,6 para um valor de corte angular de $44,42^{\circ}$ com sensibilidade de 0,59 e especificidade de 0,49 (Tabela 9/ Figura 8).

Tabela 9. Acurácia, sensibilidade e especificidade do ACV (ângulo craniovertebral) dos indivíduos com presença ou ausência de relato de dor dos indivíduos com e sem dor de intensidade maior que 3 em uma Escala Numérica de Dor (END) graduada de 0-10. 


\begin{tabular}{|c|c|c|c|c|c|}
\hline $\begin{array}{c}\text { Comparações } \\
\text { Subgrupos }\end{array}$ & $\begin{array}{c}\text { Relato de } \\
\text { Dor }\end{array}$ & $\begin{array}{c}\text { Valor } \\
\text { de } \\
\text { corte }\end{array}$ & $\begin{array}{c}\text { Área da } \\
\text { Curva } \\
\text { ROC }\end{array}$ & Sensibilidade & Especificidade \\
\hline $\mathrm{ACV}$ & $\begin{array}{l}\text { Com dor } \\
(n=81) \text { vs. } \\
\text { Sem dor } \\
(n=76)\end{array}$ & $44,42^{\circ}$ & $\begin{array}{c}0,6(0,46- \\
0,64)\end{array}$ & 0,59 & 0,49 \\
\hline
\end{tabular}

ROC (receiver operator characteristic curve)

ROC > 0,9: alta acurácia

$0,7<$ ROC $<0,9:$ moderada acurácia

$0,5<$ ROC $<0,7$ : baixa acurácia

ROC $<0,5$ : resultado ao acaso

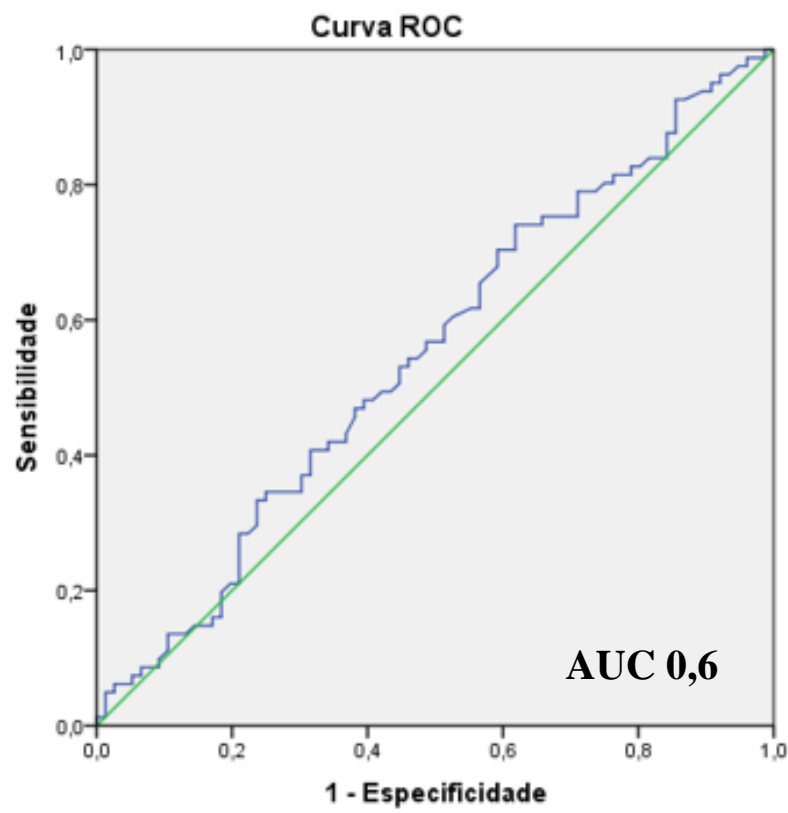

Figura 8. Curva ROC (receiver operator characteristic). Área sob a curva (AUC) para avaliação postural da protrusão de cabeça por fotogrametria nos grupos normal, leve, moderado e severo relacionados com o relato da presença ou ausência de dor. Baixa acurácia para o valor de corte de $44,42^{\circ}$.

\subsubsection{Lordose Cervical}

Quando observamos os subgrupos denominados normal e hiperlordose com e sem dor, foi obtido um valor de acurácia de 0,53 para um valor de corte de $14,02^{\circ}$ com sensibilidade 0,60 e especificidade 0,47 (Tabela 10/ Figura 9). 
Considerando a classificação da lordose cervical, quando consideramos os subgrupos normal, retificação e inversão, para o valor de corte de $14,37^{\circ}$, foi obtido valor de acurácia 0,5, com valores de sensibilidade e especificidade dos subgrupos normal e hiperlordose de 0,52 e 0,50, respectivamente (Tabela 10/ Figura 10).

Tabela 10. Acurácia, Sensibilidade e especificidade da avaliação postural através de fotogrametria para o ALC (ângulo lordose cervical) dos indivíduos com e sem dor divididos em subgrupos normal vs. hiperlordose e normal vs. retificação vs. inversão.

\begin{tabular}{|c|c|c|c|c|c|}
\hline $\begin{array}{l}\text { Comparações } \\
\text { Subgrupos }\end{array}$ & Dor & $\begin{array}{c}\text { Valor } \\
\text { de } \\
\text { corte }\end{array}$ & $\begin{array}{c}\text { Área da } \\
\text { Curva } \\
\text { ROC }\end{array}$ & Sensibilidade & Especificidade \\
\hline $\begin{array}{l}\text { Normal }(n=102) \text { vs. } \\
\text { Hiperlordose }(n=31)\end{array}$ & $\begin{array}{l}\text { Relato de dor } \\
\text { positivo }(\mathrm{n}=67) \\
\text { Relato de dor } \\
\text { negativo }(\mathrm{n}=66)\end{array}$ & $14,02^{\circ}$ & $\begin{array}{c}0,5(0,4- \\
0,6)\end{array}$ & 0,60 & 0,47 \\
\hline $\begin{array}{l}\text { Normal }(n=102) \text { vs. } \\
\text { Retificação }(n=18) \\
\text { vs. Inversão }(n=6)\end{array}$ & $\begin{array}{c}\text { Relato de dor } \\
\text { positivo }(\mathrm{n}=67) \\
\text { Relato de dor } \\
\text { negativo }(\mathrm{n}=66)\end{array}$ & $14,37^{\circ}$ & $\begin{array}{c}0,5(0,4- \\
0,6)\end{array}$ & 0,52 & 0,50 \\
\hline $\begin{array}{l}\text { ROC (receive } \\
\text { ROC }>0,9: \text { a } \\
0,7<\text { ROC }<0, \\
0,5<\text { ROC }<0, \\
\text { ROC }<0,5: \text { res }\end{array}$ & $\begin{array}{l}\text { perator characteristic } \\
\text { acurácia } \\
\text { toderada acurácia } \\
\text { aixa acurácia } \\
\text { ado ao acaso }\end{array}$ & & & & \\
\hline
\end{tabular}




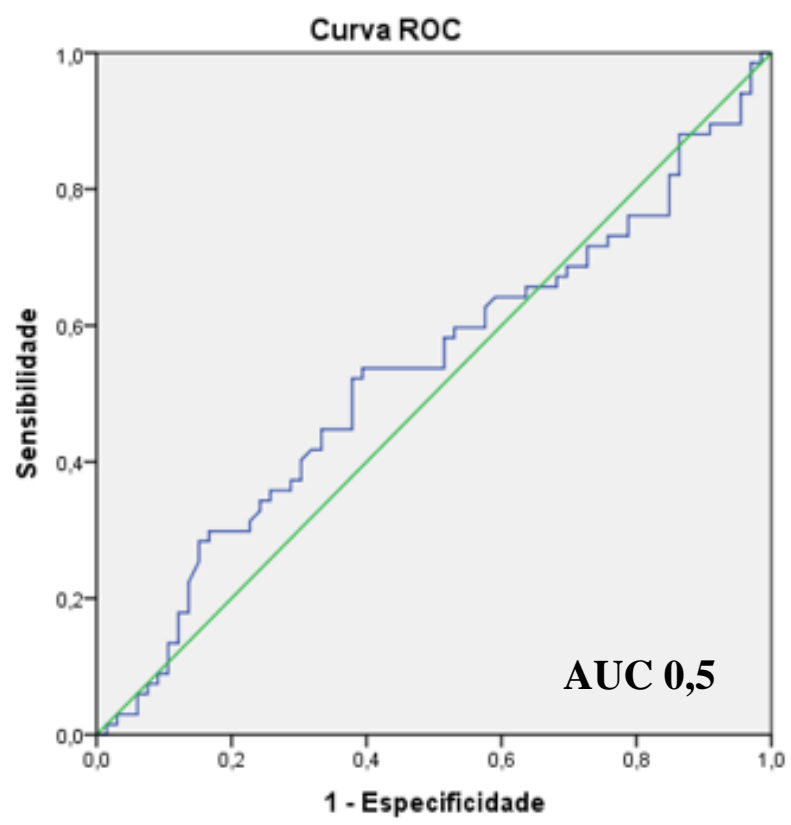

Figura 9. Curva ROC (receiver operator characteristic). Área sob a curva (AUC) para avaliação postural da lordose cervical por fotogrametria nos grupos normal e hiperlordose relacionados com o relato da presença ou ausência de dor. Baixa acurácia para o valor de corte de $14,02^{\circ}$.

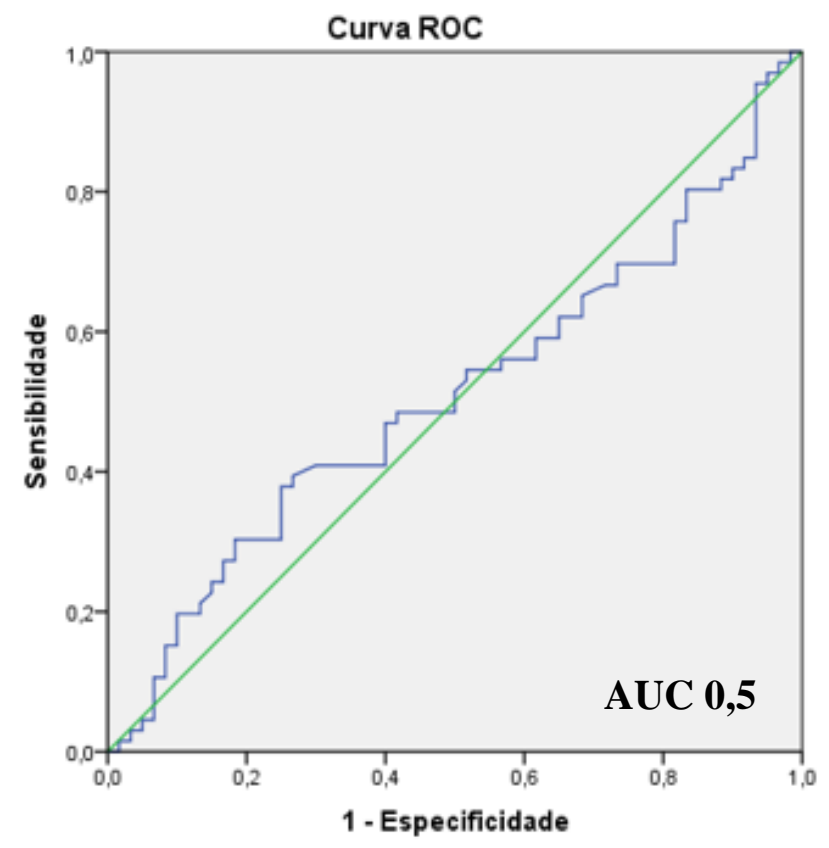

Figura 10. Curva ROC (receiver operator characteristic). Área sob a curva (AUC) para avaliação postural da lordose cervical por fotogrametria nos grupos normal, retificação e inversão relacionados com o relato da presença ou ausência de dor. Baixa acurácia para o valor de corte de $14,37^{\circ}$. 


\subsection{Acurácia das medidas de postura craniocervical obtidas por fotogrametria} para detectar a presença ou ausência de incapacidade relacionada à cervical através do questionário Índice de Incapacidade Relacionada à Dor no Pescoço (NDI-BR)

Foi verificada também a acurácia da medida de protrusão de cabeça por fotogrametria na detecção da ausência/presença de incapacidade relacionada à dor cervical através da aplicação do questionário Índice de Incapacidade Relacionada à Dor no Pescoço (NDI-BR). Uma acurácia de 0,46 com valores de sensibilidade 0,56 e especificidade 0,40 para o valor de corte angular de 42,74 (Tabela 11/ Figura 11) foi obtida. E para a classificação lordose cervical obtivemos um valor de acurácia 0,43 com valor de sensibilidade de 0,48 e especificidade 0,40 para o valor de corte de $13,25^{\circ}$ (Tabela 11/ Figura 11).

Tabela 11- Acurácia, sensibilidade e especificidade das medidas do ACV (ângulo craniovertebral) e ALC (ângulo lordose cervical) por fotogrametria para detectar incapacidade relacionada à dor cervical através do NDI-BR (Índice de incapacidade relacionada ao pescoço)

\begin{tabular}{ccccc}
\hline Incapacidade & $\begin{array}{c}\text { Valor de corte } \\
\text { do ângulo }\end{array}$ & $\begin{array}{c}\text { Área da } \\
\text { Curva } \\
\text { ROC }\end{array}$ & Sensibilidade & Especificidade \\
\cline { 1 - 3 } Com incapacidade $^{\&}$ & ACV: $42,74^{\circ}$ & $0,5(0,37-$ & 0,56 & 0,40 \\
$(\mathrm{n}=80)$ vs. & & $0,55)$ & & \\
Sem incapacidade ${ }^{\&}$ & ALC: $13,25^{\circ}$ & $0,4(0,34-$ & 0,48 & \\
$(\mathrm{n}=77)$ & & $0,52)$ & & 0,40 \\
\hline
\end{tabular}

\& Classificação de incapacidade Segundo o NDI-BR (Indice de incapacidade relacionada ao pescoço) $10-28 \%$ (5-14 pontos) - incapacidade leve;

$30-48 \%$ (15- 24 pontos) - incapacidade moderada;

$50-68 \%$ ( 25 - 35 pontos) - incapacidade severa;

$72 \%$ ou mais (36 pontos ou mais) - incapacidade completa.

ROC (receiver operator characteristic curve)

ROC > 0,9: alta acurácia

$0,7<$ ROC $<0,9$ : moderada acurácia

$0,5<$ ROC $<0,7$ : baixa acurácia

ROC $<0,5$ : resultado ao acaso 


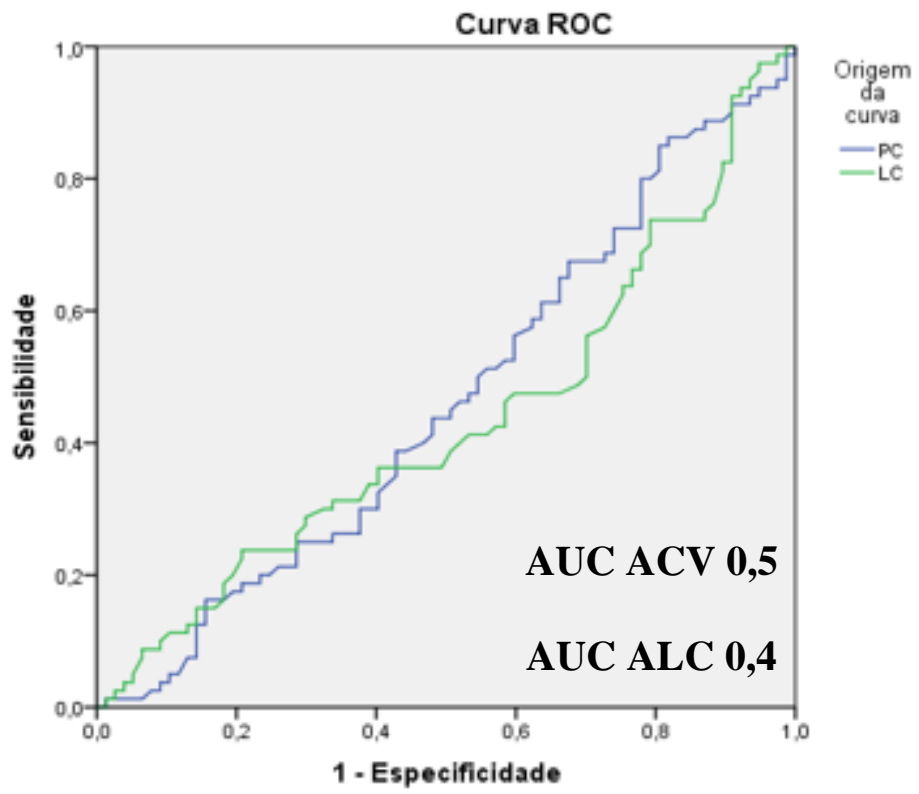

Figura 11. Curva ROC (receiver operator characteristic). Área sob a curva (AUC) para avaliação postural dos ângulos craniovertebral (ACV) e lordose cervical (ALC) por fotogrametria verificando a presença ou ausência de dor incapacidade relacionada à dor cervical. Baixa acurácia para o valor de corte de $42,74^{\circ}$ para protrusão de cabeça e resultado ao acaso para o valor de corte $13,25^{\circ}$ para lordose cervical.

\subsection{Acurácia das medidas de postura craniocervical por inspeção visual para detectar a presença ou ausência incapacidade relacionada à dor cervical (NDI-BR)}

$\mathrm{Na}$ avaliação postural por inspeção visual, quando observamos a presença ou ausência de incapacidade relacionada à dor cervical dos indivíduos através da apliação do questionário Índice de incapacidade relacionada ao pescoço (NDI-BR), encontramos um valor de acurácia de 0,47 com valores de sensibilidade 0,35 e especificidade 0,38 para a classificação de protrusão de cabeça, com valor de corte na categoria normal vs. leve/moderado/severo. Já para a classificação da lordose cervical obtivemos um valor de acurácia 0,50 com valor de sensibilidade de 0,34 e especificidade 0,36, para a classificação de lordose cervical, com valor de corte na categoria normal vs. hiperlordose/retificação/inversão (Tabela 14/ Figura 15). 
Tabela 12- Acurácia das medidas de ACV e ALC por inspeção visual para detectar o relato positivo de dor cervical com intensidade maior que $3 \mathrm{em}$ uma escala numérica de dor graduada de 0-10 (END) e incapacidade relacionada a dor.

\begin{tabular}{|c|c|c|c|c|}
\hline Dor & & $\begin{array}{c}\text { Área da Curva } \\
\text { ROC }\end{array}$ & Sensibilidade & Especificidade \\
\hline \multirow[t]{2}{*}{$\begin{array}{l}\text { Presença ou ausência } \\
\text { de dor }\end{array}$} & $\mathrm{ACV}$ & $0,5(0,38-0,56)$ & 0,35 & 0,38 \\
\hline & ALC & $0,5(0,41-0,59)$ & 0,34 & 0,36 \\
\hline \multirow[t]{2}{*}{$\begin{array}{l}\text { Presença ou ausência } \\
\text { de dor }>3\end{array}$} & $\mathrm{ACV}$ & $0,5(0,40-0,58)$ & 0,38 & 0,36 \\
\hline & ALC & $0,5(0,42-0,60)$ & 0,36 & 0,34 \\
\hline $\begin{array}{l}\text { ROC }(\text { receiver operat } \\
\text { ROC }>0,9: \text { alta acurá } \\
0,7<\text { ROC }<0,9 \text { : moder } \\
0,5<\text { ROC }<0,7 \text { : baixa } \\
\text { ROC }<0,5 \text { : resultado a }\end{array}$ & $\begin{array}{l}\text { icteristic } \\
\text { rácia }\end{array}$ & & & \\
\hline
\end{tabular}

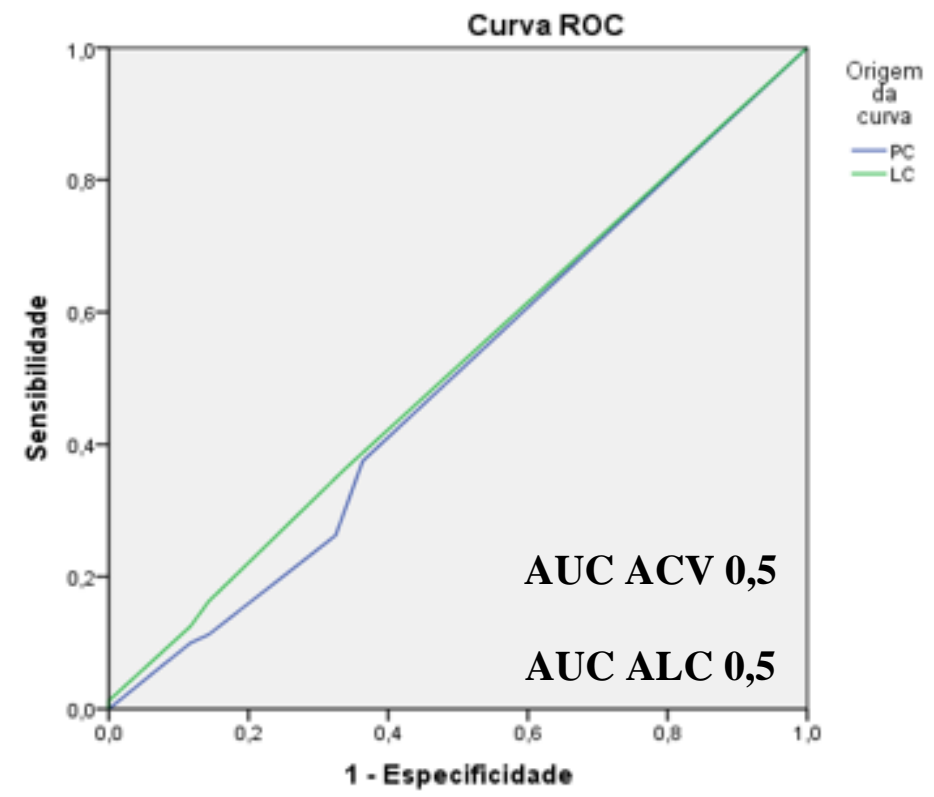

Figura 12. Curva ROC (receiver operator characteristic). Área sob a curva (AUC) para avaliação postural dos ângulos craniovertebral (ACV) e lordose cervical (ALC) por inspeção visual relacionando o relato da presença ou ausência de incapacidade relacionada à dor cervical. AUC ACV 0,5 (baixa acurácia) e AUC ALC 0,5 (baixa acurácia).

Ao realizarmos o test t entre os grupos com e sem dor e com e sem incapacidade, não encontramos diferenças significativas entre os valores médios angulares entre os grupos na postura craniocervical. Para o ângulo crâniovertebral (ACV) o valor médio 
encontrado para o grupo com dor foi de $43,9^{\circ}$ e para o grupo sem dor de $44,8^{\circ}$. Em relação a incapacidade encontramos, para o grupo com incapacidade o valor médio angular de $43,9^{\circ}$ e para o grupo sem incapacidade $44,7^{\circ}$ (Tabela 13 )

Já para o ângulo lordose cervical (ALC) o valor médio encontrado para o grupo com dor foi de $13,6^{\circ}$ e para o grupo sem dor de $13,8^{\circ}$. Em relação a incapacidade encontramos, para o grupo com incapacidade o valor médio angular de $13,3^{\circ}$ e para o grupo sem incapacidade $14,2^{\circ}$ (Tabela 13 ).

Tabela 13- Valor médio dos ângulos entre os grupos com e sem dor e grupos com e sem incapacidade dos ângulos craniovertebral (ACV) e lordose cervical (ALC) da postura craniocervical

\begin{tabular}{|c|c|c|}
\hline $\begin{array}{c}\text { Postura } \\
\text { craniocervical }\end{array}$ & Indivíduos & $\begin{array}{l}\text { Valor de corte } \\
\text { do ângulo (DP) }\end{array}$ \\
\hline \multirow{5}{*}{$\begin{array}{c}\text { Ângulo } \\
\text { crâniovertebral } \\
\text { - ACV }\end{array}$} & Com incapacidade ${ }^{\&}$ & $43,92^{\circ}\left(5,01^{\circ}\right)$ \\
\hline & Sem icapacidade ${ }^{\&}$ & $44,72^{\circ}\left(5,30^{\circ}\right)$ \\
\hline & \multicolumn{2}{|c|}{ Valor t: $0,97 / p=0,33$} \\
\hline & Com dor & $43,86^{\circ}\left(5,08^{\circ}\right)$ \\
\hline & Sem dor & $44,79^{\circ}\left(5,22^{\circ}\right)$ \\
\hline \multicolumn{3}{|c|}{ Valor t: $1,12 / \mathrm{p}=0,25$} \\
\hline \multirow{5}{*}{$\begin{array}{l}\text { Ângulo lordose } \\
\text { cervical - ALC }\end{array}$} & Com incapacidade ${ }^{\&}$ & $13,32^{\circ}\left(4,16^{\circ}\right)$ \\
\hline & Sem icapacidade ${ }^{\&}$ & $14,18^{\circ}\left(4,18^{\circ}\right)$ \\
\hline & \multicolumn{2}{|c|}{ Valor t: $1,29 / \mathrm{p}=0,20$} \\
\hline & Com dor & $13,63^{\circ}\left(4,16^{\circ}\right)$ \\
\hline & Sem dor & $13,85^{\circ}\left(4,22^{\circ}\right)$ \\
\hline
\end{tabular}

Valor t: $0,37, p=0.74$

\& Classificação de incapacidade Segundo o NDI-BR (Indice de incapacidade relacionada ao pescoço) $10-28 \%$ (5-14 pontos) - incapacidade leve;

$30-48 \%$ (15- 24 pontos) - incapacidade moderada;

$50-68 \%$ ( 25 - 35 pontos) - incapacidade severa;

$72 \%$ ou mais (36 pontos ou mais) - incapacidade completa. 


\section{\begin{tabular}{l|l} 
Discussão & 62
\end{tabular}}

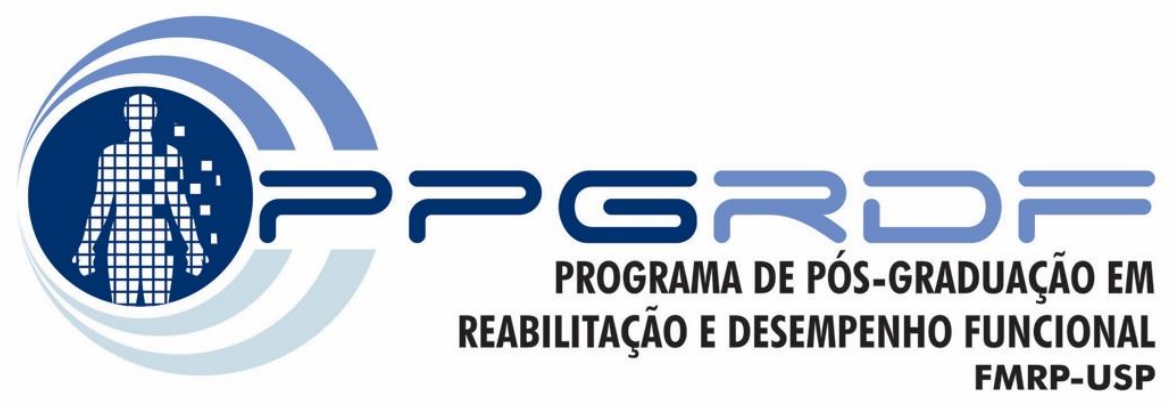

DISCUSSÃO

“É muito melhor lançar-se em busca de conquistas grandiosas, mesmo expondo-se ao fracasso, do que alinhar-se com os pobres de espírito, que nem gozam muito nem sofrem muito, porque vivem numa penumbra cinzenta, onde não conhecem nem vitória, nem derrota."

Theodore Roosevel 


\section{DISCUSSÃO}

O objetivo inicial deste trabalho foi identificar os valores de acurácia, sensibilidade e especificidade da fotogrametria em relação inspeção visual para avaliação da postura craniocervical através da análise de fotografias no plano sagital.

Os demais objetivos foram 1) Verificar a confiabilidade intra e interexaminadores da avaliação por inspeção visual da postura craniocervical no plano sagital; 2) Verificar a confiabilidade intra-examinadores da fotogrametria para avaliação da postura craniocervical no plano sagital; 3) Estudar os valores de corte mais adequados para diferençar as posturas crâniocervicais em normal e não normal através da fotogrametria em relação à inspeção visual; 4) Analisar a acurácia da análise de inspeção visual e fotográfica de protrusão de cabeça e lordose cervical para identificar os indivíduos com relato positivo ou negativo de dor e indivíduos com presença ou ausência de incapacidade relacionada à dor cervical.

Assim, ao longo dos parágrafos abaixo os resultados pertinentes aos objetivos acima listados foram elencados.

\subsection{Concordância intra e interexaminadores para avaliação dos ângulos por inspeção postural visual e fotogrametria}

Em nossos resultados, para a análise da concordância intra-examinadores foram observados valores médios de kappa considerados muito bons em $80 \%$ das avaliações de teste-reteste para as análises qualitativas da postura da cabeça, e para a lordose cervical foram observados valores médios considerados moderados em $60 \%$ e muito bons em $40 \%$ das avaliações de teste-reteste. Já para a análise da concordância interexaminadores na avaliação qualitativa foram observados valores médios de Kappa 
considerados muito bons em $60 \%$ das comparações entre pares de examinadores para a avaliação de postura da cabeça, e muito bons ou execelentes para também $60 \%$ das comparações por pares para avaliação da lordose cervical. Além disso, a concordância interexaminadores geral através do cálculo do CCI para análise por inspeção visual, demonstrou níveis moderado e excelente para postura da cervical e cabeça, respectivamente. Assim, apesar de termos encontrado um nível moderado de confiabilidade interexaminador, nossos achados sugerem que a avaliação postural por inspeção visual da lordose cervical demonstra valores apenas aceitáveis de confiabilidade, sugerindo maior nível de erro na obtenção da medida.

Corroborando com nossos achados, Nam et al. (2013), encontraram um excelente nível de confiabilidade intra-examinador $(0,91)$, e um bom nível de confiabilidade interexaminador na avaliação por inspeção visual da protrusão de cabeça (0,75). Já no estudo realizado por Gadotti et al. (2013), os autores também verificaram a confiabilidade interexaminadores da avaliação da postura craniocervical através de inspeção visual, porém esta, não se mostrou confiável.

Passier et al. (2010) realizaram um estudo com o objetivo de determinar a confiabilidade da avaliação por inspeção visual do alinhamento da cabeça e cervical realizada por fisioterapeutas. Os autores concluíram que a avaliação da postura craniocervical realizada pelos avaliadores foi de validade questionável na identificação dos desvios em até $5^{\circ}$ a partir da postura neutral, quando as análises por inspeção visual foram comparadas a análise quantitativa.

A maioria dos estudos referem pobres níveis de concordância interexaminadores e níveis moderados para a concordância intra-examinador para a avaliação postural craniocervical. Em 2003, Van Genderen et al. sugeriram que um treinamento prévio dos avaliadores poderia melhorar os níveis de confiabilidade interexaminadores da técnica 
de avaliação postural por inspeção visual, mas não foram encontrados estudos que realizaram esta comparação. Em nosso estudo, apesar de não terem recebido treinamento prévio, todos os avaliadores convidados para a realização da avaliação postural por inspeção visual eram fisioterapeutas formados e com pelo menos 5 anos de experiência na prática clínica. Desta forma, tal experiência pode explicar os melhores níveis de confiabilidade encontrados para classificação da protrusão de cabeça e lordose cervical.

Tratando- se da avaliação quantitativa, nossos achados também mostraram que o método proposto para a quantificação das assimetrias posturais craniocervicais pela fotogrametria é confiável para as duas medidas angulares estudadas, quando avaliadas por um mesmo examinador.

Na avaliação postural por fotogrametria obtivemos valores de CCI entre 0.99 0.96 para a análise através dos ângulos ACV e ACL, que concordam com valores publicações prévias disponíveis na literatura (DUNK, LALONDE e CALLAGHAN; 2005). Dunk, Lalonde e Callaghan (2005) verificaram a confiabilidade da avaliação postural por fotogrametria dos ângulos da coluna vertebral nas vistas posterior e sagital na posição vertical. Em seus resultados, encontraram uma confiabilidade de boa a excelente $(\mathrm{CCI}>0,75)$ para os ângulos mensurados no plano sagital, quando comparados aos ângulos obtidos no plano frontal ( $\mathrm{CCI}<0,7$, considerados fracos e moderados). Assim, os autores sugerem que as medidas obtidas no plano sagital são mais reprodutíveis que as obtidas no plano frontal (DUNK, LALONDE E CALLAGHAN, 2005). Saad et al. (2012) verificaram confiabilidade excelente inter e intraexaminadores para a avaliação postural por meio de fotogrametria. Fortin et al (2011) também demonstraram bons níveis de confiabilidade intra e interexaminadores para esta ferramenta de análise. Além disso, Iunes et al. (2009), observaram maior concordância 
interexaminadores para a avaliação por meio de fotogrametria do que através da observação visual.

No estudo de Gadotti et al. (2013), os autores verificaram a confiabilidade intra e interexaminadores das avalições quantitativas da postura craniocervical através de fotografias e radiografias. Foram observados bons níveis de concordância, com exceção de um dos ângulos utilizados para verificação da lordose cervical (ângulo de inclinação cervical entre C2, C4 e C7) interexaminadores. Salahzadeh et al. (2014), inferiram através dos seus achados que a fotogrametria teve excelente confiabilidade intra e interexaminadores se tratando da postura craniocervical, assim como Ruivo, PezaratCorreia, Carita (2015), que também encontraram os mesmos níveis de confiabilidade na avaliação da postura craniocervical e dos ombros.

Os resultados de muitos testes clínicos são quantitativos e fornecidos em uma escala contínua (AKOBENG, 2006). O erro padrão da medida (EPM, em inglês Standard Error of Measurement) é igual à raiz quadrada da variância de erro de uma análise, seja incluindo ou excluindo diferenças sistemáticas (TERWEE et al., 2007). Diretamente relacionado com o erro padrão da medida é possível determinar a mínima diferença detectável (MMD, em inglês Smallest Detectable Change). Um instrumento é clinicamente válido quando o EPM é menor do que a MDD. Isto também significa que essas medidas podem ser utilizadas para decidir se uma verdadeira alteração relevante ocorreu (SCHOLTES; TERWEE; POOLMAN, 2001).

Em nosso trabalho foram observados valores de Erro Padrão da Medida (EPM) de 0,73 (ACV) e 0,42 (ALC) e Mínima Diferença Detectável (MDD) de 2,02 (ACV) e 1,16 (ALC) para a confiabilidade intra-examinadores. Valores similares de $\operatorname{EPM}\left(0,73^{\circ}\right)$ para o ângulo de ALC foram obtidos no estudo de Ferreira et al. (2010). Para o ACV, Salahzadeh et al. (2014) relataram valor de $1,94^{\circ}$. 
Poucos estudos como o nosso descreveram os valores de EPM dos traçados utilizados para análise da postura craniocervical. Porém trata-se de um dado importante e futuros estudos precisam ser conduzidos para confirmação de nossos achados, principalmente para utilização da fotogrametria com confiança na prática clínica.

Dessa maneira, nossos resultados ressaltam melhores níveis de confiabilidade intra e interexaminadores para a análise quantitativa (fotogrametria) do que para análise qualitativa da postura craniocervical.

\subsection{Acurácia das medidas de protrusão de cabeça e lordose cervical da fotogrametria em relação à inspeção visual}

A maioria dos estudos encontrados não analisaram a acurácia da medida de avaliação da postura craniocervical. Em nosso estudo, um dos objetivos foi verificar os níveis de acurácia, sensibilidade e especificidade entre a fotogrametria e inspeção visual para avaliação da postura craniocervical. A hipótese era de haver bons valores de sensibilidade e especificidade da fotogrametria em relação inspeção visual, considerada neste estudo como o teste de referência para avaliação da postura craniocervical.

A partir dos valores de acurácia encontrados para postura da cabeça, o valor de corte angular que obteve maior AUC (Area Under the Curve) $(0,8)$ e maiores valores de sensibilidade $(0,72)$ e especificidade $(0,70)$ foi $42,07^{\circ}$, quando consideramos como postura "normal" os indivíduos classificados pela inspeção visual como normal, normal/leve e leve. Essa classificação está de acordo com o proposto por Kendall et al. (1970), na qual eles sugerem que indivíduos com protrusão de cabeça leve podem ser considerados dentro de parâmetros de normalidade para protrusão de cabeça. 
Já para o ângulo de lordose cervical, o valor de 15,38ºbteve uma AUC de 0,8 e valores de sensibilidade e especificidade 0,80 e 0,63, respectivamente. Esse valor de corte identifica a diferença entre um indivíduo classificado com uma lordose cervical normal de indivíduos classificados com uma lordose cervical invertida ou retificada. Já o valor de corte encontrado para diferenciar indivíduos classificados com lordose cervical normal de indivíduos classificados com hiperlordose foi de $12,05^{\circ}$, com AUC de 0,7 e valores de sensibilidade e especificidade de 0,74 e 0,72 , respectivamente.

Testes de sensibilidade determinam a probabilidade de uma verdadeira classificação positiva, por outro lado, testes de especificidade determinam a probabilidade de uma verdadeira classificação negativa (LIEBREGTS; SONNE; POTVIN, 2016).

Furlanetto et al. em uma recente revisão sistemática (2016), verificaram a aplicabilidade da fotogrametria para avaliação da postura da coluna vertebral. Esta revisão demonstrou que a fotogrametria pode ser amplamente utilizada no ambiente de pesquisa científica, permitindo assim a avaliação não só da coluna vertebral, mas também de outros segmentos corporais em ambos os planos sagital e frontal. Os autores chamam a atenção para o fato de que, embora a fotogrametria seja uma opção viável, válida e reprodutível para a avaliação da coluna, ainda existe uma falta de estudos que forneçam tanto a magnitude das curvaturas, quanto a classificação de diagnóstico da postura da coluna vertebral, através de significado clínico às medidads obtidas.

A sensibilidade e especificidade de um teste variam de acordo com o nível que é escolhido como o ponto de corte da curva ROC. Trata-se de uma técnica gráfica para descrever e comparar a precisão de testes de diagnóstico, obtida através da representação gráfica da sensibilidade de um teste no eixo Y contra 1-especificidade no eixo X (AKOBENG, 2007), minimizando assim, os vieses. 
Alguns estudos prévios compararam os resultados obtidos através das análises quantitativa e qualitativa da postura craniocervical (GADOTTI et al., 2013; GADOTTI, BIASOTTO-GONZALEZ, 2010; SALAHZADEH et al., 2014; SILVA et al., 2010. Gadotti e Biasotto-Gonzalez (2010) verificaram diferenças nos valores angulares obtidos na fotogrametria entre subgrupos com diferentes níveis de protrusão de cabeça classificados por meio da inspeção visual. Já Silva et al. (2010) verificaram pobre correlação entre os métodos (validade de construto). Entretanto, apenas a postura da cabeça foi considerada nesses estudos (BIASOTTO-GONZALEZ, 2010; SALAHZADEH et al., 2014) e análises de acurácia, sensibilidade e especificidade, não foram empregadas, como recomendado pelo STARD (BOSSUYT et al., 2003; BOSSUYT et al., 2015).

Adicionalmente, Döhnert e Tomasi (2008) investigaram a sensibilidade e a especificidade da fotogrametria computadorizada na detecção da escoliose idiopática adolescente através da análise radiográfica. Os ângulos obtidos através da fotogrametria computadorizada não demonstraram níveis de sensibilidade e especificidade suficientes para serem recomendadoz isoladamente como screening escolar da escoliose idiopática no adolescente. Entretanto, neste estudo, os autores argumentam que erros de medida interexaminadores podem ter ocorrido, uma vez que, por questões éticas, o exame não foi realizado sempre pelo mesmo avaliador, assim, optou-se por examinadores do sexo feminino para as alunas e masculino para os alunos.

Há uma escassez de trabalhos na literatura analisando a acurácia das medidas da fotogrametria em relação à inspeção visual, principalmente relacionadas à postura craniocervical. Este é o primeiro estudo que além de analisar a acurácia das medidas, estabeleceu valores de corte para diferenciar indivíduos com e sem desalinhamentos quanto a postura craniocervical. 
Iunes et al. (2009) afirmaram é crítico definir valores de normalidade para interpretação das medidas relativas às curvaturas vertebrais obtidas pela fotogrametria, pois no plano sagital. A verificação da confiabilidade e acurácia de medidas pode contribuir para minimização de falsos diagnósticos e para a definição de parâmetros de referência para uso na prática clínica. É possível que esses valores de referência possam ser utilizados como base para estratégias de intervenção ancoradas na modificação de padrões posturais, bem como para identificação de possíveis subgrupos posturais e estratégias de tratamento específicas.

Assim, este estudo traz dados inovadores, já que nenhum estudo prévio demonstrou os níveis de acurácia, sensibilidade e especificidade da avaliacão de postura quantitativa vs. qualitativa, como realizado neste estudo. Além do mais, em nosso estudo determinamos valores de corte na postura de cabeça apenas para diferenciar protrusões de cabeça moderadas e severas. Já para a postura cervical, identificamos valores de corte que diferenciam lordose cervical normal de hiperlordose, e lordose cervical normal de retificação/inversão. Entretanto, futuros estudos precisam ser conduzidos para confirmar nossos achados.

\subsection{Classificação dos subgrupos por inspeção visual e dos ângulos traçados pela avaliação postural através da fotogrametria}

De acordo com nossos resultados, a amplitude dos ângulos medidos na análise quantitativa da postura da cabeça foi: (1) 44 a 46 graus para a postura normal da cabeça; (2) 42 a 46 graus para leve protrusão de cabeça; e (3) 37 a 42 graus para protrusão de cabeça moderada/severa. Observou-se uma sobreposição dos ângulos medidos entre os grupos de "postura normal da cabeça" vs. "leve protrusão da cabeça", uma vez que nenhuma diferença entre esses subgrupos foi demonstrada pela ANOVA. Em 
concordância com nossos resultados, uma publicação prévia relatou essa sobreposição na amplitude dos ângulos entre esses dois subgrupos (GADOTTI e BIASOTTOGONZALEZ, 2010). Esses resultados são fundamentais para a análise de acurácia, sugerindo que apenas protrusão de cabeça moderada/severa obtidas por meio de análises qualitativas, são passíveis de detecção pela análise quantitativa.

Em contraposição a nossos achados, Silva et al. (2010) não verificaram bons níveis de validade concorrente entre os métodos de avaliação da postura craniocervical qualitativa vs. quantitative para postura da cabeça. Uma das possíveis explicações para diferenças entre nossos achados pode estar relacionada ao tamanho amostral utilizado em seu estudo, de 40 voluntárias, e a análise estatística da acurácia que não foi empregada no mesmo. Adicionalmente, as imagens em nosso estudo contavam com a disponibilização de um fio de prumo como referencial de vertical para condução das análises. Para todos os registros fotográficos, um fio de prumo foi posicionado $33 \mathrm{~cm} \mathrm{da}$ voluntária, a fim de fornecer uma referência vertical verdadeira para visualização dos desalinhamentos posturais.

Sendo assim, é possível atribuir categorias de classificação ao ângulos obtidos na fotogrametria considerando-se como referência a análise por inspeção visual. Favorecendo a interpretação dos achados quantitativos que por sua vez apresentaram melhores níveis de confiabilidade.

Gadotti e Biasotto Gonzalez (2010), sugeriram em seu estudo valores médios angulares para identificação de protrusão de cabeça $\left(37^{\circ}-51^{\circ}\right)$ e postura de cabeça normal $\left(33^{\circ}-39^{\circ}\right)$. Porém esses dados diferem dos nossos achados principalmente pela metodologia adotada, pois os autores utilizaram um traçado diferente do utilizado em nosso estudo, mensurando a postura da cabeça através de três pontos, sendo eles mento, meato auditivo externo e manúbrio. Além disso, avaliaram apenas a postura da cabeça e 
não avaliaram a postura da cervical e consideraram um tamanho amostral $(n=29)$ bem menor que o utilizado em nosso estudo.

Salahzadeh et al. (2014), realizaram um estudo comparando três diferentes ângulos para medir a postura craniocervical, determinando assim se a fotogrametria poderia discriminar três grupos categorizados com base no método observacional. Para o ângulo craniocervical eles encontraram um valor de corte de $41,9^{\circ}, \mathrm{DP}=3,9^{\circ}$ para o grupo moderado/severo, $48,7^{\circ}, \mathrm{DP}=2,5^{\circ}$ para o grupo protrusão de cabeça leve e $55^{\circ}$, $\mathrm{DP}=3,3^{\circ}$ para o grupo normal. $\mathrm{O}$ que corrobora com nossos achados, em que o grupo normal está acima de $44^{\circ}$ e o grupo protrusão de cabeça se encontra abaixo do mesmo. Porém o estudo não analisou a acurácia, sensibilidade e especificidade das medidas utilizadas, o que contribuiria para maximizar os achados, através de uma estatística mais robusta, e reduzir o nível de viés.

Já para a postura da coluna cervical, o ângulo de lordose cervical traçado na união de três linhas que passam por occipital, C4 e C7 até uma linha vertical posterior, é um método bastante utilizado (IUNES et al., 2009; BELLI et al., 2009; PEZZAN et al., 2011). Por outro lado, não há estudos que tenham verificado diferenças nos valores do ALC entre os subgrupos classificados quanto aos diferentes perfis de postura cervical.

Para hiperlordose cervical através do ALC, o valor de 12,05 obteve o melhor valor de acurácia $(0,7)$ bem como, valores adequados de sensibilidade e especificidade $(>0,70)$. Assim, de acordo com nossos achados, valores abaixo de $12^{\circ}$ parecem ser adequados para diferenciar indivíduos classificados com hiperlordose cervical. Já para as análises de inversão de curvatura cervical/cifose e retificação, o valor de corte de $15,38^{\circ}$, com valores de 0,80 para sensibilidade e 0,63 para especificidade foram obtidos. Nossos dados sugerem que os valores de normalidade para lordose cervical fisiológica estariam entre $12^{\circ}-15^{\circ}\left(\mathrm{EPM}: 0,42^{\circ}\right)$ para valores obtidos na análise da postura 
quantitativa através do ALC. Por outro lado, é necessário considerar que especialmente para os padrões de curvatura retificada e invertida, o valor de especificidade foi de 0,63 , demonstrado que $37 \%$ dos sujeitos podem ter sido incluídos nas análises como falsospositivos.

Desta forma, para a postura da coluna cervical, a amplitude dos ângulos medidos na análise quantitativa foi: (1) 13 a 14 graus para a lordose normal; (2) 9 a 12 graus para hiperlordose e (3) 14 a 18 graus para retificação/cifose de curvatura. Diferentemente dos resultados obtidos para a postura da cabeça, não se observou sobreposição do intervalo de ângulos entre os subgrupos obtidos através da classificaçao de postura cervical e a diferença significativa entre os subgrupos foi confirmada pela ANOVA. Entretanto, cabe destacar que alguns indivíduos receberam diagnósticos mistos (Por exemplo: Retificação/Inversão; situação em que para $40 \%$ das avaliações foi atribuida a categoria retificação e $40 \%$ como inversão). Dessa maneira, não podemos descartar a possibilidade de sobreposições.

Um dos poucos estudos que também verificou a acurácia de uma medida diagnóstica para verificação da coluna cervical foi o estudo de McAviney et al. (2005). O traçado de tangente posterior foi utilizado para mensuração da curvatura cervical através de radiografias. O valor de corte de $20^{\circ}$ demonstrou os melhores valores de sensibilidade $(0,71)$ e especificidade $(0,74)$. Entretanto, não é possível traçar comparações entre nossos achados e os de McAviney et al. (2005) devido a diferenças entre os métodos (traçados) e objetivo da análise de acurácia, já que no estudo citado o objetivo foi verificar a acurácia do ângulo de tangente posterior para detecção dos subgrupos sintomático e assintomático para dor cervical.

O método para avaliação da postura cervical tangente posterior, foi originalmente descrito por Albers (1954) e Gore et al. (1986). Este traçado é realizado 
através de linhas tangentes desenhadas nas margens de corpos vertebrais posteriores, e o ângulo é medido onde as linhas se cruzam (HARRISON et al., 2004).

Assim, apesar da existência de softwares de avaliação postural que permitem quantificar ângulos posturais e as distâncias entre os segmentos, faltam dados que dêm amparo para à atribuição de classificações diagnósticas para os valores obtidos. Enfatiza-se a necessidade de definição de valores de referência para as análises de postura quantitativa não somente para a postura craniocervical, mas também para outros diferentes segmentos corporais (IUNES et al., 2009).

\subsection{Acurácia das medidas de protrusão de cabeça e lordose cervical por fotogrametria e inspeção visual para detectar a presença ou ausência de relato de dor cervical e incapacidade}

Quando observamos a acurácia da avaliação da postura da cabeça através da fotogrametria nos subgrupos sintomáticos e assintomáticos para dor cervical, foi observada uma acurácia baixa $(0,5<\mathrm{ROC}<0,7)$ para o ACV. O mesmo aconteceu considerando-se a classificação da postura cervical (ACL)

É possível que alterações de postura estejam presentes de igual forma entre indivíduos com e sem dor cervical. Nejati et al. (2014) também não verificaram diferenças no ACV entre participantes sintomáticos vs. assintomáticos para dor cervical. Entretanto, os autores verificaram valores médios de $37^{\circ} \mathrm{em}$ ambos os grupos, valores bem abaixo dos valores observados para protrusão de cabeça em nosso estudo, e em relação ao que é observado na literatura para sujeitos saudáveis $\left(50^{\circ}\right.$ a $\left.57^{\circ}\right)$ (VISSCHER 
et al., 2002; ARMIJO-OLIVO et al., 2011). Além disso, os traçados foram realizados na postura sentada do trabalhador, o que pode gerar valores do ACV diferentes.

Nossos achados demonstraram o valor de corte de $44^{\circ}$ para detecção de indivíduos sintomáticos e assintomáticos para dor cervical, porém com acurácia baixa $(0,6)$ e valores de sensibilidade e especificidade de 0,59 e 0,49 , respectivamente.

Já para a postura cervical realizamos duas comparações entre subgrupos sintomáticos e assintomáticos para dor cervical considerando os subgrupos normal vs hiperlordose e os subgrupos normal vs retificação/inversão. Também para essas análises, foram observados valores baixos de acurácia (0,5 em ambas). Para a comparação com o subgrupo hiperlordose verificamos um valor de corte de $14,02^{\circ}$ com valor de sensibilidade 0,60 e especificidade 0,47 . Já para o grupo com inversão e retificação o valor de corte foi de $14,37^{\circ}$ com valor de sensibilidade 0,52 e especificidade 0,50 .

Da mesma maneira, quando avaliamos a acurácia das medidas da postura craniocervical associadas à incapacidade relacionada à dor cervical (através do NDIBR), encontramos também uma acurácia baixa com valores de corte de $42,74^{\circ}$ com sensibilidade 0,56 e especificidade 0,40 para protrusão de cabeça e valor de corte $13,25^{\circ}$ com sensibilidade 0,48 e especificidade 0,40 para lordose cervical.

Desta forma, nossos achados de acurácia das medidas de avaliação postural qunatitativa e qualitativa para detectar dor e incapacidade demonstraram baixa acurácia $(0,5<$ ROC $<0,7)$, além de valores baixos de sensibilidade e especificidade, sugerindo que os valores obtidos tanto na análise quantitativa quanto qualitativa da postura não são adequados para diferenciar indivíduos com e sem inpacidade cervical e com e sem relato de dor. 
Corroborando com nossos achados, Grob, Frauenfelder, Mannion (2006) realizaram um estudo com uma amostra de 107 indivíduos de ambos os gêneros com idade superior a 45 anos, foram divididos em um grupo com dor cervical e outro grupo sem dor cervical. Os achados deste estudo não demonstraram associação entre o alinhamento sagital da coluna cervical e a presença de dor cervical. Porém uma limitação deste estudo foi que a amostra não era aleatória e os indivíduos do grupo com dor não tinham a dor cervical como principal queixa. Eles também encontraram que em mulheres, o grau de lordose cervical tende a aumentar com a idade (GROB, FRAUENFELDER, MANNION, 2006)

Harrison, Barry-Greb, Wojtowicz (1996) tinham como objetivo determinar um método confiável para medição da postura da cabeça, prático para a o uso clínico em indivíduos com e sem dor cervical. Para isso as medidas angulares foram realizadas através de um goniômetro. Eles também não encontraram diferenças significativas entre os grupos, com um valor de corte angular de $49,3^{\circ}$ para pacientes sem dor e $49,4^{\circ}$ para pacientes com dor.

Em contraposição a nossos achados, algumas publicações recentes na literatura ressaltam a importância da avaliação da postura estática da cabeça e coluna vertebral em sujeitos com disfunção cervical (LAU et al., 2010, YIP et al., 2008, MCAVINEY et al., 2005).

McAviney et al. (2005) realizaram um estudo utilizando o traçado de tangente posterior, analisaram 277 radiografias para identificar se havia relação entre a postura craniocervical e queixas de dores cervicais. Eles concluiram que pacientes com ângulo de lordose cervical de $20^{\circ}$ ou menos eram mais propensos a relatar dor cervicogênica, e indivíduos inclusos no intervalo de $31^{\circ}$ a $40^{\circ}$ se mostraram predominantemente assintomáticos. Ao investigarem a acurácia destas medidas obtiveram uma AUC de 0,80 
com uma sensibilidade de 0,72 e especificidade de 0,74 para o valor de $20^{\circ}$ como ângulo de corte. Porém, a curvatura cervical normal assintomática foi em média de $25^{\circ}$, valor sugerido como padrão mínimo para a hiperlordose cervical. Este valor encontra-se próximo ao encontrado por Gore et al. (1986) de $23^{\circ}$ e por Owens e Hoiris (1990) de $22,3^{\circ}$, valores esses encontrados através da análise de traçados radiográficos e, portanto, não podem ser comparados aos achados do presente estudo.

Em um estudo retrospectivo publicado por Harrison et al. (2004), sendo seus dados radiográficos de controle coletados cerca de 10 anos antes, eles descobriram que o grau de lordose medida com a técnica de tangente posterior foi capaz de distinguir, com precisão moderada, indivíduos com e sem dor crônica cervical (sensibilidade de 0,46, especificidade 0,97), e entre aqueles com e sem dor cervical aguda (sensibilidade de 0,67, especificidade 0,61). Entretanto não foi verificada diferença significativa entre os grupos para os valores médios do ângulo de tangente posterior.

Silva et al. (2009) realizaram um estudo na qual analisaram a postura da cabeça relacionada a presença ou ausência de dor cervical crônica não-traumática. Eles encontraram em seus resultados que indivíduos com dor tinham a cabeça mais protrusa, ou seja, o ângulo entre o tragus e a $\mathrm{C} 7$ menor $\left(45,4^{\circ}, \mathrm{DP}=6,8^{\circ}\right)$, em relação aos indivíduos sem dor $\left(48,6^{\circ}, \mathrm{DP}=7,1^{\circ}\right)$. Porém a acurácia deste achado não foi investigada. Yip et al. (2008) também verificaram uma redução no ângulo da lordose cervical em pacientes com relato de dor cervical.

Lau et al. (2010) realizaram um estudo no qual um de seus objetivos era verificar a relação entre dor cervical e a postura cervical e torácica no plano sagittal. Os indivíduos com dor cervical apresentaram o ACV menor $\left(40,1^{\circ} \mathrm{DP}=6,7^{\circ}\right)$ em relação ao $\mathrm{ACV}$ do grupo controle $\left(48,4^{\circ} \mathrm{DP}=5,5^{\circ}\right)$. Porém, o ângulo torácico foi um melhor preditor para presença de dor cervical, quando comparado ao ACV. 
Gore et al. (1986) e Harrisson et al. (2004) relataram em seus estudos que a lordose cervical tende a aumentar com a idade em indivíduos assintomáticos. Não comparamos a lordose cervical dos indivíduos com e sem dor cervical e sua relação com a idade, assim sugerimos que futuros estudos verifiquem essas relações. Além disso, Visscher, de Boer e Naeije (1998), relataram que a classificação da curvatura da coluna cervical pode sofrer influência do gênero. Os autores verificaram, por meio de radiografias, a predominância de uma postura parcialmente invertida na cervical de mulheres, enquanto que nos homens a curvatura lordótica foi a mais frequentemente observada. Recomenda-se para futuros estudos a comparação entre amostras de gêneros diferentes, o que não pode ser realizado no presente estudo por termos recrutado um banco de dados composto apenas por indivíduos do gênero feminino.

Com relação à presença ou ausência de incapacidade relacionada à dor cervical obtida através NDI-BR, também não verificamos níveis aceitáveis de acurácia $(\mathrm{ROC}>0,7)$ para as medidas de postura craniocervical obtidas através da fotogrametria e inspeção visual. Segundo Hardacker et al. (1997), as alterações degenerativas da coluna cervical são frequentemente acompanhadas por um uma diminuição em altura anterior ou posterior da coluna vertebral, o que resulta numa alteração do perfil sagital da coluna cervical.

Não encontramos estudos na literatura relacionando incapacidade a alteraçoes da postura craniocervical. Nossos achados sugerem que não há uma relação entre dor/ incapacidade vs. postura craniocervical. Entretanto, estudos futuros precisam ser conduzidos em amostras mais amplas para se verificar possíveis associações entre postura craniocervical vs. dor/incapacidade e indivíduos com diferentes disfunções musculoesquelética da região craniocervical.

\subsection{Limitações do estudo}


Algumas das limitações deste estudo são: a) em nosso estudo consideramos apenas mulheres, estudos futuros precisam verificar se os valores de acurácia são influenciados por diferenças entre os gêneros. Nesse sentido, Raine e Towney (1997) não relataram diferenças significativas para o ACV entre os gêneros; b) nossos dados são aplicáveis para indivíduos na faixa etária entre 25-45 anos, estudos futuros poderiam se voltar para verificação da influência da idade nesses achados, por exemplo, em crianças. A literatura sugere que o ACV possa ser influenciado pelo envelhecimento. Desta forma, estudos futuros, poderiam verificar associações entre idade e os ângulos ACV e ALC; c) futuros estudos poderiam incluir um maior número de examinadores, bem como adotar um procedimento de treinamento prévio para realização da análise postural qualitativa. É possível que o treinamento minimize os valores baixos de concordância observados para o ALC; d) futuros estudos também poderiam garantir um tamanho amostral com um número maior de participantes com alterações posturais, já que após a divisão nos subgrupos tivemos poucos participantes com inversão de $\begin{array}{lll}\text { curvatura } & \text { cervical, } & \text { por }\end{array}$ 


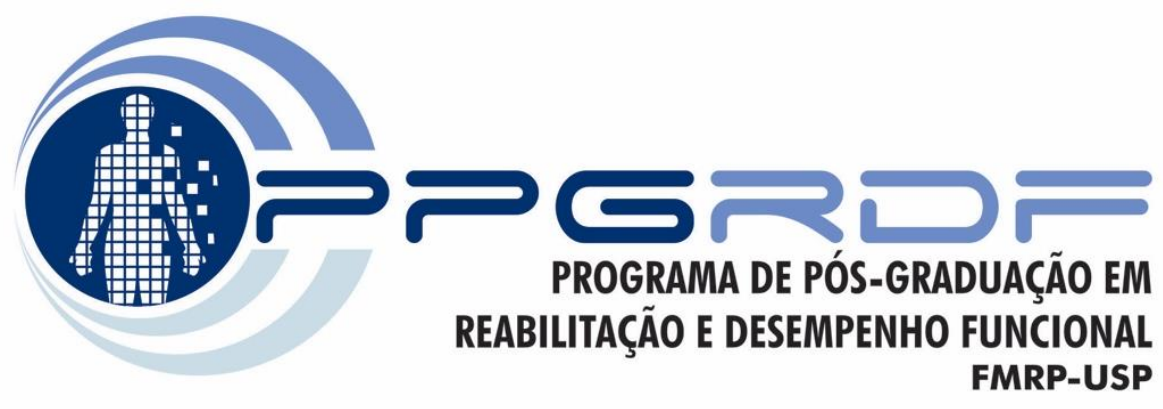

CONCLUSÃO

"A motivação é o que nos faz começar. O hábito é o que nos mantém no caminho." Jim Ryun 


\section{CONCLUSÃO}

- Nossos resultados demonstraram níveis aceitáveis de acurácia, sensibilidade e especificidade da análise quantitativa da postura craniocervical em relação à análise qualitativa para obtenção dos ângulos craniovertebral (ACV) e de lordose cervical (ALC) em mulheres;

- Foram verificados níveis de concordância e confiabilidade intraexaminador e interexaminadores aceitáveis para a maioria das comparações por pares na obtenção da classificação da postura craniocervical obtida através da inspeção visual no plano sagital;

- Foram verificados níveis de confiabilidade intra-examinador e interexaminadores aceitáveis para os ângulos obtidos na análise quantitativa da postura craniocervical no plano sagital;

- Não foram encontrados bons índices para discriminar indivíduos sintomáticos vs. assintomáticos para dor cervical ou subgrupos com e sem incapacidade relacionda à dor cervical;

- Nossos resultados dão suporte para o uso de ângulos na análise de postura quantitativa que discriminam indivíduos com protrusão da cabeça moderada/severa $\left(\mathrm{ACV}<40^{\circ}, \mathrm{EPM}: 0,73^{\circ}\right)$ e indivíduos com alterações da postura cervical em hiperlordose e retificação/cifose cervical (hiperlordose: $\mathrm{ALC}<12^{\circ}$ e retificação ou cifose: $\mathrm{ALC}>15^{\circ}, \mathrm{EPM}: 0,42^{\circ}$ ) em relação à postura considerada normal através da avaliação qualitativa; 


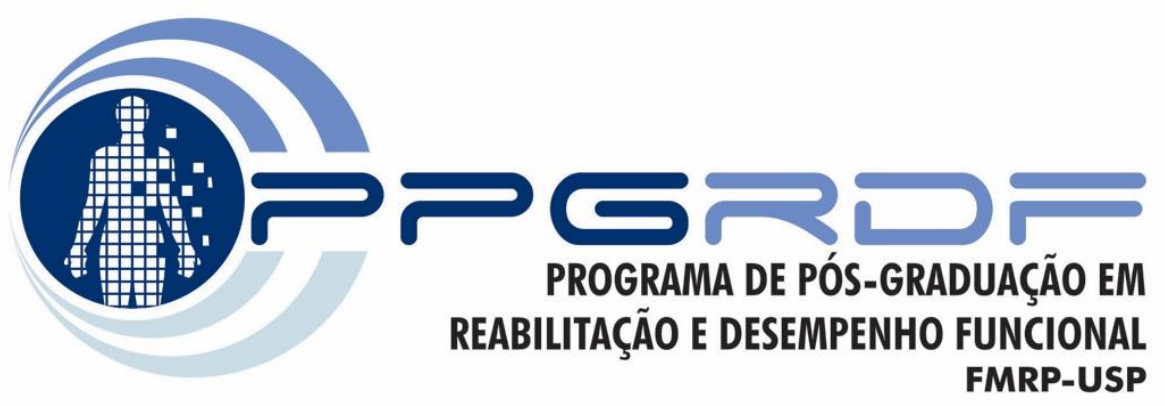

"A mente que se abre a uma nova ideia nunca mais volta ao seu tamanho original." Albert Einstein 


\section{REFERÊNCIAS}

1. AKOBENG, A.K. Understanding diagnostic tests 3: receiver operating characteristic curves. Acta Paediatrica. 2007; 96 (5): 644-647.

2. ALBERS, D. Eine Studie über die Funktion der Halswirbelsäule bei dorsaler und ventraler Flexão. 1954. Fortschr Geb Röntgenstr. 81: 606-615.

3. ALTMAN, D.G.; BLAND, J.M. Diagnostic tests 3: receiver operating characteristic plots. BMJ 1994; 309: 188.

4. ANASTASI, A.; URBINA, S. Psychological Testing (7th.). Upper Saddle River, NJ: Prentice-Hall.1997.

5. ARMIJO-OLIVO, S.; RAPPOPORT, K.; FUENTES, J, GADOTTI IC, MAJOR PW, WARREN S, THIE NMR, MAGEE DJ. Head and Cervical Posture in Patients with Temporomandibular Disorders. J Orofac Pain. 2011; 25(3):199209.

6. BELLI, J.F.; CHAVES, T.C.; DE OLIVEIRA, A.S.; GROSSI, D.B. Analysis of body posture in children with mild to moderate asthma. Eur J Pediatr. 2009;168(10):1207-16.

7. BISTER, D.; EDLER, R.J.; TOM, B.D.M.; PREVOST, A.T. Natural head posture - considerations of reproducibility. Eur J Orthood 2002; 24(5): 457-70.

8. BOSSUYT, PM et al. STARD 2015: an updated list of essential items for reporting diagnostic accuracy studies. BMJ. 2015, 28;351:h5527. doi: 10.1136/bmj.h5527.

9. BRICOT, B. Posturologia. $2^{\mathrm{a}}$ ed. São Paulo: Ícone Editora; 2001.

10. BRINK, Y. et al. The spinal posture of computing adolescents in a real-life setting. BMC Musculoskelet Disord, v. 15, p. 212, 2014. ISSN 1471-2474. 
11. CAILliET, R. - Sindromes Dolorosas da Cabeça e da Face, Rio de Janeiro, Revinter, 1997. 233p.

12. CARADONNA, D.; ALVES, F.A. Posturologia A.T.M.: Oclusão e postura. J Bras Ortodontia e Ortop Maxilar. 1997;2(12):7-13.

13. CHAVES TC, TURCI AM, PINHEIRO CF, SOUSA LM, GROSSI DB. Static body postural misalignment in individuals with temporomandibular disorders: a systematic review. Braz J Phys Ther. 2014;18(6):481-501.

14. CLAMAN, L.; PATTON, D.; RASHID, R. Standardized portrait photography for dental patients. Am J Orthod Dentofac Orthop. v.98, p.197-205, 1990.

15. COOK, C.; RICHARDSON, J. K.; BRAGA, L.; MENEZES, A.; SOLER, X.; KUME, P.; ZANINELli, M.; SOCOLOWS, F.; PIETROBON, R. Crosscultural adaptation and validation of the Brazilian Portuguese version of the Neck Disability Index and Neck Pain and Disability Scale. Spine (Phila Pa 1976). 2006, v.31, n.14, p.1621-27.

16. CUCCIA, A.M.; CARADONNA, C. The natural head position. Different techniques of head positioning in the study of craniocervical posture. Minerva stomatologica 58:11-12 (601-12). 2009.

17. DÖHNERT, M.B.; TOMASI, E. Validade da fotogrametria computadorizada na detecção de escoliose idiopática adolescente. Rev Bras Fisioter. 2008;12(4):290-7.

18. DRZAL-GRABIEC, J. et al. Examination of the compatibility of the photogrammetric method with the phenomenon of mora projection in the evaluation of scoliosis. Biomed Res Int, v. 2014, p. 162108, 2014. 
19. DUARTE, M.. Análise estabilográfica da postura ereta humana quasi-estática. 2000. 86 f. Tese (Livre Docência em Biomecânica) - Escola de Educação Física e Esporte, Universidade de São Paulo, São Paulo, 2000.

20. DUNK NM, CHUNG YY, COMPTON DS, CALLAGHAN JP. The reliability of quantifyying upright standing postures as a baseline diagnostic clinical tool. Journal of manipulative and physiological therapeutics 27:2 (91-96). 2004

21. DUNK, N.M.; LALONDE, J.; CALLAGHAN, J.P. Implications for the use of postural analysis as a clinical diagnostic tool: reliability of quantifying upright standing spinal postures from photographic images. J Manipulative Physiol Ther. 2005;28:386-392.

22. DUNLEAVY, K.; NEIL, J.; TALLON, A.; ADAMO, D.E. Reliability and validity of cervical position measurements in individuals with and without chronic neck pain. J Man Manip Ther. 2015 Sep;23(4):188-96.

23. ERIKSSON, E.; MOKHTARI, M.; POURMOTAMED, L.; HOLMDAHL, L.; ERIKSSON, H. Inter-rater reliability in a resource-oriented physiotherapeutic examination. PhysiotherTheory Pract 2000;16:95-103.

24. EY-CHMIELEWSKA, H.; CHRUSCIEL-NOGALSKA, M.; FRACZAK, B. Photogrammetry and Its Potential Application in Medical Science on the Basis of Selected Literature. Adv Clin Exp Med, v. 24, n. 4, p. 737-41, 2015 Jul-Aug 2015.

25. FARKAS, L.G.; BRYSON, W.; KLOTZ, J. Is photogrammetry of the face reliable? Plast Reconstr Surg, v. 66, n. 3, p. 346-55, Sep 1980.

26. FEDORAK, C.; ASHWORTH, N.; MARSHALL, J.; PAULL, H. Reliability of the visual assessment of cervical and lumbar lordosis: how good are we? Spine (Phila Pa 1976). 2003,15;28(16):1857-9. 
27. FERRARIO， V.F.; SFORZA， C.; TARTARGLIA， G.; BARBINI， E.; MICHIELON, G. New televisión techinique for natural head and body posture analisis. The J of Craniomand Practice 1995; 13(4): 24-55.

28. FERREIRA, M.C.; BEVILAQUA-GROSSI, D.; SPECIALI, J.G. et al.. Body posture changes in women with migraine with and without temporomandibular disorder. Brazilian J. Phys Ther. v.18, p.19-29, 2014.

29. FLAHAUlT, A.; CADILHAC, M.; THOMAS, G. Sample size calculation should be performed for design accuracy in diagnostic test studies. J Clin Epidemiol. 2005 Aug: 58(8): 859-62.

30. FORTIN, C. et al. Clinical methods for quantifying body segment posture: a literature review. Disabil Rehabil, v. 33, n. 5, p. 367-83, 2011.

31. FURLANETTO T.S., CANDOTTI C.T., COMERLATO T., LOSS J.F. Validating a postural evaluation method developed using a Digital Image-based Postural Assessment (DIPA) software. Comput Methods Programs Biomed.2012; 108:203-212.

32. FURLANETTO, T.S; SEDREZ, J.A.; CANDOTTI, C.T.; LOSS, J.F. Photogrammetry as a tool for the postural evaluation of the spine: A systematic review. World Journal of Orthopedics. 7 (2): 136-148. 2016.

33. GADOTTI, I.C.; ARMIJO-OLIVO, S.; SILVEIRA, A.; MAGEE, D. Reliability of the craniocervical posture assessment: visual and angular measurements using photographs and radiographs. J Manipulative Physiol Ther. 2013; 36(9):61925. http://dx.doi.org/ 10.1016/j.jmpt.2013.09.002

34. GADOTTI, I.C.; BIASOTTO-GONZALEZ, D.A. Sensitivity of clinical assessments of sagittal head posture. Journal of Evaluation in Clinical Practice. 2010; 16(1): 141-4. 
35. GANGNET, N.; POMERO, V.; DUMAS, R.; SKALLI, W.; VITAL, J.M. Variability of the spine and pelvis location with respect to the gravity line: a three-dimensional stereoradiographic study using a force platform. Surg Radiol Anat. 2003;25(5- 6):424-33.

36. GONZALEZ, H.E.; MANNS, A. Forward head posture: its strutural and functional influence on the stomatognathic system: a conceptual study. Journal of Craniomandibular Practice, v. 14, n. 1, p. 71-80, 1996.

37. GORE, D.; SEPIC, S.; GARDNER, G. Roentgenographic findings of the cervical spine in asymptomatic people. Spine, 11(521-524). 1986.

38. GRIMMER-SOMERS, K1.; MILANESE, S.; LOUW, Q. Measurement of cervical posture in the sagittal plane. J Manipulative Physiol Ther. 2008 Sep; 31(7):509-17.

39. GROB, D1.; FRAUENFELDER, H.; MANNION, A.F. The association between cervical spine curvature and neck pain. Eur Spine J. 2007 May; 16(5):669-78. Epub 2006 Nov 18.

40. HALEY, S.M.; FRAGALA-PINKHAM, M.A. Interpreting change scores of tests and measures used in physical therapy. Physical Therapy. 2006. 86, 735743.

41. HARDACKER, J.W.; SHUFORD, R.F.; CAPICOTTO, P.N.; PRYOR, P.W. Radiographic standing cervical segmental alignment in adult volunteers without neck symptoms. Spine (1997); 22(13):1472-1480;

42. HARRISON, D.D.; HARRISON, D.E.; JANIK, T.J.; CAILLIET, R.; FERRANTELLI, J.R.; HAAS, J.W.; HOLLAND, B. Modeling of the sagittal cervical spine as a method to discriminate hypolordosis: results of elliptical and 
circular modeling in 72 asymptomatic subjects, 52 acute neck pain subjects, and 70 chronic neck pain subjects. Spine.2004;29(22):2485-2492.

43. HARRISON, A.L.; BARRY-GREB, T.; WOJTOWICZ, G. Clinical measurement of head and shoulder posture variables J Orthop Sports Phys Ther 1996 23(6):353-61.

44. IUNES, D.H.; BVILAQUA-GROSSI, D.; OLIVEIRA, A.S.; CASTRO, F.A.; SALGADO, H.S. Comparative analysis between visual and computerized photogrammetry postural assessment. Rev Bras Fisioter. 2009; 13(4):308-15.

45. IUNES, D.H.; CASTRO, F.A.; SALGADO, H.S.; MOURA, I.C.; OLIVEIRA, A.S.; BEVILAQUA-GROSSI, D. Confiabilidade intra e interexaminadores e repetibilidade da avaliação postural pela fotogrametria. Rev Bras Fisioter. 2005;9(3):327-34.

46. JOHNNSON, G.M. The correlation between surfasse measurement of head and neck posture and the anatomic position of the upper cervical vertebrae. Spine. 23:8 (921-7). 1998

47. KENDALL, F.P.; MCCREARY, E.K.; PROVANCE, P.E. Músculos: provas e funções. 5a ed. São Paulo: Manole; 2007.

48. KENDALL, F.P.; MCCREARY, E.K.; PROVANCE, P.E. Músculos: provas e funções. $5^{\mathrm{a}}$ ed. São Paulo: Manole; 1995.

49. KIM, M. H.; YOO, W. G. Comparison of the Hamstring Muscle Activity and Flexion-Relaxation Ratio between Asymptomatic Persons and Computer Workrelated Low Back Pain Sufferers. J Phys Ther Sci, v. 25, n. 5, p. 535-6, May 2013.

50. LAU, H. M.; CHIU, T. T.; LAM, T. H. Measurement of craniovertebral angle with Electronic Head Posture Instrument: Criterion validity. J Rehabil Res Dev, 
v. 47 , n. 9 , p. $911-8,2010$.

51. LEE, W.Y.; OKENSON, J.P.; LINDROTH, J. The relationship between forward head posture and temporomandibular disorders. J Orofac Pain. 1995;9(2):161-7.

52. MAGEE, D. Avaliação Musculoesquelética. São Paulo: Manole, 2002.

53. MAHER, C.G.; LATIMER, J.; COSTA, L.O.P. The relevance of cross-cultural adaptation and clinimetrics for physical therapy instruments. Rev Bras Fisioter. 2007. 11: 245-52.

54. MARQUES, A. P. Cadeias musculares: um programa para ensinar avaliação fisioterapêutica global. São Paulo: Manole, 2000.

55. MATCHAR, D.B.; ORLANDO, L.A. The Relationship Between test and Outcome. In: Price CP, editor. Evidence- Based Laboratory Medicine; Principles, Practice and Outcomes. 2. Washington DC, USA: AACC Press; 2007. pp. 53-66.

56. McAVINEY, J.; SCHULZ, D.; BOCK, R.; HARRISON, DE.; HOLLAND, B. Determining the relationship between cervical lordosis and neck complaints. J Manipulative Physiol Ther. 2005 Mar-Apr; 28(3):187-93.

57. MORADI, N. et al. Intrarater and interrater reliability of sagittal head posture: a novel technique performed by a physiotherapist and a speech and language pathologist. J Voice, 2014, v. 28, n. 6, p. 842. e 11-6.

58. NAM, SH, SON SM, Kwon JW, Lee NK. The Intra- and Inter-rater Reliabilities of the Forward Head Posture Assessment of Normal Healthy Subjects. J Phys Ther Sci. 2013 Jun;25(6):737-9.

59. NAYLER, J. R. Clinical Photography: A guide for the clinician.J. Postgrad Med. 2003, v.49,n.3, p. 256-62. 
60. NEJATI, P.; LOTFIAN, S.; MOEZY, A.; NEJATI, M. The relationship of forward head posture and rounded shoulders with neck pain in Iranian office workers. Medical journal of the Islamic Rupublic of Iran. 2014, v.28, n.26.

61. NISHIYAMA, A.; KINO, K.; SUGISAKI, M.; TSUKAGOSHI, K. Influence of phychosocial factors and habitual behavior in temporomandibular disorder Related symptoms in a working population in Japan. Open Dent J. p.240-247, 2012.

62. NORMAND, M.C.; DESCARREAUX, M.; HARRISON, D.D.; HARRISON, D.E.; PERRON, D.L.; FERRANTELLI, J.R. et al. Three dimensional evaluation of posture in standing with the posture print: an intra-and inter-examiner reliability study. Chiropr Osteopat. 2007;15:15.

63. NORMAND, M.C.; HARRISON, E.; CALLIET, R. BLACK, P.; HARRISON, D.D.; HOLLAND, B. Reliability and measurement error of the Biotonix Video Posture evaluation system - Part I: inanimate objects. J Manipulative Physiol Ther 2002; 25(4): 246-50.

64. OBUCHOWISKI, N.A.; LIEBER, M.L.; WIANS, F.H. ROC Curves in clinical chemistry: uses, misuses, and possible solutions. Clin Chem 2004;50: 1118-25.

65. OWENS, E, HOIRIS, K. Cervical curvature assessment using digitized radiographic analysis. Chiropr Res J. 4 (47-62). 1990.

66. PASSIER L.N., NASCIEMENTO M.P., GESCH J.M., HAINES T.P.. Physiotherapist observation of head and neck alignment. Physiother Theory Pract. 2010 Aug;26(6):416-23

67. PENHA, P.J.; JOÃO, S.M.; CASAROTTO, R.A, AMINO, C.J.; PENTEADO, D.C. Postural assesment of girls between 7 and 10 years of age. Clinics. 2005;60(1): fisioterapêutica global. 2. ed. São Paulo: Manole, 2005. 
68. PEREIRA, O.S. A utilização da análise computadorizada como método de avaliação das alterações posturais: um estudo preliminar. Fisioter Mov. $2003 ; 16(2): 17-25$.

69. PEZZAN, P.A.O.; JOÃO, S.M.; RIBEIRO, A.P.; MANFIO, E.F. Postural assessment of lumbar lordosis and pelvic alignment angles in adolescent users and nonusers of high-heeled shoes. J Manipulative Physiol Ther.2011;34:614621.

70. PORTNEY, L.; WATKINS, M. Foundations of Clinical Research - Applications to Practice. 2009.

71. PRADHAM, N. S. et al. Mandibular deviations in TMD and non-TMD groups related to eye dominance and head posture. J Clin Pediatr Dent, v. 25, n. 2, p. 147-55, 2001.

72. RAINE, S.; TWOMEY, L. T. Head and shoulder posture variations in 160 asymptomatic women and men. Arch Phys Med Rehabil.v.78, p.1215-23, 1997.

73. RODRIGUES, A.C.C.; ROMEIRO, C.A.P.; PATRIZZI, L.J. Evaluation of thoracic kyphosis in older adult women with osteoporosis by means of computerized biophotogrammetry. Braz J Phys Ther. 2009; 13:205-209.

74. RUIVO, R.M.; PEZARAT-CORREIA， P.; CARITA， A.I. Intrarater and interrater reliability of photographic measurement of upper-body standing posture of adolescents. J Manipulative Physiol Ther. 2015 Jan;38(1):74-80.

75. SAAD, K. R. et al. Reliability of photogrammetry in the evaluation of the postural aspects of individuals with structural scoliosis. J Bodyw Mov Ther, v. 16, n. 2, p. 210-6, Apr 2012. 
76. SACCO, I.C.N.; ALIBERT, S.; QUEIROZ, B.W.C.; PRIPAS, D. KIELING, I.; KIMURA, A.A. et al. Confiabilidade da fotogrametria em relação a goniometria para avaliação postural de membros inferiores. Rev Bras Fisioter. 2007;11(5):411-17.

77. SALAHZADEH, Z1.; MAROUFI, N1.; AHMADI, A1.; BEHTASH, H2.; RAZMJOO, A3.; GOHARI, M4.; PARNIANPOUR, M5. Assessment of forward head posture in females: observational and photogrammetry methods. J Back Musculoskelet Rehabil. 2014;27(2): 131-9.

78. SANDOVAL, P.; HENRÍQUEZ, J.; FUENTES, R., CABEZAS, G.; ROLDÁN, R. Curvatura cervical. Estudiocefalométricoenposición de reposo clínico postural. RevMed Chile 1999; 127(5): 547-55.

79. SANTOS, A. Diagnóstico clínico postural: um guia prático. São Paulo - SP: Summus Editorial, 2001.

80. SANTOS, M.M.; SILVA, M.P.C.; SANADA, L.S.; ALVES, C.R.J. Photogram metric postural analysis on healthy seven to ten-year-old children:interrater reliability Rev Bras Fisioter 2009 13(4):350-5.

81. SILVA, A.G.; PUNT, T.D.; JOHNSON, M.I. Reliability and validity of head posture assessment by observation and a four-category scale. Man Ther. 2010; 15(5): 490-5. 
82. SILVA, A.G.; PUNT, T.D.; SHARPLES, P. VILAS-BOAS, J.P.; JOHNSON, M.I. Head posture and neck pain of chronic nontraumatic origin: a comparison between patients and pain-free persons. Arch Phys Med Rehabil. 2009 Apr;90(4):669-74.

83. SIM, J.; WRIGHT, C.C. The kappa statistic in reliability studies: use, interpretation, and sample size requirements. Phys Ther. 2005 Mar;85(3):25768.

84. SIMON, L. et al. Biomécanique du rachis lombaire et éducation posturale. Revue du Rhumatisme. v.55, n.5, p.415-420, 1988.

85. SINGH, D.K.; BAILEY, M.; LEE, R. Biplanar measurement of thoracolumbar curvature in older adults using an electromagnetic tracking device. Arch Phys Med Rehabil. 2010;91:137-142.

86. SINGLA, D.; VERGAR, Z. Methods of postural assessment used for sports persons. J Clin Diagn Res, v. 8, n. 4, p. LE01-4, Apr 2014.

87. SOUCHARD, P. E. Fundamentos da reeducação postural global: princípios e originalidade. São Paulo: É Realizações, 2003.

88. SZCZYGIEL, E. et al. Biomechanical influences on head posture and the respiratory movements of the chest. Acta Bioeng Biomech, v. 17, n. 2, p. 143-8, 2015.

89. SZETO, G. P.; STRAKER, L. M.; O'SULLIVAN, P. B. A comparison of symptomatic and asymptomatic office workers performing monotonous keyboard work--2: neck and shoulder kinematics. Man Ther, v. 10, n. 4, p. 28191, Nov 2005a. 
90. TOMMASELLI, A.M.G.; SILVA, J.F.C.; HASEGAWA, J.K.; GALO, M.; DAL POZ, A.P. Fotogrametria: aplicações a curta distância. FCT 40 anos. Perfil cientifico educacional. Presidente: Meneguetti Jr e Alves; 1999. p. 147-59.

91. VAN GENDEREN, F.; De BIE, R.; HELDERS, P.; VAN, MEETEREN, N. Realiability research: towards a more clinically relevant approach. Phys Ther $\operatorname{Rev} 2003 ; 8:$ 169-76.

92. VAN MAANEN, C.J.; ZONNENBERG, A.J.; ELVERS, J.W.; OOSTENDORP, R.A. Intra/interrater reliability of measurements on body posture photographs. Cranio. 1996; 14(4): 326-31.

93. VISCCHER, C. M.; De BOER, W.; LOBBRZOO, F.; HABETS, L. L.; NAEIJE, M. Is there a relationship between head posture and craniomandibular pain? Journal of Oral Rehabilitation, v.29, n.11, p.1030-1036, 2002.

94. VISCCHER, C.M.; DE BOER, W.; NAEIJE, M. The relationship between posture and curvature of the cervical spine. Journal of manipulative and physiological therapeutics. 21:6 (388-391), 1998.

95. WATSON, A.W.; MAC DONNCHA C. A reliable technique for the assessment of posture: assessment criteria for aspects of posture. J Sports Med Phys Fitness. 2000; 40(3): 260-70.

96. WATSON, A.W.S. Procedure for the production of high quality photographs suitable for the recording and evaluation of posture. Ver Fisioter Univ. São Paulo 1998; 5(1): 20-6.

97. WATSON, D. H.; TROTT, P. H. Cervical headache: an investigation of natural head posture and upper cervical flexor muscle performance. Cephalalgia, v. 13, n. 4, p. 272-84; discussion 232, Aug 1993. 
98. WEBER, P.; CORRÊA, E.C.R.; MILANESI, J.M.; SOARES, J.C.; TREVISA, M.E. Craniocervical posture: cephalometric and biophotogrammetric analysis. Braz J Oral Sci. 2012; 11: 416-421.

99. YIP, C. H.; CHIU, T. T.; POON, A. T. The relationship between head posture and severity and disability of patients with neck pain. Man Ther, v. 13, n. 2, p. 148-54, May 2008.

100. ZONNENBERG, A.J.J.; MAANEN, V.; ELVERS, J.W.H.; OOSTENDORP, R.A.B. Intra/interrater reliability of measurements on body posture photographs. J Cranomand Pract 1996; 14(4): 326-31. 
Referências $\mid 96$

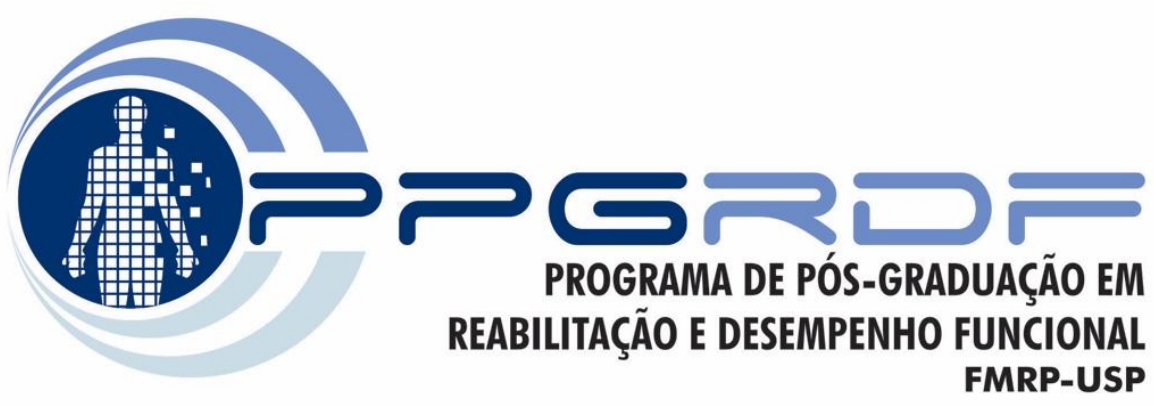

ANEXOS E APÊNDICES

"O maior líder é aquele que reconhece a sua pequenez, extrai força da sua humildade e experiência da fragilidade.'

Augusto Cury 


\section{ANEXO 1 - Documento de aprovação do projeto "Sensibilidade e especificidade da avaliação da postura craniocervical: fotogrametria versus análise de inspeção visual" pelo Comitê de Ética em Pesquisa}

HOSPITAL DAS CLÍNICAS DA FACULDADE DE MEDICINA DE RIBEIRÃO PRETO DA UNIVERSIDADE DE SÄO PAULO

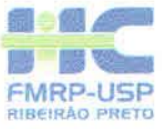

Ribeirão Preto, 10 de dezembro de 2015

Oficio $\mathrm{n}^{\circ} 4373 / 2015$

$\mathrm{CEP} / \mathrm{MGV}$

PROCESSO HCRP $\mathrm{n}^{\circ} 17328 / 2015$

Prezadas Pesquisadoras,

O trabalho intitulado "SENSIBILIDADE E ESPECIFICIDADE DA AVALIAC̄AO DA POSTURAL CRANIOCERVICAL: FOTOGRAMETRIA VERSUS ANÁLISE DE INSPEÇÃO VISUAL", foi analisado pelo Comitê de Ética em Pesquisa, em sua $419^{\text {a }}$ Reuniâo Ordinária realizada em 07/12/2015, e enquadrado na categoria: APROVADO, bem como solicitacão de dispensa de aplicacão do Termo de Consentimento Livre e Esclarecido.

De acordo com Carta Circular $n^{\circ}$ 003/2011/CONEP/CNS, datada de 21/03/2011, o sujeito de pesquisa ou seu representante, quando for o caso, deverá rubricar todas as folhas do Termo de Consentimento Livre e Esclarecido - TCLE - apondo sua assinatura na última do referido Termo; o pesquisador responsável deverá da mesma forma, rubricar todas as folhas do Termo de Consentimento Livre e Esclarecido - TCLE - apondo sua assinatura na última página do referido Termo.

Este Comite segue integralmente a Conferência Internacional de Harmonização de Boas Práticas Clínicas (IGH-GCP), bem como a Resolução $n^{\circ}$ 466/2012 CNS/MS.

Lembramos que devem ser apresentados a este CEP, o Relatório Parcial e o Relatório Final da pesquisa.

Atenciosamente.

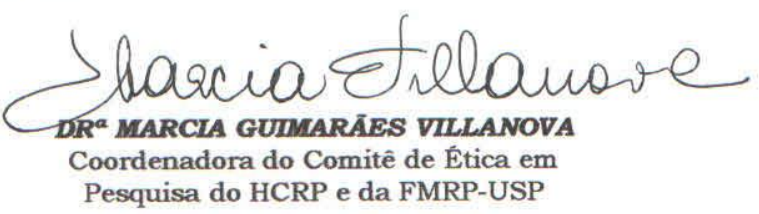

Ilustrissimas Senhoras

THAIS CRISTINA CHAVES

RAQUEL DESCIE VERALDI LEITE (Orientanda)

Depto. de Neurociências e Ciências do Comportamento

HOSPITAL DAS CLINICAS DA FACULDADE DE MEDICINA DE RIBEIRĀO PRETO DA UNIVERSIDADE DE SÃO PAULO Campus Universitário - Monte Alegre

Comitê de Ética em Pesquisa do HCRP e FMRP-USP FWA-00002733; IRB-00002186 e $14048-900$ Ribeirăo Preto SP 
Anexos $\mid 98$

\begin{abstract}
ANEXO 2 - Documento de aprovação do projeto "Presença de alterações degenerativas e posturais da coluna cervical e aspectos de funcionalidade e incapacidade globais em pacientes com cefaleia" pelo Comitê de Ética em Pesquisa
\end{abstract}

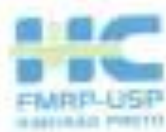

Rabeirso Preto, 11 de abril de 2012

OGicio $\mathrm{a}^{\circ} 1317 / 2012$

CFPMGV

Prezados Seahorea,

O) trabultho intitulado MPRESENCA DE ALTERMCOES DEgenERATTAS E POSTURAIS DA COLUNA CERVICAL E ASPECTOS DE FUSCIONALIDADE E INCAPACIDADE GLOBAIS EM PACIESTES COM CEFALETA", foi analisado pelo Comité de Etica em ferqulsa, em sun 043 Reunisio Ordiária realizada $\mathrm{cm} 09704 / 2012$ e enquadrudo Eselarecido APROVADO, bem como o Termo de Cansentisne o Termo de Consentimento Grupo Controle, $2^{*}$ versio de $26 / 03 / 2012$ e 26/03/2012, de acordo corm Livre e Esclarecido - Grupo Estudo

of Processo HCRP n" 15821/2011.

De aconto com Carta Circular $\mathrm{n}^{*}$ O013/2011/CONEP/CNS Aatada de 21/03/2011, o sujeito de pescquisa au seu representarte, quando for o caso, devera nubricar toclas as folhas do Termo de Consentimento Lime e

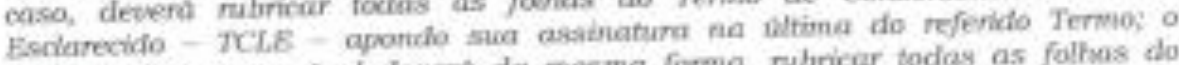

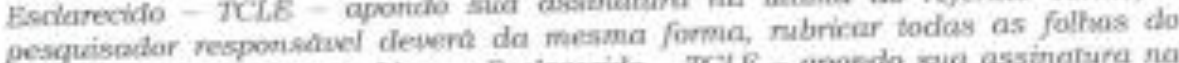
Temno de Consentimento Livre e Escharecido - TCLE - apondo sale assiriatura na Altima pigena do reforido Terma

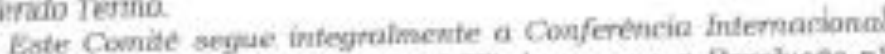

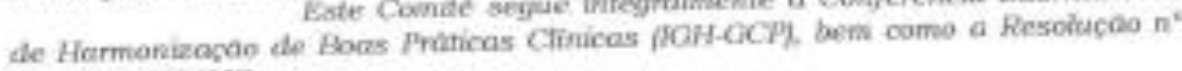
$196 / 96 \mathrm{CNS} / \mathrm{MBS}$

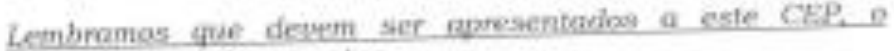

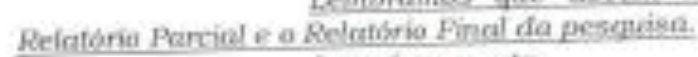

Afenciosanmente.

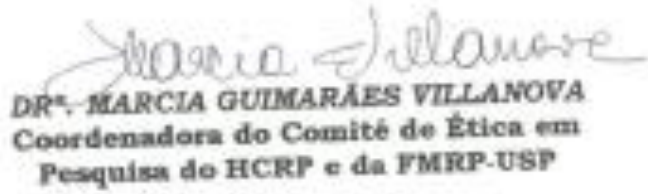

Tlustrissimes Senhores

GABRIELA NATÁLI FERRACINI

PROF, DR. JOSE GERALDO SPECIALIOOrientador)

Di-pto, de Neurociénclas e Cièncias do Comportamento 
ANEXO 3 - Documento de aprovação do projeto "Dor cervical crônica e postura em trabalhadores de escritório usuários de computador" pelo Comitê de Ética em Pesquisa

Oficio $\mathrm{n}^{\circ} 909 / 2013$

CEP/MGV

PROCESSO HCRP n $^{\circ} 17111 / 2012$

Prezadas Pesquisadoras,

O trabalho intitulado "DOR CERvical CRŌNICA E POSTURA EM TRABALHADORES DE ESCRITÓRIO USUĹRIOS DE COMPUTADOR", foi analisado pelo Comitè de Etica em Pesquisa, em sua $362^{\circ}$ Reuniâo Ordinâria realizada em 18/03/2013, e enquadrado na categoria: APROVADO, bem como o Termo de Consentimento Livre e Esclarecido Versaio 2.

Este Comite segrue intergralmente a Canferencia Intemacional de Harmonizaço de Boas Praticas Clinicas (IGH-GCP) bem como a Resoluça $n^{*} 196 / 96$ CNS/MS

Lembramos que devem ser apresentadas a este CEP. o Relatorio Parcial e o Reiatónio Final da pesquisa. De acario com Carta Circuiar $n^{\circ}$ 003/2011/CONRP/CNS, datada de 21/03/2011, o sujerto de pesquisa ou seu representante, quando for o caso, devera rubricar todas as folhas do Termo de Consertimento Live e Esciarecido - TCLE - apondo sta asstinatura na ultima do referido Termo; o pesquisador responsável deuerá da mesma forma, rubricar todas as folhas do Termo de Cansentimento Live e Bsclarecido - TCL.B - apondo sua assinatura na ditima pagina do referido Termo.

Atenciosamente.

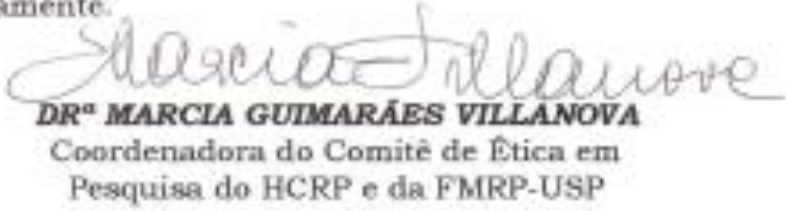

Ilustrissimas Senhoras

PROF ${ }^{2}$ DR $^{2}$ THAIS CRISTINA CHAVES

MARCELA MENDES BRACATTO (Aluna)

Depto de Neurocièncias e Ciéncias do Comportamento

Cempus Univarsitarie - Marte Alegre

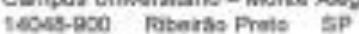

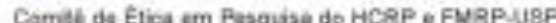
Pra-cooconas 1 Rh (016) $3602 \cdot 2228$ cepencrp. esp \& 
ANEXO 4 - Termo de Consentimento Livre e Esclarecido do projeto "Presença de alterações degenerativas e posturais da coluna cervical e aspectos de funcionalidade $e$ incapacidade globais em pacientes com cefaleia"

TERMO DE CONSENTIMENTO LIVRE E ESCLARECIDO - GE Nome do paciente:

Documento de identidade: Gênero: ( ) F ( )M

Data de nascimento:

Endereço: No. Apto

Bairro: Cidade: Estado:

CEP: Telefone: DDD ( )

O (a) Senhor (a) está sendo convidado (a) a participar da pesquisa "PRESENÇA DE ALTERAÇÕES DEGENERATIVAS E POSTURAIS DA COLUNA CERVICAL E ASPECTOS DE FUNCIONALIDADE E INCAPACIDADE GLOBAIS EM PACIENTES COM CEFALEIA", que deseja estudar a presença de alterações causadas pelo envelhecimento ou uso excessivo (degenerativas) e postural da coluna cervical e sua associação com os aspectos da vida diária. O (a) Senhor. (a) está sendo convidado a participar por apresentar cefaleia.

Caso aceite participar deste estudo, o (a) Sr. (Sra.) deverão responder aos questionários: Índice de incapacidade cervical que avalia a capacidade da coluna cervical (pescoço); Escala graduada de dor crônica que avalia a presença de sintomas de dor crônica; o Allodynia Symptom Checklist (Lista de sintoma de Alodínia) que avalia a presença de sensibilidade a um estímulo não doloroso (alodínia cutânea). A aplicação dos questionários terá duração média 15 minutos e será realizada em uma sala fechada, calma, com a presença da pesquisadora, não havendo constrangimentos aos indivíduos selecionados. A pesquisadora será sempre a mesma para todos os indivíduos. No exame radiográfico (raio-x) o Sr. (Sra) permanecerá em posição ortostática (em pé), com os braços esticados e os pés separados por uma distância de $7,5 \mathrm{~cm}$ e orientados a manter o olhar em um espelho que estará posicionado a uma distância de $1 \mathrm{~m}$ para garantir a posição neutra da cabeça. Em geral, os exames de raios $\mathrm{X}$ são muito seguros, embora qualquer exposição à radiação represente algum risco para o corpo, a quantidade utilizada em um raio $\mathrm{X}$ da coluna cervical será dosada pelo radiologista responsável. 
O (a) Senhor (a) tem o direito de escolher não participar deste estudo ou mesmo parar de participar em qualquer momento que desejar, sem que isso prejudique a continuidade do seu tratamento, ou seja, seu tratamento será exatamente o mesmo daqueles pacientes que não participarem do estudo.

Em nenhum momento durante a realização do estudo e de seu tratamento, ou durante a divulgação dos resultados do estudo, o (a) Senhor (a) terá sua identidade revelada.

A sua participação na pesquisa não lhe trará nenhum benefício direto, entretanto, os dados obtidos irão nos auxiliar no entendimento da sua doença e eventualmente proporcionar melhor tratamento no futuro para as pessoas que vierem a apresentar o mesmo problema de saúde.

A qualquer momento, o (a) Senhor (a) poderá solicitar esclarecimentos adicionais sobre sua participação na pesquisa. Em caso de dúvidas, durante ou após a participação no estudo, o (a) senhor (a) ou qualquer membro de sua família poderá contatar com os pesquisadores Gabriela Natália Ferracini e Prof. Dr. José Geraldo Speciali, pelos telefones (16) 9750-8011 e (16) 99935928.

Ribeirão Preto, de de 201_.

Nome:

Assinatura:

Ribeirão Preto, de de 201_.

Nome:

Assinatura do pesquisador responsável: 


\section{ANEXO 5 - Termo de Consentimento Livre e Esclarecido do projeto "Dor cervical crônica e postura em trabalhadores de escritório usuários de computador"}

\section{TERMO DE CONSENTIMENTO LIVRE ESCLARECIDO PARA OS \\ PARTICIPANTES DE PESQUISA}

Pesquisadores responsáveis: Profa. Dra. Thaís Cristina Chaves (chavestc@ fmrp.usp.br)

Fone: (016) 36024694 e Marcela Mendes Bragatto (marcelabragatto@hotmail.com)

Fone: (016) 81170115

\section{“DOR CERVICAL CRÔNICA E POSTURA EM TRABALHADORES DE}

\section{ESCRITÓRIO USUÁRIOS DE COMPUTADOR”}

Esclarecimento geral: Você está convidado (a) a participar de uma pesquisa que busca identificar a associação entre dores no pescoço, na face e alterações da postura do corpo em trabalhadores de escritório usuários de computador, por isso gostaríamos de contar com a sua colaboração. É possível que trabalhadores usuários de computador desenvolvam dor no pescoço e associada a esta, dores na face e alterações da postura.

Procedimento - Caso você aceite participar, serão feitos registros fotográficos de corpo inteiro na postura em pé e em trajes de banho. Você também responderá a um questionário de perguntas relacionadas à dor no pescoço e será avaliada à dor no pescoço e regiões da face através de um aparelho chamado algômetro. O equipamento será utilizado por um profissional habilitado que aplicará pressão sobre sua pele nas áreas mencionadas. Você terá em mãos um equipamento que finalizará o teste (botão on/off), assim que o você começar a sentir dor ao invés da pressão. Você não deverá sentir dor e por isso será convidado a apertar o botão no momento exato em que começar a sentir dor. Todas as avaliações serão realizadas no Laboratório de Pesquisa Interdisciplinar na Disfunção Musculoesquelética (LAPIDIM) localizado no prédio da Fisioterapia e Terapia Ocupacional dentro do campus da USP de Ribeirão Preto. A avaliação durará em torno de sessenta minutos e você poderá participar do projeto em horários alternativos fora do horário de expediente de trabalho.

Benefícios e Risco - Apesar do desconforto de ser fotografado em trajes de banho, fato este necessário para realização das análises posturais, garantiremos que a identidade você será mantida em sigilo. Sua identificação pessoal não ficará relacionada à sua imagem e apenas um examinador do estudo terá acesso às imagens de sua face, após a obtenção das fotos seu rosto será encoberto para realização das demais etapas do estudo. Caso você aceite participar, é importante destacar que não existem benefícios diretamente destinados a você durante a participação nesta pesquisa. No entanto, os dados obtidos nessa pesquisa auxiliarão no entendimento das associações entre alterações da postura, dores cervical e na face e a sobrecarga causada no corpo devido ao trabalho relacionado à postura sentada e na posição para o uso do computador. Assim, estratégias de prevenção podem ser adotadas caso os resultados desse estudo demonstrem essa associação. 
Você poderá sentir desconforto durante o exame de avaliação da dor por pressão, porém, nada que possa gerar risco a sua saúde. É importante que você entenda que não existe nenhum tipo de seguro de saúde ou de vida que possa trazer benefícios em função da sua participação neste estudo.

Liberdade de Participação - A sua participação neste estudo depende plenamente da sua vontade e autorização, estando livre para desistir em qualquer momento. Além disso, você não terá nenhum gasto financeiro adicional devido à participação nesse projeto.

Sigilo de Identidade - Caso aceite participar, é importante que fique claro que as informações obtidas nesta pesquisa não serão de maneira alguma associadas à sua identidade e não poderão ser consultadas por outras pessoas além das pesquisadoras desse estudo e nem utilizadas para outros fins que o da presente pesquisa sem a sua autorização oficial. Estas informações poderão ser utilizadas para fins científicos, ficando resguardados a sua privacidade e anonimato. Além disso, os registros fotográficos serão visualizados apenas por um examinador envolvido no projeto e os responsáveis pela pesquisa e as imagens registradas serão devidamente arquivadas no computador do laboratório e protegidas através de senha, com o acesso restrito somente aos pesquisadores.

O Sr(a) tem todo direito de procurar o pesquisador responsável para solucionar dúvidas e obter informações, antes, durante ou mesmo após o curso da pesquisa. Eventuais dúvidas sobre os aspectos éticos relacionados a essa pesquisa podem ser esclarecidas junto ao Comitê de Ética em Pesquisa do Hospital das Clínicas da Faculdade de Medicina de Ribeirão Preto (F: 36022228).

Assinatura do voluntário:

Nome do voluntário:

RG:

Data de nascimento:

Data da coleta de dados:

Assinatura do pesquisador responsável:

Nome do pesquisador:

RG:

Data da coleta:

Ribeirão Preto, de de 20 


\section{ANEXO 6 - Índice de Incapacidade Relacionada à Dor no Pescoço - NDI-BR (Neck Disability Index)}

indice de incapacidade relacionado ao Pescoço (IIRP)

Este questionảio foi criado para đar informações ao seu đoutor sobre como a sua dor no pescoço tem afetado a sua habilidade para fazer atividades điárias. Por favor,

responda a cada uma das perguntas e marque em cada seçào apenas una altemativa que melhor se aplique a vocè.

Seçảo 1 -Intensidade da dor

Eu não tenho dor nessemomento.

A dor é muito leve nesse momento.

A dor é moderada nessemomento.

- A dor é razoavelmente grande nesse momento.

A dor é muito grande nesse momento.

A dor é a pior que se possaimaginar nessemomento.

\section{Seção 2 - Cuidado pessoal (se lavar, se restir, etc)}

- Eu posso cuidar de mim mesmo(a) sem aumentar a dor.

Eu posso cuidar de mim mesmo(a) normalmente, mas isso faz aumentar a dor.

E. É doloroso ter que cuidar de mim mesmo e eu faço isso lentamente e com cuidado.

Eu preciso de ajuda, mas consigo fazer a maior parte do meu cuidado pessoal.

- Eu preciso de ajuda na maioria dos aspectos relacionados a euidar de mim mesmo(a)

Eu não me visto, me lavo com dificuldade e fico na cama.

\section{Seção 3 - Lerantar coisas}

Eu possolevantar objetos pesados sem aumentar a dor.

$\square$ Eu possolevantar objetos pesados, mas isso faz aumentar a dor.

A A dor me impede de levantar objetos pesados do chào, mas eu consigo se eles

estiverem colocados em uma boaposição, por exemplo, em una mesa.

․ A dor me impede de levantar objetos pesados, mas eu consigo levantar objetos com peso entre leve e médio se eles estiverem colocados $\mathrm{em}$ uma boa posição.

ㅁ Eu possolevantar objetos muito leves.

$\square$ Eu nảo posso levantarnem carregar absolutamente nada.

\section{Seçảo 6 - Prestar Atençảo}

- Eu consigo prestar atenção quando eu quero sem dificuldade.

- Eu consizo prestar atençào quando eu quero com uma dificuldade leve.

- Eu tenho uma dificuldade moderada em prestar atenção quando eu quero.

- Eu tenho muita dificuldade em prestar atenção quando eu quero.

- Eu tenho muitissima dificuldade em prestar atenção quando eu quero.

- Eu nà̀ consigo prestar atenção.

\section{Seçio 7 - Trabalho}

Eu posso trabalhar tanto quanto eu quiser.

ㅁ Eu só consigo fazer o trabalho que estou acostumado(a) a fazer, mas nada alem disso

口. Eu consigo fazer a maior parte do trabalho que estou acostumado(a) a fazer, mas nada além disso.

Eu nào consigo fazer o trabalho que estou acostumado(a) a fazer.

D Eu mal consigo fazer qualquer tipo de trabalho.

Eu năo consigo fazer nenhum tipo de trabalho.

\section{Seçào 8-Dirigir automöreis}

Eu posso dirigir meu carro sem nenhuma dor no pescoço.

- Eu posso dirigir meu carro tanto quanto eu queira com uma dor leve no meu pescoço.

- Eu posso dirigir meu carro tanto quanto eu queira com uma dor moderada no meu

pescoço.

- Eu não posso dingir o meu carro tanto quanto eu queira por causa de uma dor moderada no meu pescoço.

Eu mal posso dirigir por causa de uma dor forte no meu pescoço.

Eu nào posso dingir meu carro de maneira nenhuma. 
APÊNDICE A - FICHA DE AVALIAÇÃo PROTRUSÃO DE CABEÇA

Ficha de Avaliação

Avaliação postural visual - Alinhamento de cabeça

Data da avaliação

Avaliação: 16 ) ou 2()

Nome do avaliador:

Marque com um X a melhor opção.

\$

\section{Voluntária}

Normal

Leve

Moderado

Severo

\begin{tabular}{|c|l|l|l|l|}
\hline 1 & & & & \\
\hline 2 & & & & \\
\hline 3 & & & & \\
\hline 4 & & & & \\
\hline 5 & & & & \\
\hline 6 & & & & \\
\hline 7 & & & & \\
\hline 8 & & & & \\
\hline 9 & & & & \\
\hline 10 & & & & \\
\hline 11 & & & & \\
\hline 12 & & & & \\
\hline 13 & & & & \\
\hline 14 & & & & \\
\hline 15 & & & & \\
\hline 16 & & & & \\
\hline 17 & & & & \\
\hline 18 & & & & \\
\hline 19 & & & & \\
\hline 20 & & & & \\
\hline$\ldots$ & & & & \\
\hline 154 & & & & \\
\hline 155 & & & & \\
\hline 156 & & & & \\
\hline 157 & & & & \\
\hline
\end{tabular}


APÊNDICE B - FICHA DE AVALIAÇÃO LORDOSE CERVICAL

Avaliação postural visual - Alinhamento cervical

Data da avaliação

Avaliação: 1 ( ) ou $2($ )

Nome do avaliador:

Marque com um $\mathrm{X}$ a melhor opção.

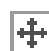

$\begin{array}{llll}\text { Voluntária Lordose normal } \quad \text { Hiperlordose } & \text { Retificação Inversão de curvatura }\end{array}$

\begin{tabular}{|c|c|c|c|c|}
\hline 1 & & & & \\
\hline 2 & & & & \\
\hline 3 & & & & \\
\hline 4 & & & & \\
\hline 5 & & & & \\
\hline 6 & & & & \\
\hline 7 & & & & \\
\hline$B$ & & & & \\
\hline 9 & & & & \\
\hline 10 & & & & \\
\hline 11 & & & & \\
\hline 12 & & & & \\
\hline 13 & & & & \\
\hline 14 & & & & \\
\hline 15 & & & & \\
\hline 16 & & & & \\
\hline 17 & & & & \\
\hline 18 & & & & \\
\hline 19 & & & & \\
\hline 20 & & & & \\
\hline$\ldots$ & & & & \\
\hline$\ldots$ & & & & \\
\hline 154 & & & & \\
\hline 155 & & & & \\
\hline 156 & & & & \\
\hline 157 & & & & \\
\hline
\end{tabular}


\begin{tabular}{l|l} 
Anexos & 107
\end{tabular} 